INSTITUT FÜR HUMANGENETIK

\title{
RESTLESS LEGS SYNDROM BEI \\ MONOZYGOTEN UND DIZYGOTEN \\ ZWILLINGEN
}

\author{
Nadine B. Groß
}

Vollständiger Abdruck der von der Fakultät für Medizin der Technischen Universität München zur Erlangung des akademischen Grades eines

\section{Doktors der Medizin}

genehmigte Dissertation.

Vorsitzender: $\quad$ Univ.-Prof. Dr. D. Neumeier

Prüfer der Dissertation:

1. Priv.-Doz. Dr. J. Winkelmann

2. Univ.-Prof. Dr. Dr. Th. R. Tölle

Die Dissertation wurde am 28.09.2009 bei der Technischen Universität München eingereicht und durch die Fakultät für Medizin am 24.03.2010 angenommen. 
Meinen Eltern in Liebe und Dankbarkeit gewidmet 


\section{INHALTSVERZEICHNIS}

1. EINLEITUNG 1

1.1. Klinische Symptomatik und Diagnostik des Restless Legs Syndroms ....................... 1

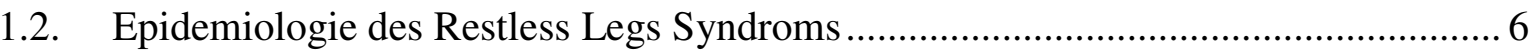

1.3. Primäres und sekundäres Restless Legs Syndrom, Assoziationen mit anderen Erkrankungen 7

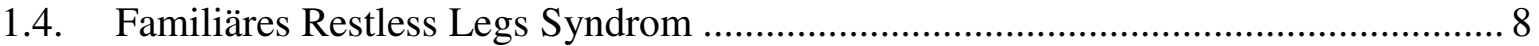

1.4.1. Kopplungsstudien bei Restless Legs Syndrom .......................................... 9

1.4.2. Assoziationsstudien bei Restless Legs Syndrom ........................................... 9

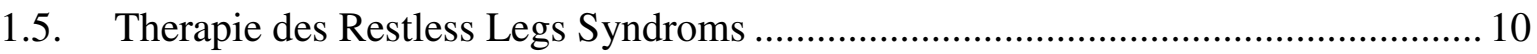

1.6. Pathophysiologie des Restless Legs Syndroms..................................................... 12

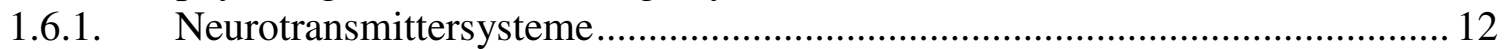

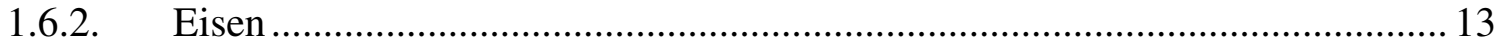

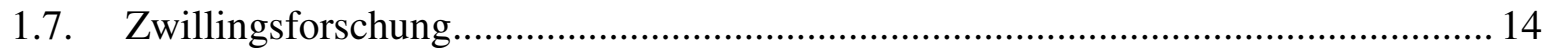

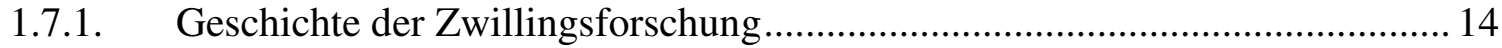

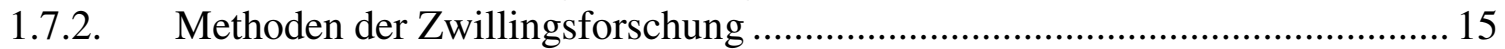

1.7.3. Restless Legs Syndrom bei Zwillingen ........................................................ 15

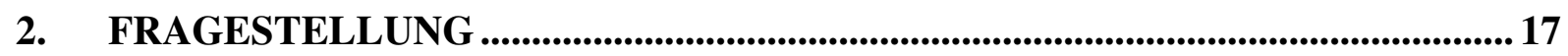

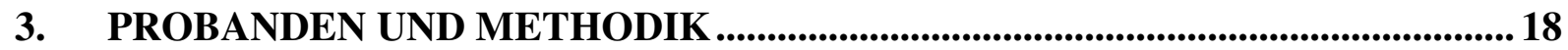

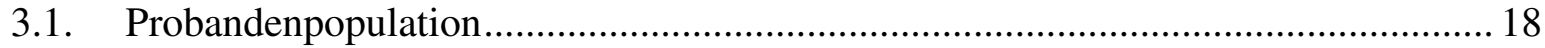

3.1.1. Probandenrekrutierung über das Zwillingsregister von HealthTwiSt.............. 18

3.1.2. Probandenrekrutierung über Spezialambulanzen für Restless Legs Syndrom und die Deutsche Restless Legs Vereinigung (RLS e.V.)................................ 19

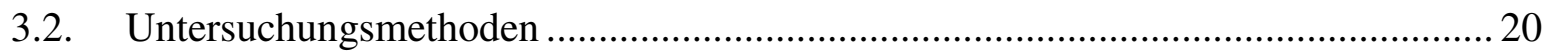

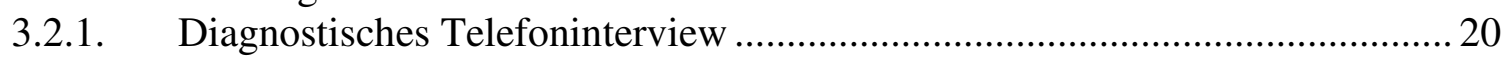

3.2.2. Blutprobe zur Zygotiebestimmung......................................................... 22

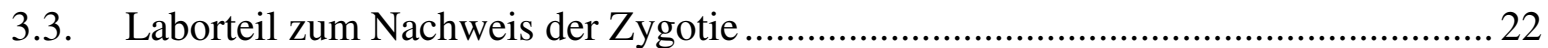

3.3.1. DNA-Extraktion aus Leukozyten des peripheren Blutes ................................ 22

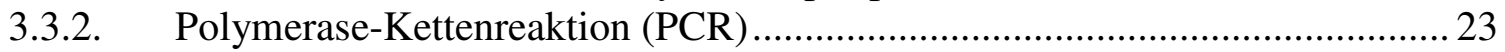

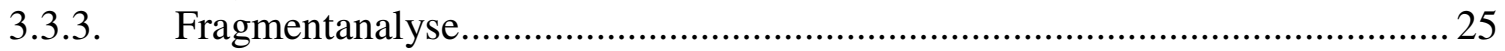

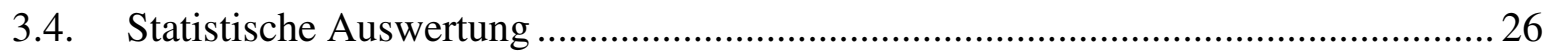

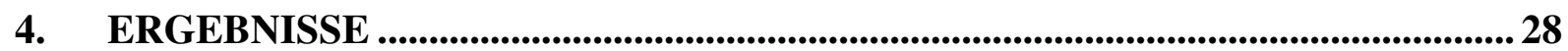

4.1. Probandenrekrutierung über das Zwillingsregister HealthTwiSt .......................... 28 
4.2. Probandenrekrutierung über Spezialambulanzen für Restless Legs Syndrom und die Deutsche Restless Legs Vereinigung, RLS e.V.

4.3. Demographische Daten der Zwillinge .................................................................... 32

4.4. Zygotie und Geschlechtsverteilung innerhalb der Zwillingspaare........................... 36

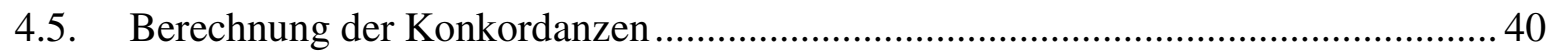

4.6. Strukturgleichungsmodell (ACE-Modell) ......................................................... 41

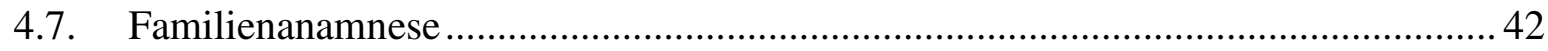

4.8. Klinische Symptomatik des Restless Legs Syndrom bei den betroffenen Zwillingsindividuen .....

4.9. Sekundäres Restless Legs Syndrom und assoziierte Erkrankungen .........................47

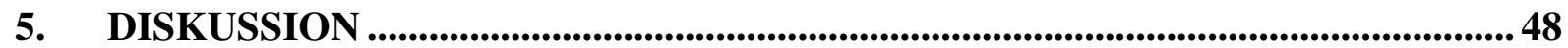

5.1. Bisherige Zwillingsstudien bei Patienten mit Restless Legs Syndrom ................... 48

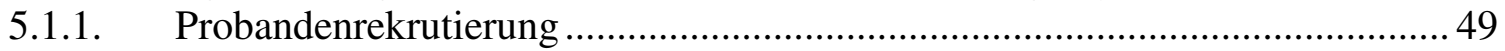

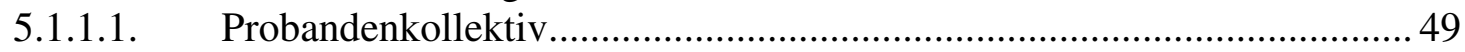

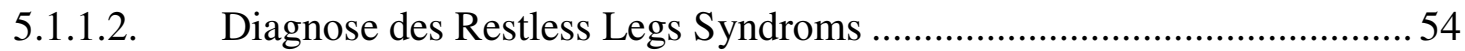

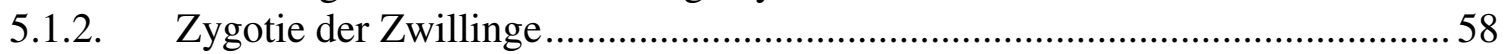

5.1.3. Konkordanzen, deren beeinflussende Faktoren und Strukturgleichungsmodell

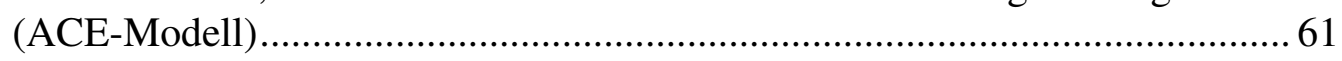

5.1.4. Zusammenhang zwischen ACE-Modell und der aktuellen genetischen Grundlage des Restless Legs Syndrom ........................................................... 68

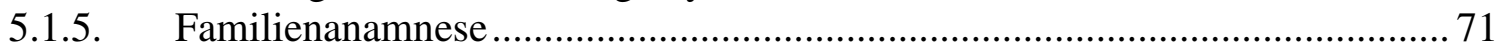

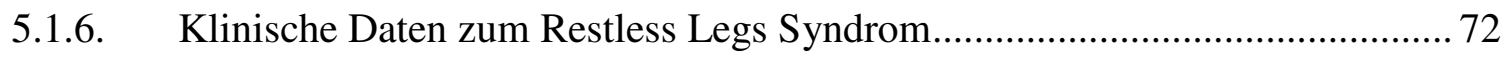

5.1.7. Sekundäres Restless Legs Syndrom ............................................................. 74

5.2. Vergleich mit Zwillingsstudien zu anderen neurologischen Erkrankungen .............76

6. KRITISCHE BETRACHUNG DER ARBEIT ..................................................... 81

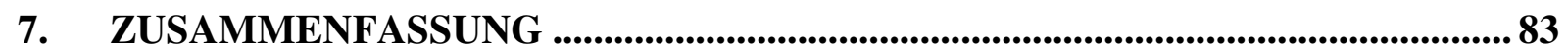

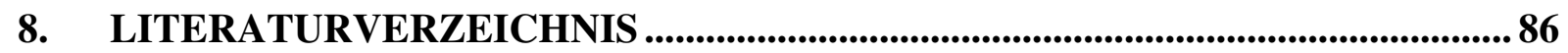

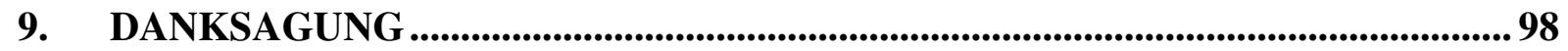

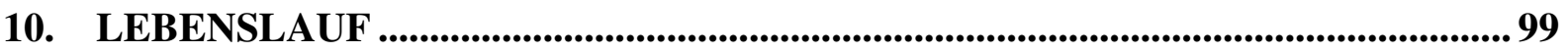




\section{ANHANG}

1 Gesundheitsfragebogen

2 Patientenanschreiben

3 Rückantwortschreiben

4 Diagnosefragebogen des diagnostischen Telefoninterviews

5 Schweregrad-Skala (IRLS) der IRLSSG 


\section{TABELLENVERZEICHNIS}

Tabelle 1: $\quad$ Diagnosekriterein der IRLSSG von 2003

Tabelle 2: $\quad$ Differentialdiagnosen des RLS 5

Tabelle 3: $\quad$ RLS-Diagnosefragen des Gesundheitsfragebogens $\quad 18$

Tabelle 4: $\quad$ Definition RLS-Diagnoseziffern 21

Tabelle 5: $\quad$ Auswahl hochpolymorpher Mikrosatellitenmarker (AmpF/STR® Identifiler® PCR Amplifikation Kit) 25

Tabelle 6: Vergleich Ergebnisse des RLS-Diagnosefragebogens und des diagnostischen Telefoninterviews

Tabelle 7: $\quad$ Zwillingsindividuen mit RLS, N=48

Tabelle 8: Alters- und Geschlechtsverteilung der Zwillingsindividuen mit RLS, $\mathrm{N}=48$

Tabelle 9: Gesamtübersicht ausgewertete Zwillingsindividuen, $\mathrm{N}=58$

(N= 48 RLS-positiv, $\mathrm{N}=10$ RLS-negativ)

Tabelle 10: Auswertung Fragmentanalyse bei gleichgeschlechtlichen

Zwillingspaaren, $\mathrm{N}=25$

Tabelle 11: Zygotie und Geschlechtsverteilung Zwillingspaare mit RLS, N=29 40

Tabelle 12: $\quad$ Konkordanzen (PWC, CWC), Relatives Risiko (RR) 41

Tabelle 13: $\quad$ Strukturgleichungsmodell (ACE-Modell) 41

Tabelle 14: $\quad$ Familienanamnese Zwillingsindividuen mit RLS, N= $48 \quad 42$

Tabelle 15 Alter bei Symptombeginn bei Zwillingsindividuen mit RLS, N=47

Tabelle 16: Latenz des Alters bei Symptombeginn bei konkordanten

Zwillingspaaren, $\mathrm{N}=18$

Tabelle 17: Häufigkeit des Auftretens der RLS-Symptome bei Zwillingsindividuen mit RLS, $\mathrm{N}=48$

Tabelle 18: $\quad$ Konkordanzen in Bezug auf Frequenz der RLS-Symptome bei konkordanten Zwillingspaaren, $\mathrm{N}=17$

Tabelle 19: $\quad$ Auswertung Punktewert-Intervall der RLS Schweregrad-Skala bei Zwillingsindividuen, $\mathrm{N}=48$

Tabelle 20: Kategorien der Schweregrad-Skala nach Punktewerten 
Tabelle 21: Extremitätenlokalisation der RLS-Symptome bei Zwillingsindividuen mit RLS, $\mathrm{N}=48$

Tabelle 22: Konkordanzen der Extremitätenlokalisation der RLS-Symptome bei konkordanten Zwillingspaaren, $\mathrm{N}=17$

Tabelle 23: Zwillingspopulation und Prävalenzen bisheriger RLS-Zwillingsstudien $\quad 50$

Tabelle 24: Diagnosemethoden bisheriger RLS-Zwillingsstudien im Vergleich

Tabelle 25: $\quad$ RLS-Diagnosefragen aus der Studie von Desai et al.

Tabelle 26: Methode der Zygotiebestimmung der bisherigen RLS-Zwillingsstudien im Vergleich

Tabelle 27: Konkordanzen (PWC, CWC) der bisherigen RLS-Zwillingsstudien im Vergleich

Tabelle 28: Formelübersicht $\mathrm{h}^{2},\left(\mathrm{~V}_{\mathrm{E}}\right)$

Tabelle 29: $\quad$ RLS-Loci in Abwandlung nach Pichler (Pichler et al. 2008)

Tabelle 30: RLS-assoziierte Genvarianten, Funktion und möglicher Zusammenhang mit RLS, in Abwandlung nach Mignot (Mignot 2007)

Tabelle 31a: Zwillingsstudien bei Parkinson-Syndrom

Tabelle 31b: Zwillingsstudien bei Essentiellem Tremor

Tabelle 31c: Zwillingsstudien bei Narkolepsie

Tabelle 31d: Zwillingsstudien bei Tourette-Syndrom 


\section{ABBILDUNGSVERZEICHNIS}

Abbildung 1: Einflussfaktoren auf die Ätiopathogenese des RLS

Abbildung 2: Auswertung der RLS-Diagnosefragen des Gesundheitsfragebogens

Abbildung 3: Anschlussuntersuchung nach Auswertung der RLS-Diagnosefragen des Gesundheitsfragebogens

Abbildung 4: Diagnosesicherung im diagnostischen Telefoninterview in der Übersicht

Abbildung 5: Fragmentanalyse Zwillingspaar 002-A/B, MZ, Marker D8S1179

Abbildung 6: Fragmentanalyse Zwillingspaar 015-A/B, DZ, Marker D8S1179

Abbildung 7: Strukturgleichungsmodell (ACE-Modell)

Abbildung 8: Vergleich ACE-Modell Desai et al. versus aktuelle Studie 


\section{ABKÜRZUNGSVERZEICHNIS}

CWC Casewise Concordance, Probandenweise Konkordanz

DZ Dizygot, zweieiig

ET Essentieller Tremor

ICD International Classification of Disease

IRLSSG Internationale Restless Legs Syndrome Study Group

k.A. keine Angaben

$\mathrm{N} \quad$ Anzahl

n Normalwert

N.A. nicht anwendbar/verfügbar/zutreffend

m Männlich

Mean Mittelwert

Min Minuten

MZ Monozygot, eineiig

OSA Obstruktives Schlafapnoe-Syndom

PCR Polymerase-Kettenreaktion

PD Parkinson Disease, Parkinson-Syndrom

PLM Periodic Limb Movements, Periodische Beinbewegungen

PLMD Periodic Limb Movement Disorder

PLMS Periodic Limb Movements in Sleep, Periodische Beinbewegungen im Schlaf

PLMW Periodic Limb Movements while awake, Periodische Beinbewegungen im Wachzustand

PWC Pairwise Concordance, Paarweise Konkordanz

RLS Restless Legs Syndrom

rpm revolutions per minute, Umdrehungen pro Minute

RR Relatives Risiko

sec Sekunden

SD Standardabweichung

TS Tourette-Syndrom

UBC University of British Columbia

UdeM Université de Montreal

vs. Versus

w Weiblich 


\section{EINLEITUNG}

\subsection{Klinische Symptomatik und Diagnostik des Restless Legs Syndroms}

Das Restless Legs Syndrom (RLS), auch Syndrom der unruhigen Beine genannt, zählt zu den häufigsten neurologischen Erkrankungen. Es ist durch einen Bewegungsdrang der Beine, seltener auch der Arme charakterisiert, der mit unangenehmen Missempfindungen in den jeweiligen Extremitäten einhergeht. Für die Patienten sind diese quälenden Empfindungen schwer zu benennen und werden durch Begriffe wie „Ziehen“, „Reißen“, „Kribbeln“, „Muskel- oder Nervenspannen“ beschrieben. Die Empfindungsqualität „Schmerz“ kann oftmals deutlich von den Missempfindungen im Rahmen eines RLS differenziert werden (Ekbom 1960; Allen \& Earley 1996). Als häufigste Lokalisation wird die Region zwischen Sprunggelenk und Knie im Bereich der Wadenmuskulatur angegeben. Die Haut scheint dabei meist keine Irritationen aufzuweisen, vielmehr werden die Beschwerden als von ,innen heraus" kommend empfunden, mit Beteiligung von Muskel und/oder Knochen (Ekbom 1960). Typischerweise treten die Beschwerden nur in Ruhe- und Entspannungsphasen auf, wenn der Patient sich hinsetzt oder hinlegt. Der imperative Bewegungsdrang in Verbindung mit den Sensationen zwingt den Patienten die betroffene Extremität zu bewegen. Verschiedene Manöver werden angewandt, die mit einer Muskelaktivität einhergehen, wie z.B. Muskelanspannen, Kreisen der Füße, Strecken oder Massieren. Häufig genügen diese Aktivitäten nicht, eine ausreichende Erleichterung zu erfahren, und der Patient muss letztendlich aufstehen und umherlaufen. Zumindest für die Zeit der Bewegung wird eine Besserung der Symptomatik erreicht. Begibt sich der Patient wieder in Ruhe, kommt es nach kurzer Zeit meist erneut zum Auftreten der Beschwerden. Das RLS hat eine zirkadiane Rhythmik, mit einem Maximum der Beschwerden am Abend sowie in der frühen Nacht und einer Besserung der Symptome zum Morgen hin (Trenkwalder et al. 1999a; Hening et al. 1999b). Dies führt bei über 90\% der Patienten im Verlauf der Erkrankung zu Ein- und Durchschlafstörungen; folglich zeigt sich bei den betroffenen Patienten eine erhöhte Tagesmüdigkeit (Montplaisir et al. 1997) und eine herabgesetzte Lebensqualität (Abetz et al. 2004; Allen et al. 2005; Cuellar et al. 2007). Darüber hinaus treten bei 80-90\% der RLSPatienten auch motorische Störungen in Form von periodischen Beinbewegungen auf, die als PLMs (periodic leg movements) bezeichnet werden. Diese können sowohl im Schlaf als auch im Wachzustand auftreten und werden daher in ,periodic leg movements during sleep 
(PLMS) and during wakefulness (PLMW)“ unterschieden (Montplaisir et al. 1997). Es handelt sich dabei um eine ruckartige, stereotype, unwillkürliche Dorsalflexion des oberen Sprunggelenks und der Großzehe, teilweise auch um eine Flexionsbewegung im Knie- und Hüftgelenk. Die Bewegungen treten ein- oder beidseitig auf und wiederholen sich in regelmäßigen Intervallen. Das Auftreten dieser PLMs muss per se keinen Krankheitswert besitzen. Erst eine Frequenz von mehr als fünf PLMS pro Stunde Schlaf (PLMS-Index > 5 pro Stunde Schlaf) wird ebenso, wie jegliche PLMs im Wachzustand (PLMW) als erhöht angesehen. Dabei können PLMS auch unabhängig von einem RLS auftreten, z.B. bei Narkolepsie oder Morbus Parkinson, ihre Präsenz ist somit nicht spezifisch für ein RLS (Montplaisir et al. 1997; Montplaisir et al. 1998).

Beim RLS handelt es sich um eine chronisch progrediente Erkrankung. Meist treten die Symptome zu Beginn in Intervallen auf, wodurch es immer wieder zu monate- bis jahrelangen Zeiträumen mit völliger Beschwerdefreiheit kommen kann. Im Verlauf der Erkrankung werden die Intervalle immer kürzer und die Symptomstärke nimmt $\mathrm{zu}$, so dass stark betroffene Patienten über tägliche Beschwerden klagen. Vollständige Remissionen werden nur in Einzelfällen beschrieben (Ekbom 1960; Walters et al. 1996).

Die Diagnose eines RLS wird rein klinisch gestellt. Hierfür wurden von der Internationalen Restless Legs Study Group (IRLSSG) erstmals 1995 einheitliche Diagnosekriterien festgelegt (Walters 1995), die 2003 aufgrund neuer Forschungsergebnisse überarbeitet wurden (Allen et al. 2003). In der vorliegenden Arbeit wurden die modifizierten Diagnosekriterien von 2003 verwendet. Zur Diagnose des RLS müssen vier essentielle Kriterien obligat erfüllt sein. Drei weitere klinische Merkmale werden als „supportive Kriterien“ abgehandelt und sollen in unklaren Fällen die Diagnose eines RLS unterstützen. Darüber hinaus wurden zusätzlich noch drei Kriterien als ,assoziierte Charakteristika“ des RLS festgelegt, die Patienten mit einem möglichen RLS genauer bewerten sollen (Allen et al. 2003) (Tabelle 1). 
Tab. 1: Diagnosekriterien des Restless Legs Syndroms

Diagnosekriterien des RLS nach der Internationalen Restless Legs Study Group

(IRLSSG) von 2003 (Allen et al. 2003)

ESSENTIELLE MINIMALKRITERIEN

1. Bewegungsdrang der Beine, gewöhnlich begleitet von oder verursacht durch unbehagliche unangenehme Empfindungen in den Beinen. (Manchmal besteht der Bewegungsdrang ohne die unangenehmen Empfindungen und manchmal sind auch die Arme oder andere Körperregionen zusätzlich zu den Beinen betroffen.)

2. Der Bewegungsdrang bzw. die unangenehmen Empfindungen beginnen oder verschlechtern sich während Ruhephasen oder bei Inaktivität wie Sitzen oder Liegen.

3. Der Bewegungsdrang bzw. die unangenehmen Empfindungen werden durch Bewegung wie Laufen oder Dehnen teilweise oder vollständig gebessert. Die Besserung hält zumindest so lange an, wie diese Aktivität ausgeführt wird.

4. Der Drang sich zu bewegen bzw. die unangenehmen Empfindungen sind abends und nachts schlimmer als während des Tages oder treten ausschließlich am Abend oder in der Nacht auf. (Wenn die Symptome stark sind, kann es sein, dass die Verschlechterung in der Nacht nicht mehr bemerkbar ist, sie muss aber früher einmal bestanden haben.)

\section{SUPPORTIVE KRITERIEN DES RLS}

- Positive Familienanamnese

Die Prävalenz des RLS ist unter Angehörigen ersten Grades von RLS-Patienten drei- bis fünfmal höher als bei Personen ohne RLS.

\section{- Ansprechen auf eine dopaminerge Therapie}

Nahezu alle RLS-Patienten zeigen einen zumindest initial positiven therapeutischen Effekt auf die Gabe von L-Dopa oder eines Dopaminagonisten in einer Dosis, die im Vergleich zur klassischen Therapiedosis eines Morbus Parkinson niedriger ist. Der initiale Effekt bleibt jedoch im Verlauf der Erkrankung nicht immer erhalten.

- Periodische Beinbewegungen (im Wachzustand oder während des Schlafs)

Periodische Beinbewegungen im Schlaf (PLMS) treten bei etwa 85\% der RLS-Patienten auf. PLMS kommen aber auch häufig in Zusammenhang mit anderen Erkrankungen in der älteren Bevölkerung vor. Bei Kindern finden sich PLMS seltener als bei Erwachsenen. 
Fortsetzung Tab. 1

\section{ASSOZIIERTE CHARAKTERISTIKA DES RLS}

- Klinische Verlauf

Der klinische Verlauf der Erkrankung kann erheblich variieren. Findet sich eine Erstmanifestation der RLS-Symptome bereits vor dem 50. Lebensjahr, ist der Verlauf in der Regel schleichend. Bei erstmaligem Auftreten der Symptome nach dem 50. Lebensjahr, zeigt sich meist eine schnellere Progredienz mit schwererem Verlauf. Bei einigen Patienten kann das RLS intermittierend auftreten oder sogar spontan für einige Jahre remittieren.

- Schlafstörungen

Ein- und Durchschlafstörungen stellen ein häufiges und wichtiges Begleitsymptom eines RLS dar, die einer besonderen Aufmerksamkeit bedürfen. Meistens sind sie der initiale Grund dafür, dass Patienten im Rahmen ihres RLS einen Arzt aufsuchen.

\section{- Körperliche Untersuchung}

Die körperliche, vor allem die neurologische Untersuchung, ist meistens unauffällig und trägt nicht zur Diagnosestellung bei, mit Ausnahme der Identifizierung sekundärer Formen eines RLS. Das Vorliegen von peripheren Neuropathien und Radikulopathien sollte ebenfalls eruiert werden, da diese in einer bisher unbekannten Weise mit einem RLS assoziiert sein können und eine spezielle Behandlung benötigen.

Darüber hinaus ermöglichen verschiedene technische und laborchemische Zusatzuntersuchungen eine Beurteilung der Patienten bei unklarer Diagnose sowie eine weitere differentialdiagnostische Einordnung. Elektrophysiologische Untersuchungen mit Bestimmung der Nervenleitgeschwindigkeit (NLG) und der Elektromyographie (EMG) sollen hierbei die Abgrenzung zu einer Polyneuropathie (PNP), die eine häufige und wichtige Differentialdiagnose eines RLS darstellt, ermöglichen. Dies kann durch die Tatsache erschwert werden, dass einige Patienten die Symptome beider Erkrankungen parallel aufweisen. Auch der Verdacht des assoziierten Auftretens einer Polyneuropathie und eines RLS wurde bereits in der Literatur diskutiert (Gemignani et al. 2006). Eine Polyneuropathie kann aber auch unabhängig von einem RLS auftreten, die sensorischen Symptome ein RLS imitieren und somit eine eindeutige Abgrenzung erschweren. Laborchemische Untersuchungen (Blutbild, Ferritin, Serumeisen, Kreatinin, Harnstoff, TSH, fT3, fT4, Vitamin B12 und Folsäure) sind zur Klassifikation eines sekundären RLS geeignet. Patienten mit idopathischen RLS zeigen in der Regel einen unauffälligen neurologischen, 
elektrophysiologischen und laborchemischen Untersuchungsbefund (Allen et al. 2003). Eine Abgrenzung des RLS von Erkrankungen mit ähnlichen Symptomen ist unter anderem aus therapeutischen Gründen von großer Bedeutung. Eine Auflistung der wichtigsten Differentialdiagnosen ist in Tabelle 2 zusammengestellt.

Tab. 2: Differentialdiagnosen des Restless Legs Syndroms

\section{Differentialdiagnosen des Restless Legs Syndroms}

(Leitlinie für Diagnostik und Therapie in der Neurologie (Diener H-C. et al. 2008))

- Polyneuropathie, Radikulopathie

- Venöse und arterielle Erkrankungen der Beine (Varizen, pAVK)

- "painful legs and moving toes syndrome" (Symptome sind nicht unbedingt abends oder nachts schlimmer und bessern sich nicht durch Bewegung)

- Chronische Schmerzsyndrome anderer Ätiologie

- Benigne Muskel-/ und Wadenkrämpfe

- Akathisie (neuroleptika-induziert)

- Einschlafmyoklonien

- Myelopathien, enger Spinalkanal

- Generalisierte innere Unruhe (z.B. im Rahmen psychischer Erkrankungen)

- Schlaf-Apnoe-Syndrom

- Periodic Limb Movement Disorder (PLMD) ohne subjektive RLS-Symptomatik

Die Durchführung einer Polysomnographie ermöglicht den Nachweis von PLMS, die als „supportive Kriterien“ die Diagnose eines RLS unterstützen können (Allen et al. 2003). Durch die detaillierte Analyse des Schlafprofils im Rahmen der polysomnographischen Untersuchung kann das Ausmaß der Schlafstörung bei RLS-Patienten präzise eingeschätzt werden. Es können aber auch andere schlafbezogene Erkrankungen aufgedeckt werden, die zu einem gestörten Schlafprofil mit Tagesmüdigkeit führen können (z.B. Schlaf-ApnoeSyndrom). Weniger genau, jedoch von geringem Aufwand, sind aktigraphische Verfahren und der Immobilisationstest. Die Aktigraphie dient der Aufzeichnung motorischer Aktivität von Patienten während der Nacht und außerhalb eines Schlaflabors. Beim Immobilisationstest wird das Auftreten von sensorischen und motorischen Symptomen eines RLS sowie von periodischen Beinbewegungen im Wachen (PLMW) durch Inaktivität des Patienten provoziert. Dieser Immobilisationstest wurde 1998 von Montplaisir als Provokationstest zur Diagnosesicherung entwickelt (Montplaisir et al. 1998). Eine weitere Möglichkeit die 
Diagnose eines RLS zu stützen bzw. Differentialdiagnosen abzugrenzen, ermöglicht der LDopa-Test, der zur Bestätigung des supportiven Diagnosekriterium „Ansprechen auf eine dopaminerge Therapie“ von Stiasny-Kolster et al. validiert wurde. Patienten sollen nach einmaliger Einnahme von 100/25 mg L-Dopa/Benserazid über einen Zeitraum von 2 Stunden ihre Symptome beobachten und alle 15 Minuten eine Intensitätsskala ausfüllen. Bei einer 50\%igen Besserung der Beschwerden konnte eine 80 - 88\%ige Sensitiviät und 100\%ige Spezifität erreicht werden (Stiasny-Kolster et al. 2006).

\subsection{Epidemiologie des Restless Legs Syndroms}

Unter Verwendung der Diagnosekriterien der IRLSSG (Walters 1995; Allen et al. 2003) wurden in zahlreichen epidemiologischen Studien mit regional unterschiedlichen Probandenkollektiven Prävalenzen zwischen $<1 \%$ und 15,3\% erhoben (Rothdach et al. 2000; Tan et al. 2001; Nichols et al. 2003; Berger et al. 2004; Allen et al. 2005). Dabei handelte es sich bei den zugrunde liegenden Studienpopulationen entweder um ein Kollektiv aus der Allgemeinbevölkerung (Berger et al. 2004; Allen et al. 2005) oder um eine RLSKlinikpopulation (Nichols et al. 2003; Hening 2004), was eine Ursache für die abweichenden Prävalenzergebnisse aus diesen Studien sein kann. Die Prävalenzen von Bevölkerungskollektiven unterschiedlicher Ethnitäten zeigen deutliche Abweichungen. So finden sich die niedrigsten Werte mit $0,1 \%$ bis 3,19\% in Asien und der Türkei (Tan et al. 2001; Sevim et al. 2003; Mizuno et al. 2005b; Rangarajan et al. 2007), während bei Studienpopulationen aus dem europäischen Raum und den USA Prävalenzen bis zu 10\% in der Bevölkerung > 65 Jahren erhoben werden konnten (Rothdach et al. 2000; Phillips et al. 2000; Berger et al. 2004; Bjorvatn et al. 2005; Hogl et al. 2005). Ob die ethnische Zugehörigkeit oder die geographische Lage einen Einfluss auf die Entstehung eines RLS haben, ist zum aktuellen Zeitpunkt nicht abschließend geklärt. Zudem wurde eine geschlechtsspezifische Häufung in der weiblichen Bevölkerung beschrieben. Im europäischen Raum zeigten sich in einigen Studien bis zu doppelt so hohe Prävalenzen bei Frauen im Vergleich zu Männern (13, 9\% vs. 6,1\% (Rothdach et al. 2000), 11,4 \% vs. 5,8\% (Ulfberg et al. 2001a; Ulfberg et al. 2001b), 13,4\% vs. 7,6\% (Berger et al. 2004), 14,2\% vs. 6,6\% (Hogl et al. 2005), 10,8\% vs. 5,8\% (Tison et al. 2005) und 9,0\% vs. 5,4\% (Allen et al. 2005)). Ebenso zeigt das Auftreten der Erkrankung eine deutliche Altersabhängigkeit. Die Anzahl der RLS-Betroffenen nimmt mit steigendem Alter bis zum Erreichen eines Plateaus um das 60. - 
70. Lebensjahr kontinuierlich zu (Lavigne \& Montplaisir 1994; Rothdach et al. 2000; Phillips et al. 2000; Ohayon \& Roth 2002; Nichols et al. 2003; Berger et al. 2004). In einigen Studien wurde sogar eine Abnahme der Prävalenz nach dem nach dem 60. Lebensjahr beschrieben (Nichols et al. 2003; Berger et al. 2004).

\subsection{Primäres und sekundäres Restless Legs Syndrom, Assoziationen mit anderen Erkrankungen}

Das RLS wird in ein primäres bzw. idiopathisches und ein sekundäres bzw. symptomatisches RLS eingeteilt. Beim primären RLS findet sich keine zugrunde liegende Erkrankung, die die Symptomatik auslöst. Das sekundäre RLS entsteht dagegen im Zusammenhang mit einer Erkrankung oder mit einer metabolischen oder hormonellen Veränderung. Hierzu zählen z.B. Eisenmangel (O'Keeffe et al. 1994; Sun et al. 1998), Urämie (Winkelman et al. 1996; Gigli et al. 2004; Siddiqui et al. 2005) und Schwangerschaft (Manconi \& Ferini-Strambi 2004). Auch im Rahmen einer medikamentösen Therapie mit Antidepressiva, Neuroleptika und anderen Dopaminantagonisten kann es zu einem iatrogen verursachten sekundären RLS kommen (Kraus et al. 1999; Wetter et al. 2002; Chang et al. 2006; Rottach et al. 2008). Durch die Behandlung der zugrunde liegenden Erkrankung sowie nach Absetzen der auslösenden Medikamente kann bei einem sekundären RLS meist eine deutlichen Besserung, bis hin zum vollständigen Verschwinden der Symptomatik, erzielt werden (O'Keeffe et al. 1994; Winkelmann et al. 2002; Wetter et al. 2002; Manconi et al. 2004; Page et al. 2008). Auch von Patientinnen, die im Rahmen einer Schwangerschaft erstmals unter einem symptomatischen RLS leiden oder eine Verschlimmerung ihrer RLS-Beschwerden erfahren, wird meist eine Symptombesserung oder ein Symptomverlust postpartum beschrieben (Goodman et al. 1988; Allen et al. 2003; Manconi et al. 2004). Darüber hinaus konnte ein erhöhtes Auftreten eines RLS in Patienpopulationen mit Polyneuropathie (Rutkove et al. 1996; Gemignani \& Marbini 2002), Diabetes mellitus (Merlino et al. 2007) und Multipler Sklerose (Manconi et al. 2008) gezeigt werden, was auf eine Assoziation dieser Erkrankungen mit einem RLS hindeutet. Das Auftreten eines RLS bei weiteren Familienmitgliedern eines RLS-Betroffenen findet sich häufiger bei der primären als bei der sekundären Form der Erkrankung (Ondo \& Jankovic 1996). Bei der Untersuchung von 300 RLS-Patienten zeigte sich, dass innerhalb der Gruppe mit einem primären RLS der Prozentsatz der betroffenen Familienmitglieder signifikant höher lag, als in der Gruppe der Patienten mit einem sekundären - speziell urämischen - RLS 
(42,3\% vs. 11,7\%) (Winkelmann et al. 2000). In der Ausprägung der RLS-Symptome wurde bisher innerhalb der beiden Gruppen (primäres vs. sekundäres RLS) kein besonderer Unterschied beschrieben. Ebenso wenig lassen sich sekundäre Formen eines RLS durch klinische Charakteristika deutlich von einem primären RLS abgrenzen, was die Identifizierung oftmals erschwert (Walters 1995; Winkelmann et al. 2000). Bei den meisten sekundären RLS-Patienten findet sich jedoch ein späterer Symptombeginn (Allen \& Earley 2000).

\subsection{Familiäres Restless Legs Syndrom}

Etwa 40-60\% der Patienten mit einem primären RLS haben eine positive Familienanamnese (Walters et al. 1996; Montplaisir et al. 1997; Winkelmann et al. 2000). Bereits Ekbom berichtete von einer familiären Häufung bei etwa einem Drittel der von ihm untersuchten RLS-Patienten und vermutete innerhalb dieser Familien einen dominanten Erbgang (Ekbom 1960). Ondo und Jankovic konnten bei einer Untersuchung von 54 Patienten mit einem primären RLS sogar bei 92\% eine positive Familienanamnese erheben (Ondo \& Jankovic 1996). Der klinische Verlauf und die Symptomatik ist bei familiären und sporadische primären RLS-Patienten ähnlich (Winkelmann et al. 2000). Unterschiede fanden sich jedoch im Alter bei Symptombeginn. Je früher die RLS-Symptome auftraten, desto häufiger konnten weitere betroffene Familienmitglieder ermittelt werden (Walters et al. 1996; Winkelmann et al. 2000; Allen et al. 2002). So konnte in einer Studie bei Patienten mit einem primären RLS und positiver Familienanamnese ein signifikant niedrigeres Alter bei Symptombeginn gezeigt werden, als bei Patienten ohne positive Familienanamnese (35,45 Jahre vs. 47,17 Jahre) (Winkelmann et al. 2000). Das Erkrankungsrisiko für Familienmitglieder von Patienten mit einem primären RLS ist signifikant höher für Verwandte ersten und zweiten Grades von RLSBetroffenen im Gegensatz zu Verwandten von gesunden Probanden (19,9\% vs. 3,5\%, $\mathrm{p}<0,001$ für Verwandte ersten Grades, 4,1\% vs. 0,5\%, p<0,003 für Verwandte zweiten Grades) (Allen et al. 2002). Darüber hinaus konnte ein Einfluss des Alters bei Symptombeginn auf das Erkrankungsrisiko für weitere Familienmitglieder demonstriert werden. Das Risiko für Verwandte ersten Grades steigt dabei mit sinkendem Alter bei Symptombeginn (Allen et al. 2002). Zudem fand sich ein Zusammenhang zwischen dem Alter der RLS-Patienten und dem Verlauf der Erkrankung. Patienten mit einem sporadischen RLS und einem späten Beginn ihrer Symptome zeigen die Tendenz zu einer schnelleren 
Krankheitsprogression, als RLS-Patienten mit einem frühen Beginn ihrer RLS-Symptome (Ondo \& Jankovic 1996; Allen \& Earley 2000). Die familiäre Aggregation des RLS ist ein Hinweis auf eine genetische Grundlage der Erkrankung. Es wird angenommen, dass es sich beim RLS um eine komplexe genetische Erkrankung handelt, deren phänotypische Ausprägung durch das Zusammenspiel der Effekte mehrerer Gene sowie durch die Interaktion mit zusätzlichen nicht-genetischen Faktoren und Umweltfaktoren zustande kommt.

\subsubsection{Kopplungsstudien bei Restless Legs Syndrom}

In Kopplungsstudien innerhalb Familien unterschiedlicher Herkunft wurden bisher sechs Gen-Loci (Chromosom 12q, 14q, 9p, 2q, 20p, 16p) identifiziert, die mit einem RLS assoziiert sind (Desautels et al. 2001; Bonati et al. 2003; Chen et al. 2004; Pichler et al. 2006; Levchenko et al. 2006; Levchenko et al. 2008). Zusätzlich zeigte eine kürzlich durchgeführte genomweite Kopplungsanalyse in einer italienischen RLS-Familie Hinweise auf einen siebten RLS-Locus auf Chromosom 19p (Kemlink et al. 2008). Die Berechnungen der Kopplungsanalysen beruhen auf der Annahme, dass es sich um einen autosomal-dominanten Erbgang handelt (Bonati et al. 2003; Chen et al. 2004; Pichler et al. 2006; Levchenko et al. 2006; Levchenko et al. 2008; Kemlink et al. 2008). Nur beim zuerst identifizierte Locus auf Chromosom $12 \mathrm{q}$ in einer französisch-kanadischen Familie liegt den Berechnungen ein autosomal-rezessiven Erbgang zurgrunde, der aufgrund der hohen Allelfrequenz pseudodominat erscheint (Desautels et al. 2001).

In keiner dieser Kopplungsregionen ließ sich eine kausale Sequenzvariante identifizieren.

\subsubsection{Assoziationsstudien bei Restless Legs Syndrom}

Durch genomweite Assoziationsstudien (GWA), bei denen häufige genetische Varianten zwischen RLS-Patienten und gesunden Kontrollprobanden aus der Normalbevölkerung verglichen wurden, konnten Varianten in den Genen MEIS1, BTBD9, LBXCOR1/MAP2K5 und PTPRD identifiziert werden, die mit einem erhöhten Risiko für ein RLS einhergehen (Winkelmann et al. 2007; Stefansson et al. 2007; Schormair et al. 2008). Bei den identifizierten Genen handelt es sich um Faktoren, die in der frühen embryonalen Entwicklung eines Organismus eine Rolle spielen. MEIS1 spielt z.B. eine wichtige Rolle bei der Entwicklung der proximodistalen Extremitätenachse (Mercader et al. 1999) und hat auch eine wichtige Funktion bei der Entwicklung des Neuralrohrs (Winkelmann et al. 2007). Die Rolle der identifizierten Genvarianten bei der Entstehung eines RLS ist bisher noch nicht bekannt und ist Gegenstand der aktuellen Forschung. Eine neue Arbeitshypothese ist, dass das 
RLS Komponenten einer neurologischen Entwicklungsstörung hat, und dass es während der Embryonalphase bereits zu einer Prädisposition für die Entstehung eines RLS kommt. Es ist aber auch möglich, dass die identifizierten Gene im Erwachsenen und im Zusammenhang mit der RLS-Erkankung eine völlig andere Funktion haben. Möglicherweise handelt es sich bei den identifizierten Varianten nicht um Mutationen innerhalb kodierender Regionen, vielmehr könnten die identifizierten genomischen Varianten auf Genregulationsebene zum Tragen kommen (Mignot 2007). Eine diagnostische Option bieten die vier identifizierten Genvarianten allerdings nicht. Es handelt sich um genetische Risikovarianten, mit einem kleinen Effekt auf den Phänotyp. Träger eines Risikoallels haben ein erhöhtes Risiko an RLS zu erkranken (Odds ratio (OR): bis zu 1,7). Bei Trägern aller Risikoallele steigt das Risiko auf eine OR von bis zu 9.

\subsection{Therapie des Restless Legs Syndroms}

Wichtigste Therapieform zur pharmakologischen Behandlung eines RLS ist die dopaminerge Therapie mit Levodopa (in Kombination mit einem Decarboxylasehemmer) oder mit einem Dopaminagonisten. Die dopaminerge Therapie hat sowohl einen Effekt auf die sensible, als auch auf die motorische Komponenten des RLS, mit Reduzierung des PLM-Index (Hening et al. 1999a). Vorteil der Therapie mit Levodopa/Decarboxylasehemmer ist der rasche Wirkungseintritt von etwa 30 Minuten, sodass es als Bedarfsmedikation und bei intermittierend auftretendem RLS besonders geeignet ist (Silber et al. 2004). Therapie der ersten Wahl bei täglich auftretendem mittlerem bis schwerem RLS stellen Dopaminagonisten dar (Hening et al. 2004; Hening 2007). Die längere Halbwertzeit im Gegensatz zu Levodopa/Decarboxylasehemmer ermöglicht eine Symptombesserung über einen längeren Zeitraum. Hierdurch kann die Häufigkeit der Medikamenteneinnahmen reduziert werden und eine Wirkung über die gesamte Schlafphase in der Nacht erreicht werden. Redoundphänomene, mit einem Wirkverlust der Medikamente vor Ende der RLSSymptomatik und Wiederauftreten der Beschwerden, treten unter Dopaminagonisten daher seltener auf (Guilleminault et al. 1993). Als spezifische Nebenwirkung einer dopaminergen Therapie bei RLS-Patienten findet sich das Phänomen der Augmentation. Hierbei handelt es sich um eine Verschlechterung der Beschwerden mit früherem Einsetzen der Symptome im Tagesverlauf und/oder Befall von anderen Körperregionen unter konstanter dopaminerger Therapie. Etwa 70-80\% der Patienten entwickeln unter einer täglichen Einnahme von 
Levodopa/Decarboxylasehemmer eine Augmentation, die meist ein Absetzten des Medikamentes und den Wechsel auf ein alternatives Präparat erfordert (Allen \& Earley 1996; Earley \& Allen 1996). Deutlich seltener und in milderer Ausprägung findet sich eine Augmentation bei der Therapie mit Dopaminagonisten (Earley \& Allen 1996; Ondo et al. 2004). Bei unzureichendem Behandlungserfolg oder Komplikationen durch die dopaminergen Medikamente (z.B. Augmentation) bietet sich ein Therapieversuch mit Opioiden an, die ebenfalls einen positiven Effekt auf die sensible und motorische (PLM-Index) Komponente des RLS haben (Walters et al. 2001). Alternativ werden auch Antiepileptika wie Gabapentin sowie Benzodiazepine, meist als Kombinationstherapie eingesetzt (Hening et al. 1999a; Garcia-Borreguero et al. 2002; Happe et al. 2003).

Sekundäre RLS-Fälle müssen anamnestisch von der primären Form differenziert werden, da sich der Therapieansatz bei beiden Formen unterscheidet. So sollten erniedrige Serumeisenund/oder Ferritinwerte durch Eisensubstitution auf hochnormale Werte eingestellt werden. Oftmals lässt sich hierdurch eine deutliche Besserung der Beschwerdesymptomatik erzielen (O'Keeffe et al. 1994; Earley et al. 2004). Patienten, die im Rahmen einer terminalen Niereninsuffizienz eine RLS-Symptomatik entwickeln, berichten nach einer Nierentransplantation in den meisten Fällen von einer deutlichen Besserung ihrer Beschwerden (Winkelmann et al. 2002). Beim Auftreten eines RLS in der Schwangerschaft sollte möglichst auf eine medikamentöse Therapie verzichtet werden. Ist eine medikamentöse Therapie nicht zu umgehen, stehen Benzodiazepine und Opiate als Medikamentengruppen zur Verfügung. Die bisherige Datenlage zur Sicherheit dieser Medikamente bei der Verabreichung in der Schwangerschaft wird als ausreichend bewertet (Djokanovic et al. 2008). Alternativ bieten sich konservativ lindernde Verfahren, wie z.B. Bewegungstherapie an, sowie die Gewährleistung einer optimalen Eisensubstitution. Ultima ratio ist die vorzeitige Beendigung der Schwangerschaft mittels Sectio, da es nach der Geburt meist zu einer akuten Besserung der Beschwerden kommt (Manconi et al. 2004). 


\subsection{Pathophysiologie des Restless Legs Syndroms}

Bis heute ist die pathophysiologische Grundlage zur Entstehung eines RLS nicht genau geklärt. Es spielen sowohl genetische, als auch nicht-genetische Faktoren, wie z.B. metabolische Veränderungen (veränderter Eisenstoffwechsel, Schwangerschaft, Urämie) und/oder Umweltfaktoren bei der Entstehung eines RLS eine entscheidende Rolle (Winkelman 2006).

Genetische Faktoren könnten hierbei das Risiko erhöhen ein RLS zu entwickeln. Treffen zusätzlich nicht-genetische Faktoren auf eine bestimmte Konstellation von Risiko-Varianten, könnte das Zusammenspiel genetischer und nicht-genetischer Faktoren letztendlich zur Manifestation eines RLS führen.

\subsubsection{Neurotransmittersysteme}

Das Ansprechen der RLS-Symptome auf eine dopaminerge Therapie deutet auf eine Beteiligung des dopaminergen Neurotransmittersystems hin (Montplaisir et al. 1986; Trenkwalder et al. 1995; Earley \& Allen 1996; Stiasny et al. 2000). Meist fanden sich in Untersuchungen des nigrostriatalen dopaminergen Systems mittels funktioneller bildgebender Verfahren unauffällige Messergebnisse im Vergleich von RLS-Patienten und gesunden Kontrollpersonen (Eisensehr et al. 2001; Michaud et al. 2002; Tribl et al. 2004). Wenige Studien lieferten dagegen Hinweise auf eine Affinitätsstörung oder absolute Verminderung striataler postsynaptischer Dopamin-D2-Rezeptoren (Michaud et al. 2002) sowie auf eine zentrale striatale und extrastriatale dopaminerge Hypo- bzw. Dysfunktion (Turjanski et al. 1999; Ruottinen et al. 2000; Cervenka et al. 2006). Diese Messergebnisse konnten in einer weiteren Untersuchung jedoch nicht verifiziert werden (Trenkwalder et al. 1999b). Insgesamt lieferten die bisher durchgeführten vergleichenden Bildgebungsstudien zur Beurteilung der striatalen Rezeptorkonzentration und deren Bindungsverhalten uneinheitliche Resultate.

Der positive Behandlungserfolg zahlreicher RLS-Patienten mit Opiaten gibt zudem Hinweise auf eine mögliche Beteiligung des endogenen Opiatsystems (Trzepacz et al. 1984; Hening et al. 1986; Walters et al. 1993; Lauerma \& Markkula 1999). Veränderungen im Bindungsverhalten von Opioidrezeptoren konnten in einer PET-Untersuchung jedoch nicht gezeigt werden (von Spiczak et al. 2005). 


\subsubsection{Eisen}

Das Auftreten eines sekundären RLS wird häufig durch einen latenten oder manifesten Eisenmangel mit erniedrigtem Ferritinspiegel im Serum ausgelöst (O'Keeffe et al. 1994; Sun et al. 1998). Eine Besserung der Symptome lässt sich bei dieser sekundären Form des RLS oftmals durch eine adäquate Eisensubstitution erzielen (O'Keeffe et al. 1994; Earley et al. 2004). Gegenstand mehrere Studien war die Untersuchung des Zusammenhangs von Eisenstoffwechsel und RLS-Symptomen. Mittels MRT-Untersuchung konnte bei RLSPatienten eine signifikant erniedrigte, regionale Eisenverteilung in der Substantia nigra und, zu einem geringeren Ausmaß, auch im Putamen gezeigt werden (Allen et al. 2001). Zudem korrelierte das Ausmaß dieses regionalen Eisendefizits mit der Schwere der RLS-Symptome, d.h. bei Patienten mit niedrigstem zentralen Eisengehalt wurden die schwersten Symptome anamnestiziert (Allen et al. 2001). Histopathologisch ließen sich bei der Untersuchung von post mortem Gehirngewebe von RLS-Patienten im Vergleich zu Gehirngewebe von neurologisch gesunden Kontrollpersonen, bezüglich der Zellform keine Unterschiede feststellen. Es fanden sich jedoch in der gleichen Studie eine verminderte Färbung von Eisen und H-Ferritin (Speicherform des Ferritins) sowie eine Reduzierung der TransferrinRezeptoren (Connor et al. 2003). Eine funktionelle Störungen des Eisenstransportes in neuromelaninhaltigen Zellen als pathologische Grundlage des RLS wird daher von einigen Arbeitsgruppen diskutiert (Connor et al. 2003). Liquoruntersuchungen ergaben bei RLSPatienten im Vergleich zu Kontrollen erniedrigte Ferritin-Werte bei erhöhtem Transferrin (Earley et al. 2000; Clardy et al. 2006), während der Serumspiegel dieser Eisenparameter in beiden Gruppen unauffällig war (Earley et al. 2000). In Zusammenhang mit dem in der MRT ermittelten erniedrigten Eisengehalt in den Basalganglien (Allen et al. 2001) deuten diese Ergebnisse auf einen erniedrigten Eisenmetabolismus im zentralen Nervensystem von RLSPatienten hin.

Ein Zusammenhang zwischen Eisenstoffwechsel und dopaminerger Funktion wird über die Aktivität der Tyrosinhydroxylase angenommen, die das geschwindigkeitsbestimmende Enzym bei der Synthese von Dopamin darstellt und deren Aktivität eisenabhängig ist. Niedrige Aktivitäten dieses Enzyms könnten zu einer verminderten Dopaminsynthese führen, wodurch für die adäquate Signalübertragung an der postsynaptischen Membran weniger Transmitter zur Verfügung steht (Beard \& Connor 2003). 


\subsection{Zwillingsforschung}

\subsubsection{Geschichte der Zwillingsforschung}

Die Methode der Zwillingsforschung wurde im Jahr 1875 durch den britischen Wissenschaftler Francis Galton durch die Veröffentlichung eines Artikels über Zwillinge mit dem Titel „The History of Twins, as a Criterion of the Ralative Powers of Nature an Nurture“ begründet (Galton 1876). Er vermutete durch die Untersuchung von Zwillingen, dass deren Lebensgeschichte sowohl anlagebedingt, als auch durch Umweltfaktoren geprägt sein könnte (Galton 1876). Die Unterscheidung monozygoter (MZ) und dizygoter (DZ) Zwillinge war damals nicht möglich, so wurde von Francis Galton auch kein Vergleich der Ähnlichkeiten in Bezug auf bestimmte Eigenschaften zwischen MZ und DZ Zwillingspaaren beschrieben. Um das Jahr 1920 wurde erkannt, dass es zwei unterschiedliche Typen von Zwillingen gibt (Rende et al. 1990). MZ Zwillinge entstehen aus einer einzigen, durch ein Spermium befruchteten Eizelle und haben daher identische Erbanlagen, während DZ Zwillinge aus zwei Eizellen entstehen, die von zwei Spermien befruchtet wurden. Sie stimmen durchschnittlich nur in der Hälfte ihrer Gene überein und sind verwandt wie normale Geschwister. Durch dieses Verständnis bot die Zwillingsforschung neue Möglichkeiten (Rende et al. 1990). Im Jahr 1924 wurden zeitgleich von dem deutschen Dermatologen Hermann Siemens und von Curtis Merriman, einem Dozenten der Universität in Wisconsin, die klassische Methoden der Zwillingsforschung beschrieben (Rende et al. 1990; Boomsma et al. 2002). Durch den Vergleich des Auftretens bestimmter Merkmale oder Erkrankungen bei MZ und DZ Zwillingen sollte der erbliche Einfluss auf diese Merkmale abgeschätzt werden (Rende et al. 1990; Boomsma et al. 2002). Zu dieser Zeit wurde der Einfluss des Erbgutes auf das Wesen des Menschen überbewertet, Umweltfaktoren spielten nach damaliger Ansicht keine relevante Rolle. Diese Ideologie war im Nationalsozialismus die Basis für zahlreiche menschenunwürdige und kriminelle Experimente mit Zwillingen, wodurch die Zwillingsforschung ein äußerst negatives Ansehen erhielt (Matalon Lagnado \& Cohn Deke 1994). Erst in der heutigen Zeit wurde klar, dass der Einfluss des Erbgutes in intensiver Wechselwirkung mit Faktoren aus der Umwelt steht. Der Begriff der Epigenetik, also die Beeinflussung einer Merkmalsausprägung durch molekulare Veränderungen DNA, ohne Veränderung der definierten DNA-Sequenz, die durch nicht-genetische Faktoren aus der Umwelt ausgelöst werden, lieferte neue Ansätze zur Interpretation von Zwillingsstudien und vergrößerte deren Aussagewert. 


\subsubsection{Methoden der Zwillingsforschung}

Bei der Entstehung von Krankheiten oder Merkmalen eines Phänotyps spielen sowohl genetische Faktoren als auch Umweltfaktoren eine Rolle. Ziel der Untersuchung von MZ und DZ Zwillingen ist es, den genetischen Beitrag bei der Entstehung von Erkrankungen abzuschätzen. Darüber hinaus soll die Frage beantwortet werden, in welchem Ausmaß Erkrankungen durch genetische Faktoren bedingt sind und wie stark der Einfluss der Umwelt auf die Ätiologie und Ausprägung von Krankheiten ist. Kann der Einfluss nicht-genetischer Faktoren aus der Umwelt gezeigt werden, erhofft man mit dieser Methode eine mögliche Identifizierung spezieller Umweltfaktoren. Seit Anfang des zwanzigsten Jahrhunderts wird hierfür die Methode der „Klassischen Zwillingsforschung“ verwendet, bei der die Ähnlichkeit in Bezug auf ein phänotypisches Merkmal, z.B. eine Krankheit, zwischen MZ und DZ Zwillingspaaren verglichen wird (Boomsma et al. 2002). Gemeinsam aufwachsende MZ und DZ Zwillinge entwickeln sich zudem in einem ähnlichen Umfeld und erfahren die gleiche Erziehung. Sind sich MZ Zwillinge hinsichtlich einer Krankheit ähnlicher als DZ Zwillinge, so deutet dies auf einen größeren genetischen Einfluss bei der Entstehung der Erkrankung hin. Wenn jedoch die Ähnlichkeit hinsichtlich einer Krankheit bei monozygoten und dizygoten Zwillingen keinen großen Unterschied zeigt, haben Umweltfaktoren einen größeren Einfluss (Boomsma et al. 2002).

Für die Studie in der vorliegenden Arbeit wird die zuvor beschriebene Methode der „Klassischen Zwillingsforschung“ angewandt. Weiterführende Modelle im Rahmen der Zwillingsforschung sollen hier nur kurz erwähnt werden. So besteht zusätzlich die Möglichkeit getrennt aufwachsende MZ Zwillinge auf ein Merkmal zu untersuchen und diese gegebenenfalls mit zusammen aufgewachsenen MZ Zwillingen zu vergleichen. Hierdurch lässt sich der Einfluss nicht-genetischer Faktoren abschätzen mit der Möglichkeit diese zu identifizieren. Ebenso können die Korrelationen zwischen MZ und DZ Zwillingen mit normalen Geschwistern, Adoptivgeschwistern, anderen Familienmitgliedern oder mit einer Kontrollgruppe aus der Allgemeinbevölkerung verglichen werden (Andrew et al. 2001; Boomsma et al. 2002).

\subsubsection{Restless Legs Syndrom bei Zwillingen}

Ekbom, einer der Erstbeschreiber des RLS im letzten Jahrhundert, berichtete bereits über ein MZ Zwillingspaar. Bei beiden Zwillingsgeschwistern konnte er leichte RLS-Symptome diagnostizieren. Die Mutter der Zwillinge war schwer an RLS erkrankt (Ekbom 1960). Bisher wurden drei Zwillingsstudien zur Beurteilung des Einflusses genetischer Faktoren auf die 
Entstehung und Ausprägung eines RLS veröffentlicht (Ondo et al. 2000; Desai et al. 2004; Xiong et al. 2007). In einer US-amerikanischen Studie mit zwölf MZ Zwillingspaaren konnte innerhalb von zehn Paaren bei beiden Zwillingsgeschwistern ein RLS diagnostiziert werden. Hieraus wurde eine Paarweise Konkordanz von 83,3\% ermittelt. DZ Zwillingspaare wurden in dieser Studie nicht untersucht, ein Vergleich der Konkordanzen zwischen MZ und DZ Zwillingspaaren und somit die Abschätzung des Anteils genetischer und nicht-genetischer Faktoren bei der Entstehung eines RLS war nicht möglich (Ondo et al. 2000). Eine aktuellere Studie aus Großbritanien untersuchte 911 MZ und 983 DZ weibliche Zwillingspaare in Bezug auf eine RLS. Es ergaben sich Probandenweise Konkordanzen (CWC) von $61 \%$ bei den MZ und $45 \%$ bei den DZ Zwillingen und eine Heritabilität von 54\%. Eine ungenaue Phänotypisierung des RLS durch die Verwendung von zwei Diagnosefragen, die unabhängig von den Diagnosekriterien der IRLSSG erstellt wurden sowie der Einschluss von nur weiblichen Probanden schränkt die Aussagekraft der Ergebnisse ein. Die Zygotie wurde größtenteils mittels standardisierten Fragebögen und nur bei einer Minderheit durch Genotypisierung bestimmt (Desai et al. 2004). In einer weiteren Untersuchung des RLS bei $140 \mathrm{MZ}$ und $132 \mathrm{DZ}$ kanadischen Zwillingspaaren wurden kürzliche Probandenweise Konkordanzen (CWC) von 53,7\% für MZ und 15,4\% für DZ Zwillingspaare errechnet. Sekundäre RLS-Formen, deren Familiarität möglicherweise niedriger als beim primären RLS eingeschätzt werden muss, wurden nicht aus der Studie ausgeschlossen. Die Zygotiebestimmung der Zwillinge erfolgte bei allen Zwillingspaaren mittels Zygotiefragebogen, auf eine molekulargenetische Untersuchung wurde verzichtet (Xiong et al. 2007).

Zur genauen Beurteilung der Konkordanzen bei MZ und DZ Zwillingen und dem Vergleich dieser untereinander ist eine sorgfältige Phänotypiesierung notwendig. Es sollte daher auf die Verwendung der einheitlichen Diagnosekriterien der IRLSSG (Walters 1995; Allen et al. 2003) zur Diagnose eines RLS geachtet werden. Ein persönlicher oder telefonischer Kontakt erhöht dabei gegenüber der Verwendung von Selbstbeurteilungsfragebögen die Diagnosesicherheit. Hierdurch wird auch der Vergleich der Ergebnisse aus verschiedenen RLS-Studien möglich. Nicht nur die sorgfältige klinische Phänotypisierung des RLS, sondern auch die korrekt und einheitlich determinierte Zygotie mittels Genotypisierung, sichert die Qualität der Studienergebnisse und ermöglicht eine Vergleichbarkeit von Zwillingsstudien untereinander. Zudem bedarf das zugrundeliegende Probandenkollektiv einer besonderen Auswahl mit dem Anspruch möglichst die Allgemeinbevölkerung zu repräsentieren. 


\section{FRAGESTELLUNG}

Das RLS ist eine komplex-genetische Erkrankung. Es wird vermutet, dass sowohl genetische, als auch nicht-genetische Faktoren an der Pathogenese der Erkrankung beteiligt sind. Nichtgenetische Faktoren können hierbei bestimmte Umweltfaktoren sein (z.B. Ernährungszustand und Ernährungsgewohnheiten, geographischer Lebensraum, psychische Belastungssituationen und dauerhafte Stressituationen) oder metabolische Faktoren (z.B. Hormon- und Stoffwechselveränderungen) sein. Ziel der vorliegenden Arbeit ist es, die erbliche Komponente bei der Entstehung eines RLS abzuschätzen und das Ausmaß der Interaktion von genetischen und nicht-genetischen Faktoren zu beurteilen.

Das Modell der Zwillingsuntersuchung bietet hierfür eine geeignete Methode. Wir haben in dieser Arbeit MZ und DZ Zwillingspaare auf das Vorhandensein eines RLS untersucht und die jeweiligen Konkordanzen ermittelt. Anhand dieser soll in einer Konkordanz-DiskordanzAnalyse die Häufigkeit der konkordanten und diskordanten Zwillinge zwischen den MZ und DZ Zwillingspaaren verglichen werden. Aus diesen Daten sollen Erblichkeitsschätzungen berechnet werden, die Informationen darüber geben sollen, zu welchem Anteil additivgenetische Einflüsse (A) sowie gemeinsame (C) und getrennte Umwelteinflüsse (E) an der Ausprägung eines RLS beteiligt sind (Abbildung 1). Nicht-genetische Einflussfaktoren werden im Folgenden als Umwelteinflüsse bezeichnet.

Abb. 1: Einflussfaktoren auf die Ätiopathogenese des RLS

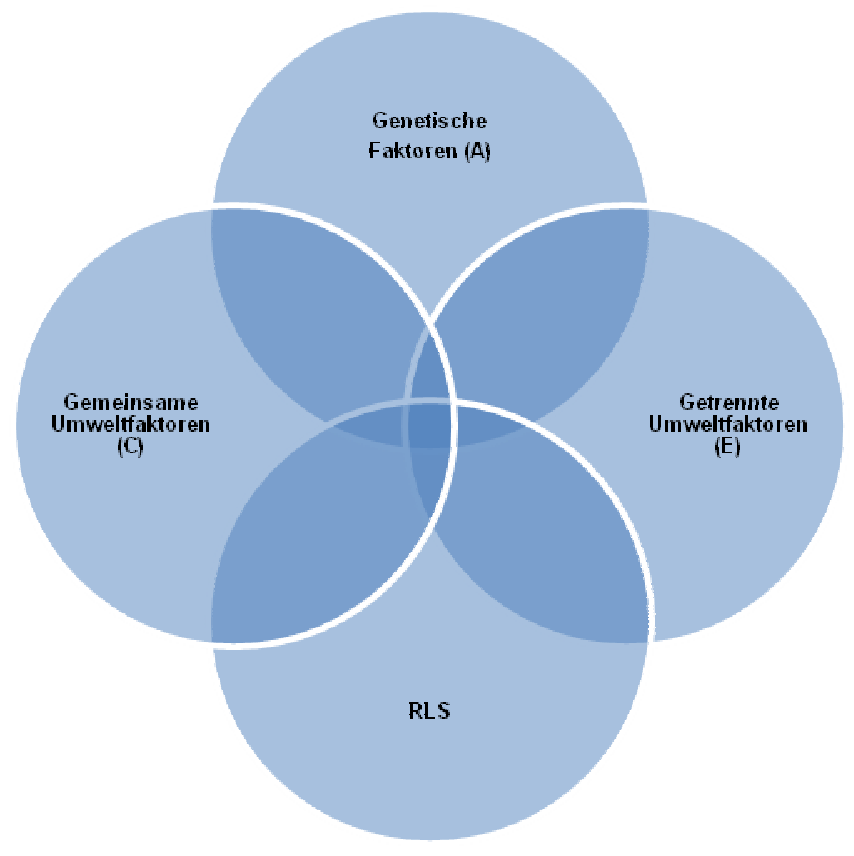




\section{PROBANDEN UND METHODIK}

\subsection{Probandenpopulation}

Die Probandenpopulation wird aus zwei unterschiedlichen Kollektiven zusammengestellt. Das erste Kollektiv repräsentiert Zwillingspaare aus der Allgemeinbevölkerung, die sich dem Zwillingsregister des Unternehmens HealthTwiSt GmbH in Berlin angeschlossen haben. Das zweite Probandenkollektiv wurde aus einer RLS-Patientenpopulation über die RLS-Ambulanz des Max-Planck-Instituts für Psychiatrie in München in Zusammenarbeit mit dem Institut für Humangenetik des Helmholtz Zentrums in München sowie der Deutschen Restless Legs Vereinigung (RLS e.V.), einer Patientenorganisation, rekrutiert.

\subsubsection{Probandenrekrutierung über das Zwillingsregister von HealthTwiSt}

Der Grundgedanke zum Aufbau des Berliner Zwillingsregisters HealthTwiSt wurde 1994 im Rahmen einer Studie gelegt, die zur Erforschung der Erblichkeit des Blutdrucks und der Reaktion auf Stress durchgeführt worden ist. Im Jahr 2006 verzeichnete das Zwillingsregister, das als Privatunternehmen geführt wird, mehr als 1700 Zwillingspaare (Busjahn 2006). Zur Registrierung füllen interessierte Zwillingspaare einen Gesundheitsfragebogen aus, der Daten zur Person, zu Lebensgewohnheiten und zum Gesundheitszustand beinhaltet (Anhang 1). Diesem Gesundheitsfragebogen wurden für unsere Studie zusätzlich drei Fragen zur Diagnose eines RLS hinzugefügt (Anhang 1, Fragen 12.3; 12.4; 12.5), die in Tabelle 3 aufgeführt sind.

Tab. 3: RLS-Diagnosefragen des Gesundheitsfragebogens

\section{RLS-Diagnosefragen des Gesundheitsfragebogens}

(Berger et al. 2004)

1. Haben Sie Missempfindungen wie Kribbeln, „Ameisenlaufen“ oder Schmerzen in den Beinen, verbunden mit einem Bewegungsdrang? (Anhang 1, Frage 12.3)

2. Treten diese Symptome nur in Ruhe bzw. beim Einschlafen auf und lassen sie sich durch Bewegung bessern? (Anhang 1, Frage 12.4)

3. Sind die Symptome abends schlimmer als morgens? (Anhang 1, Frage 12.5) 
Diese „diagnostischen Fragen“ wurden in bisherigen epidemiologischen Studien zum RLS verwendet (Rothdach et al. 2000; Berger et al. 2004) und beinhalten die essentiellen Diagnosekriterien der IRLSSG (Walters 1995; Allen et al. 2003).

Die drei RLS-Diagnosefragen wurden von den Probanden persönlich ausgefüllt. Mit Hilfe dieser RLS-Diagnosefragen sollten alle über HealthTwiST registrierten Zwillingspaare ermittelt werden, die potentiell von der Symptomatik eines RLS betroffen sind. So konnte durch eine erste Selektion RLS-verdächtiger Zwillingspaare eine Eingrenzung des gesamten Zwillingskollektivs, das im Zwillingsregister registriert ist, erreicht werden. Dabei wurden alle Zwillingspaare, von denen mindestens ein Zwillingspartner innerhalb eines untersuchten Paares mindestens eine der drei RLS-Diagnosefragen mit „Ja“ beantwortet hatte, als Zwillingspaare mit „möglichem $R L S$ “ klassifiziert. Die Namen und Kontaktdaten der entsprechenden Zwillingspaare wurden im Einverständnis der Probanden an das Institut für Humangenetik des Helmholtz Zentrums in München weitergeleitet. Diese Zwillingspaare erhielten daraufhin ein Anschreiben (Anhang 2), in dem sie über den Ablauf und den Hintergrund einer anschließenden Studie informiert wurden, die zur weiteren Untersuchung der von ihnen beantworteten RLS-Diagnosefragen bezüglich eines „möglichen RLS“ durchgeführt werden soll. Diese Anschlussuntersuchung wurde mit dem Ziel der Diagnosesicherung eines „,möglichen $R L S$ “ durchgeführt. Um an der Studie teilnehmen zu können, sollten alle kontaktierten Zwilling ein Rückantwortschreiben (Anhang 3) mit Name, Adresse, Telefonnummer und der bevorzugten Erreichbarkeit ausfüllen und an das Institut für Humangenetik des Helmholtz Zentrums in München in einem vorgefertigten Rückumschlag zurückschicken. Alle Zwillingspaare, die keine Rückantwort zurücksendeten, wurden aus der Studie ausgeschlossen. Zwillinge, von dessen Zwillingspartner lediglich die Rückantwort fehlte, wurden angerufen und über die Notwendigkeit der Teilnahme beider Zwillingspartner informiert. Falls einer der Zwillingspartner nicht teilnehmen wollte, wurden beide Zwillinge aus der Studie ausgeschlossen. Es wurden nur vollständige Zwillingspaare, die ihre mündliche oder schriftliche Studieneinwilligung gegeben hatten, in die Anschlussuntersuchung zur Diagnosesicherung eines RLS eingeschlossen.

\subsubsection{Probandenrekrutierung über Spezialambulanzen für Restless Legs Syndrom und die Deutsche Restless Legs Vereinigung (RLS e.V.)}

Aus den Klinikakten und Stammbäumen von RLS-Patienten, die sich bis 2006 in ambulanter oder stationärer Behandlung im Max-Planck-Institut für Psychiatrie in München befanden oder an Familienuntersuchungen zur genetischen Erforschung des RLS durch das Institut für 
Humangenetik des Helmholtz Zentrums in München teilnahmen, wurden zusätzlich Zwillingspaare mit RLS ermittelt. Die Patienten wurden telefonisch oder während ihres stationären oder ambulanten Krankenhausaufenthaltes kontaktiert und über die Studie zur Untersuchung des RLS bei MZ und DZ Zwillingen informiert.

Weitere Zwillingspaare wurden über die Deutsche Restless Legs Vereinigung (RLS e.V.) rekrutiert. Hierfür wurde auf Informationsveranstaltungen der Deutschen Restless Legs Vereinigung die Studie zur Untersuchung eines RLS bei MZ und DZ Zwillingen vorgestellt. Zudem wurde in der Zeitschrift der Deutschen Restless Legs Vereinigung eine Studienanzeige mit Informationen zum Hintergrund und Ziel der Studie sowie den Kontaktdaten der Studienzentrale zur weiteren Probandensuche veröffentlicht.

\subsection{Untersuchungsmethoden}

Die Untersuchungsmethode gliedert sich in zwei Abschnitte:

1. Diagnostisches Telefoninterview zur Sicherung der klinischen Diagnose eines RLS

2. Asservierung von Blut zur genetischen Untersuchung der Zygotie

\subsubsection{Diagnostisches Telefoninterview}

Die Sicherung der klinischen Diagnose eines RLS erfolgte bei allen Zwillingsindividuen in einem standardisierten telefonischen Interview von ca. 45-minütiger Dauer. Dieses wurde zu den von den Zwillingen im Rückantwortschreiben bevorzugt angegeben Zeiten durchgeführt. Alle untersuchten Zwillingsindividuen erhielten nach dem Telefoninterview eine Identifikationsnummer zur Anonymisierung der erhobenen Daten.

Grundlage des telefonischen Interviews war ein für diese Zwillingsstudie erstellter Fragebogen (Anhang 4). Dieser lässt sich in vier Abschnitte gliedern. Im ersten Abschnitt werden Daten zur Identifikation der Zwillingsindividuen (Name, Geschlecht und Geburtsdatum), zur Zwillingsgeburt und zur Sozialanamnese erhoben. Es folgen im zweiten Abschnitt Fragen zum Schlafverhalten bzw. Schlafrhythmus sowie zu Schlafstörungen. Der dritte Abschnitt befasst sich mit der Diagnosestellung des RLS anhand der vier essentiellen Diagnosekriterien sowie der drei Zusatzkriterien der IRLSSG (Walters 1995; Allen et al. 2003). Zusätzliche Fragen zu den klinischen Charakteristika des RLS (z.B. Alter bei Symptombeginn, Lokalisation der Beschwerden, Auftreten in der Schwangerschaft, 
individuelle Beschreibung der Beschwerden) sowie $\mathrm{zu}$ assoziierten Symptomen und Erkrankungen (z.B. ein Eisenmangel, Aufmerksamkeitsdefizit-Hyperaktivitäts-Syndrom (ADHS), Wachstums-schmerzen in der Kindheit, Einfluss von Alkohol und des weiblichen Zyklus auf die RLS-Symptomatik) werden hier ebenfalls abgefragt. Im letzten Abschnitt werden die Krankheitsanamnese weiterer Vorerkrankungen und die aktuelle Medikamentenanamnese erhoben. Diesem Fragebogen folgt die Schweregrad-Skala (IRLS) der IRLSSG zur Selbstbeurteilung, die ebenfalls im telefonischen Interview abgefragt wurde (Walters et al. 2003) (Anhang 5).

Die Diagnosesicherheit wurde nach Auswertung des diagnostischen Telefoninterviews anhand von Diagnoseziffern weiter differenziert. Tabelle 4 zeigt die Definition und Verteilungskriterien der Diagnoseziffern.

Tab. 4: Definition RLS-Diagnoseziffern

\begin{tabular}{|c|l|}
\hline Diagnoseziffer & \multicolumn{1}{|c|}{ Diagnose } \\
\hline $\mathbf{1}$ & $\begin{array}{l}\text { RLS sicher und alle vier diagnostischen Kriterien erfüllt } \\
+\quad \text { unterstützt durch Ansprechen auf dopaminerge Therapie oder } \\
\text { Polysomnographie (PSG) }\end{array}$ \\
\hline $\mathbf{2}$ & RLS sicher und alle vier diagnostischen Kriterien erfüllt \\
\hline $\mathbf{3}$ & RLS wahrscheinlich (nur drei von vier Kriterien erfüllt) \\
\hline $\mathbf{4}$ & RLS möglich (weniger als drei Kriterien erfüllt) \\
\hline $\mathbf{5}$ & sicher kein RLS \\
\hline $\mathbf{6}$ & Diagnose unbekannt \\
\hline $\mathbf{7}$ & Sonstige (Anamnese unklar etc.) \\
\hline
\end{tabular}

Zwillingsindividuen, die alle vier Diagnosekriterien erfüllt haben und zusätzlich eine Besserung der RLS-Symptomatik durch eine dopaminerge Therapie (,Supportives Kriterium“) erfahren, erhalten die Diagnoseziffer ,1“. Zwillingsindividuen ohne den Nachweis des Ansprechens auf eine dopaminerge Therapie, bei allen vier erfüllten Diagnosekriterien, erhalten die Diagnoseziffer ,2“. Die Diagnoseziffer , ,3“ wurde allen Zwillingsindividuen mit drei erfüllten Diagnosekriterien zugeteilt.

Als ,sicher $\boldsymbol{R} \boldsymbol{L S}$-positiv“ wurden alle Zwillingsindividuen mit den Diagnoseziffern „1“ und „2“ klassifiziert. Als „wahrscheinlich RLS-positiv“ galten Zwillingsindividuen mit der Diagnoseziffer ,3“. Als „möglich RLS-positiv“ wurden Zwillingsindividuen mit der 
Diagnoseziffer „„4“ klassifiziert. Diese Zwillinge wurden in der Studie nicht ausgewertet, da sie nicht sicher als RLS positiv oder negativ bewertet werden konnten.

\subsubsection{Blutprobe zur Zygotiebestimmung}

Bei jedem Individuum innerhalb eines gleichgeschlechtlichen Zwillingspaares mit RLS erfolgte eine Blutabnahme zur genetischen Untersuchung der Zygotie. Hierfür erhielten die jeweiligen Zwillinge auf dem Postweg je zwei beschriftete EDTA-Röhrchen (je 7,5 ml) und Transportbehälter. Die hinzugefügten Informationsschreiben für Probanden und Hausärzte sollten die ordnungsgemäße Probengewinnung und Versendung der Blutröhrchen sichern. Zusätzlich enthielt die Sendung eine Einverständniserklärung, die vom Patienten unterschrieben zurückgesendet werden musste. Ein frankierter und adressierter Rückumschlag lag der Postsendung bei. Die Zwillinge wurden gebeten, eine Blutentnahme mit dem zugesandten „Blutset“ und unter Vorlage des Informationsschreiben bei der nächsten Vorstellung beim Hausarzt vornehmen zu lassen. Diese Blutabnahme konnte mit einer Routineblutabnahme verbunden werden.

\subsection{Laborteil zum Nachweis der Zygotie}

Das Prinzip des Zygotienachweises beruht auf der Amplifikation spezieller DNA-Fragmente (hochpolymorphe Mikrosatellitenmarker) mittels Polymerasen-Ketten-Reaktion (PCR). In der anschließenden Fragmentanalyse wird die Größe der erhaltenen PCR-Produkte der Zwillinge ermittelt und mit den PCR-Produkten des jeweiligen Zwillingspartners verglichen. Abweichungen in der Fragmentgröße innerhalb eines Zwillingspaares sprechen für ein DZ Zwillingspaar.

\subsubsection{DNA-Extraktion aus Leukozyten des peripheren Blutes}

Von allen gleichgeschlechtlichen Zwillingspaaren wurde zur Gewinnung der genomischen DNA venöses EDTA-Blut verwendet (Miller, III \& Costa 1988). 10 ml EDTA-Blut wurden mit $30 \mathrm{ml}$ eiskaltem RBC Lysis Puffer versetzt, 15 min auf Eis inkubiert und mehrere Male durch Invertieren gut gemischt. In dieser Zeit lysieren die Erythrozyten im hypotonen Puffer, während die Leukozyten intakt bleiben und im anschließenden Zentrifugationsschritt (2500 rpm, 10 min bei $4^{\circ} \mathrm{C}$ ) sedimentiert werden können. Nach vorsichtigem Abkippen des 
Überstandes wurde das Leukozyten-Pellet in $5 \mathrm{ml}$ SE-Puffer resuspendiert und $25 \mu \mathrm{l}$ Proteinkinase K $(10 \mathrm{mg} / \mathrm{ml})$ und $250 \mu \mathrm{l}$ SDS (20\%) zugegeben. Die Suspension wurde bei Raumtemperatur über Nacht inkubiert. Durch Zugabe von $3 \mathrm{ml}$ saturiertem $\mathrm{NaCl}$ (ca. 6M, autoklaviert) wurden danach die abgebauten Proteinreste ausgefällt und bei $40^{\circ} \mathrm{C}$ abzentrifugiert (15 min bei $3500 \mathrm{rpm}$ ). Der klare DNA-haltige Überstand wurde abgegossen und mit einem Volumen Isopronalol ausgefällt. Die DNA, als ausgefallenes Knäuel, wurde mit einem sterilen Glashäkchen entnommen und in 0,2 $\mathrm{ml} 70 \%$ igem Ethanol gewaschen, anschließend in 1000-1800 $\mu$ l sterilem TE-Puffer bei Raumtemperatur über Nacht gelöst.

\subsubsection{Polymerase-Kettenreaktion (PCR)}

\section{Prinzip:}

Die Amplifikation der spezifischen DNA-Abschnitte wird durch eine thermostabile DNAPolymerase enzymatisch katalysiert. Zwei Startersequenzen, die sogenannten Primer, grenzen dabei den zu vervielfältigenden DNA-Abschnitt ein und bilden die Bindungsstelle für die DNA-Polymerase. Die Reaktion erfolgt in einem Thermocycler unter Durchlauf definierter temperaturabhängiger Zyklen.

\section{Reaktionsablauf:}

Um einen korrekten Ablauf der Reaktion zu ermöglichen, ist ein definierter StandardReaktionsansatz mit folgenden Komponenten nötig:

\section{Standard-Reaktionsansatz:}

10 x PCR-Puffer (Art: Qiagen)

Einzelansatz:

$\mathrm{MgCl} 2$ (Puffer enthält 15.mM,+25 mM Lösung)

$$
2,0 \mu 1
$$

dNTP-Mix

$2,0 \mu \mathrm{l}$

Forward Primer $(100 \mathrm{pmol} / \mu \mathrm{l})$

$0,1 \mu 1$

Reverse Primer (100 pmol/ $\mu \mathrm{l})$

$0,1 \mu \mathrm{l}$

$\mathrm{H}_{2} \mathrm{O}$ (Millipore /Ampuwa /Reinstwasser)

$14,7 \mu \mathrm{l}$

Probanden-DNA (Template)

$1,0 \mu 1$

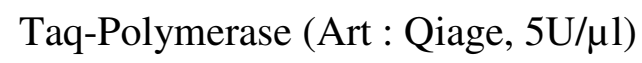

$0,1 \mu \mathrm{l}$

\section{$20,0 \mu \mathrm{l}$}

Diese Komponenten werden in 96er PCR-Mikrotiterplatten zusammenpipettiert und gut miteinander vermischt. Das Reaktionsgemisch durchläuft in einem programmierten Thermocycler folgende temperaturabhängigen Schritte, die sich in Zyklen wiederholen: 
- Denaturierung: Die doppelsträngige DNA wird auf $+95^{\circ} \mathrm{C}$ für $20 \mathrm{sec}$ erhitzt, um durch die Auflösung der Wasserstoffbrückenbindungen die beiden DNA-Stränge voneinander zu trennen, so dass nur noch Einzelstränge vorliegen.

- Annealing (Primerhybridisierung): Die Temperatur wird im Anschluss an die Denaturierung für $30 \mathrm{sec}$ auf $+55^{\circ} \mathrm{C}$ gesenkt, wodurch es zur Anlagerung der Primer an das 3`-Ende der DNA-Einzelstränge kommt.

- Extension: Es folgt wieder ein Anstieg der Temperatur auf $+72^{\circ} \mathrm{C}$ für $60 \mathrm{sec}$. Während dieser Phase wird die DNA-Polymerase aktiv und synthetisiert durch Anlagerung freier Nukleotide an den Primer in $5 \rightarrow 3 `$ Richtung einen neuen Doppelstrang.

Durch die Verdopplung des Ausgangssubstrats bei jedem Amplifikationszyklus kommt es zu einer exponentiellen Vermehrung der kopierten DNA-Fragmente. Insgesamt werden 35 PCRZyklen im Thermocycler durchgeführt. Vor der Einleitung des ersten Zyklus erfolgt eine Initiale Denaturierung über $15 \mathrm{~min}$ bei $+95^{\circ} \mathrm{C}$. Dieser Schritt ist notwendig, um die thermostabile hot start Taq-Polymerase zu aktivieren. Nach Abschluss des letzten Zyklus erfolgt die Finale Extension bei $+72{ }^{\circ} \mathrm{C}$ für $10 \mathrm{~min}$, um die Amplifikationsschritte zu beenden und eine doppelsträngige DNA zu erhalten.

\section{Verwendete Mikrosatellitenmarker:}

Unter Verwendung von acht hochpolymorphen Tetranukleotid-Mikrosatellitenmarker wurden für jedes zu untersuchende Zwillingsindividuum acht spezifische DNA-Fragmente in getrennten Ansätzen amplifiziert. Die verwendeten acht Mikrosatellitenmarker wurde aus dem „AmpFlSTR $®$ Identifiler® PCR Amplification Kit““ ausgewählt. Hierbei handelt es sich um ein „Standard-Kit“, das in der forensischen Medizin zur Identifizierung menschlicher Individuen verwendet wird. Dieses „Kit“ enthält insgesamt 15 fluoreszierende Mikrosatellitenmarker (CSF1P0, D2S1338, D3S1358, D5S818, D7S820, D8S1179, D13S317,

D16S539, D18S51, D19S433, D21S11, FGA, TH01, TPOX, vWA) zur Koamplifikation von 15 STR-Loci (Sort-Tandem-Repeat). Die in dieser Arbeit verwendeten TetranukleotidMikrosatellitenmarker sind im Folgenden aufgelistet (Tabelle 5). 
Tab. 5: Auswahl hochpolymorpher Mikrosatellitenmarker (AmpFlSTR® Identifiler® PCR Amplification Kit)

\begin{tabular}{|c|c|}
\hline & Mikrosatellitenmarker \\
\hline 1 & D 8 S1179 \\
2 & D13S317 \\
3 & D5S818 \\
4 & D16S539 \\
5 & D3S1358 \\
6 & D21S11 \\
7 & D18S51 \\
8 & D7S820 \\
\hline
\end{tabular}

\subsubsection{Fragmentanalyse}

\section{Prinzip:}

Die amplifizierten DNA-Fragmente wurden durch eine Gelelektrophorese im elektrischen Feld nach ihrer Molekülgröße aufgetrennt. Größere DNA-Fragmente laufen langsamer durch das Gel als kürzere. Anhand eines mitlaufenden Größenstandards (Formamid-GS500LIZ) mit genau definierten Banden lässt, sich die Länge der einzelnen DNA-Fragmente bestimmen.

\section{Reaktionsansatz:}

PCR-Produkt (1:100 verdünnt)

$1,0 \mu 1$

Formamid-GS500LIZ (1:100 verdünnt)

$\frac{12,0 \mu \mathrm{l}}{13,0 \mu \mathrm{l}}$

\section{Durchführung:}

Der oben aufgeführte Reaktionsansatz wurde für jede Probe auf eine 96er Sequenzierplatte pipettiert. Im Thermocycler erfolgte bei $+95^{\circ} \mathrm{C}$ für 2 min die Denaturierung der doppelsträngigen DNA in einen DNA-Einzelstrang. Im Anschluss an den Denaturierungsschritt wurde das Reaktionsgemisch 5 min auf Eiswasser abgekühlt. Die nun wieder als Einzelstrang vorliegenden DNA-Fragmente wurden in dem Applied Biosystems 3730 DNA Analyzer (ABI 3730 Sequenzer) analysiert, wo sie im POP7-Gel anhand ihrer Fragmentgröße aufgetrennt wurden. 


\section{Auswertung:}

Die Auswertung der Fragmentanalyse erfolgte mit der GeneMapper ${ }^{\mathrm{TM}}$ Software Version 3.0. Innerhalb jedes Zwillingspaares mussten mindestens sieben der acht Mikrosatellitenmarker auswertbar sein. Der Ausfall eines Markers wurde in dieser Arbeit akzeptiert, da in der Literatur die Wahrscheinlichkeit einer korrekt determinierter Zygotie bei der Auswertung von fünf Mikrosatellitenmarkern mit 99\% angegeben wird (Becker et al. 1997). Erbrachten alle Mikrosatellitenmarker (mindestens sieben auswertbare Marker) identische Fragmentgrößen auf beiden Allelen, wurden die Zwillingspaare als MZ klassifiziert, beim Nachweis einer abweichenden Fragmentgröße nur eines Allels, wurde eine erneute Genotypisierung des betreffenden Zwillingspaares mit zusätzlichen Marker durchgeführt, um technische Fehler auszuschließen. Beim Nachweis abweichender Fragmentgröße mehrerer Allele (mindestens zwei abweichende Fragmentgrößen) innerhalb eines Zwillingspaares, wurde dieses als DZ klassifiziert.

\subsection{Statistische Auswertung}

Zur Beurteilung der Korrelation zwischen den Zwillingspaaren wurden Paarweise Konkordanzraten (pairwise concordance, PWC) und Probandenweise Konkordanzraten (casewise concordance, CWC) für MZ und DZ Zwillingspaare berechnet. Die PWC ist definiert als die Anzahl der konkordanten Zwillingspaare geteilt durch die Summe aus konkordanten und diskordanten Zwillingspaaren $(\mathrm{C} / \mathrm{C}+\mathrm{D}$, mit $\mathrm{C}=$ Anzahl der konkordanten Zwillingspaare und D = Anzahl der diskordanten Zwillingspaare). Die CWC ist definiert als die Anzahl der konkordanten Zwillingsindividuen geteilt durch die Summe aus konkordanten Zwillingsindividuen und diskordanten Zwillingspaaren $(2 \mathrm{C} / 2 \mathrm{C}+\mathrm{D}$, mit $\mathrm{C}=$ Anzahl der konkordanten Zwillingspaare und $\mathrm{D}=$ Anzahl der diskordanten Zwillingspaare). Aus der PWC wurde die Erblichkeit mittels Strukturgleichungsmodell (structural equation modelling, ACE-Modell) unter Verwendung der Mx Software (Neale et al. 2002) abgeschätzt. Hierzu wurde die tetrachorischen Korrelation berechnet. Diese Berechnung beruht auf der Annahme, dass eine latente normalverteilte Risikovariable mit einem Schwellenwert vorliegt, der zu der beobachteten Häufigkeit der Erkrankung führt. Die Korrelation dieser latenten Risikovariablen wird jeweils innerhalb der MZ und DZ Zwillinge ermittelt. Basierend auf der tetrachorischen Korrelation, wurde der relative Varianzanteil additiv-genetischer Einflüsse (A) sowie gemeinsamer (C) und getrennter (E) Umwelteinflüsse bestimmt. Im Rahmen dieses 
Modells werden genetische und umweltbedingte Effekte gebildet, die als ungemessene (latente) Variable einen Beitrag zu einer möglichen multivariaten phänotypischen Differenz zwischen MZ und DZ Zwillingen leisten (Boomsma et al. 2002).

Die statistische Auswertung der vorliegenden Daten erfolgte mittels des SPSS Software Paketes 16.0 (SPSS Inc., Chicago, USA) sowie mittels Microsoft Excel 2003. p-Werte < 0,05 wurden dabei als signifikant erachtet. Kategoriale Variablen wurden untereinander mittels des exakten Tests nach Fisher verglichen. 


\section{ERGEBNISSE}

\subsection{Probandenrekrutierung über das Zwillingsregister HealthTwiSt}

Insgesamt wurde der Gesundheitsfragebogen, der die drei RLS-Diagnosefragen beinhaltet (Walters 1995; Berger et al. 2004), an 638 MZ und DZ Zwillingsindividuen aus 319 Zwillingspaaren aus dem Berliner Zwillingsregister von HealthTwiSt geschickt. Hieraus konnten insgesamt $49 \mathrm{MZ}$ und $\mathrm{DZ}$ Zwillingspaare ( $=98$ Zwillingsindividuen) für die anschließende Untersuchung ermittelt werden, innerhalb derer mindestens eine der drei RLSDiagnosefragen positiv beantwortet wurde.

Die erste Frage (Frage 12.3: Missempfinden und Bewegungsdrang, siehe Anhang 1) wurde von 62 Individuen $(9,7 \%)$ positiv beantwortet. Die zweite Frage (Frage 12.4: Symptome in Ruhe mit Besserung bei Bewegung, siehe Anhang 1) wurde von 50 Probanden (7,8\%) positiv beantwortet. Die dritte Frage (Frage 12.5: Symptome abends oder nachts schlimmer, siehe Anhang 1) wurde von 42 Zwillingsindividuen $(6,6 \%)$ positiv beantwortet. Innerhalb der 49 Zwillingspaare (N= 98 Individuen) haben insgesamt 34 Zwillingsindividuen (34,7\%) alle drei Diagnosefragen mit „Ja“ beantwortet, 23 Zwillingsindividuen (23,5\%) haben zwei Diagnosefragen mit „Ja“ beantwortet und fünf Zwillingsindividuen $(5,1 \%)$ haben jeweils nur eine Diagnosefrage mit „Ja“ beantwortet (Abbildung 2).

Das Alter der 49 Zwillingspaare (N=98 Zwillingsindividuen) lag zwischen 19 und 75 Jahren mit einem Durchschnittsalter von 44,67 Jahre (SD +/- 15,12 Jahre). Der Anteil an Frauen überwog mit 74,5\% (N=73) gegenüber den männlichen Zwillingsindividuen mit $25,5 \%(\mathrm{~N}=$ 25). 
Abb. 2: Auswertung der RLS-Diagnosefragen des Gesundheitsfragebogens

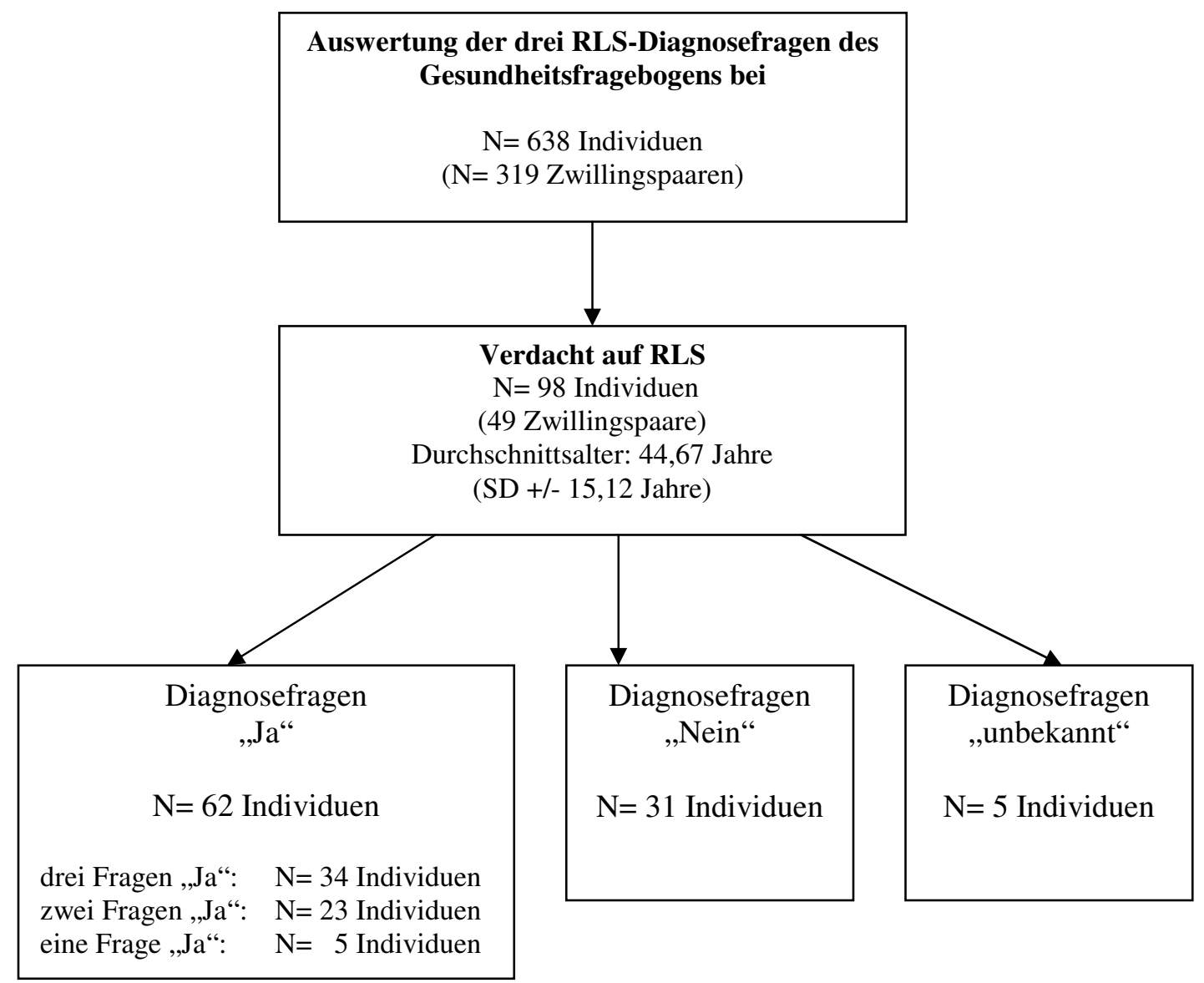

Insgesamt bestätigten 57 der 98 Zwillingsindividuen ihre Bereitschaft zur Teilnahme an der Studie zur weiteren Untersuchung der anhand der Diagnosefragen erhobenen möglichen RLSBeschwerden. Hieraus lässt sich eine Rücklaufquote von $58,2 \%$ errechen. Von den 41 Individuen (41,8\%), die keine Rückantwort zurückschickten, waren neun Zwillingsindividuen $(9,2 \%)$ unbekannt verzogen. Gründe für eine fehlende Rückantwort konnten bei den restlichen 32 Individuen nicht eruiert werden. Aus den 57 Zwillingsindividuen ließen sich 27 komplette Zwillingspaare bilden. Drei Zwillingsindividuen wurden aufgrund fehlender Zusage des jeweiligen Zwillingspartners aus der Studie ausgeschlossen. Einer dieser Zwillingspartner war verstorben, ein weiterer konnte aufgrund einer Alzheimer-Demenz nicht befragt werden und der dritte Zwillingspartner war auch nach mehrfachen Versuchen nicht zu kontaktieren. Ein weiteres Zwillingspaar konnte wegen Aufenthalt in Neuseeland und USA telefonisch nicht befragt werden und wurde ebenfalls aus der Studie ausgeschlossen. Insgesamt wurde bei 26 vollständigen Zwillingspaaren (53,1\% der 49 Zwillingspaare, die mittels drei RLSDiagnosefragen ermittelt wurden) ein telefonisches Interview zur anschließenden Diagnosesicherung eines RLS erfolgreich durchgeführt (Abbildung 3). 
Insgesamt konnten im Rahmen des diagnostischen Telefoninterviews von den 26 untersuchten Zwillingspaaren 17 Zwillingspaare (N= 34 Zwillingsindividuen) mit einem RLS identifiziert werden. Das bedeutet, dass mindestens ein Zwillingsindividuum innerhalb eines Zwillingspaares einmal im Leben die Symptome eines RLS wahrgenommen hatte. Innerhalb dieser 17 Zwillingspaare ( $\mathrm{N}=34$ Zwillingsindividuen) wurden 24 Zwillingsindividuen als „sicher RLS-positiv“, vier Zwillingsindividuen als „möglich RLS-positiv“ und weitere sechs Zwillingsindividuen als „RLS-negativ“ klassifiziert (Abbildung 3).

Abb. 3: Anschlussuntersuchung nach Auswertung der RLS-Diagnosekriterien des Gesundheitsfragebogens

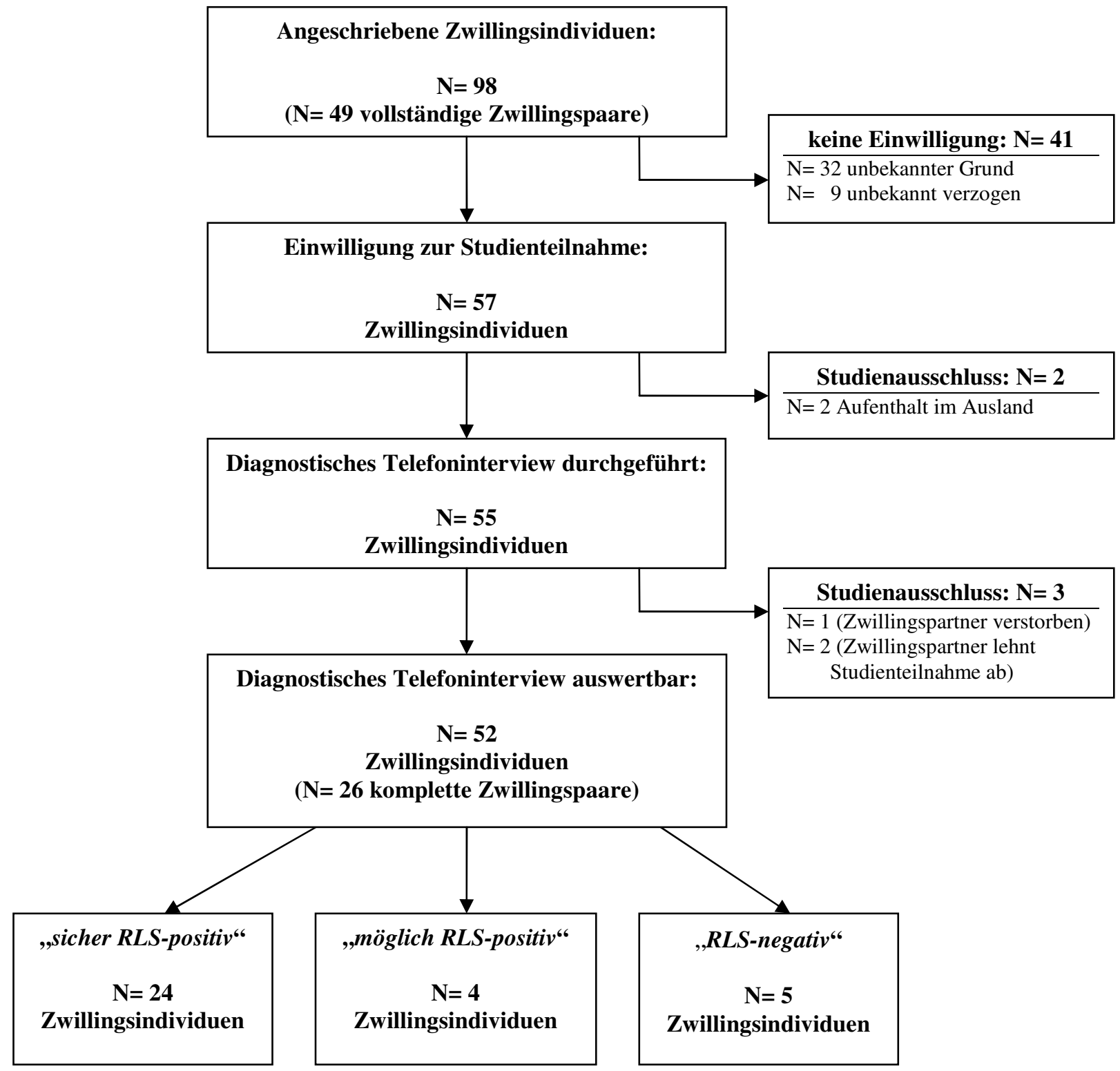


Von den 24 Zwillingsindividuen, bei denen im diagnostischen Telefoninterview ein ,sicheres RLS“ diagnostiziert wurde, haben elf Zwillingsindividuen (45,8\%) alle drei RLSDiagnosefragen im Gesundheitsfragebogens positiv beantwortet, fünf Zwillingsindividuen (20,8\%) haben zwei RLS-Diagnosefragen positiv beantwortet und zwei Zwillingsindividuen $(8,4 \%)$ haben eine RLS-Diagnosefragen positiv beantwortet. Weitere sechs Zwillingsindividuen (25,0\%) wurden im Rahmen des diagnostischen Telefoninterviews als „sicher RLS-positiv“ diagnostiziert, sie beantworteten jedoch keine der drei RLSDiagnosefragen des Gesundheitsfragebogens positiv (Tabelle 6).

Tab. 6: Vergleich Ergebnisse der RLS-Diagnosefragen und des diagnostischen Telefoninterviews

\begin{tabular}{|c|c|c|c|c|}
\hline \multicolumn{2}{|c}{} & \multicolumn{3}{|c|}{ Diagnostischen Telefoninterview $^{(2)}$} \\
\cline { 3 - 5 } & $\begin{array}{c}\text { RLS sicher } \\
(\mathbf{n})\end{array}$ & $\begin{array}{c}\text { RLS möglich } \\
(\mathbf{n})\end{array}$ & $\begin{array}{c}\text { RLS negativ } \\
(\mathbf{n})\end{array}$ \\
\hline \multirow{3}{*}{$\begin{array}{c}\text { RLS- } \\
\text { Diagnosefragen }\end{array}$} & $\begin{array}{c}\text { 3 positive } \\
\text { Diagnosefragen }\end{array}$ & 11 & 1 & 1 \\
\cline { 2 - 5 } $\begin{array}{c}\text { 2 positive } \\
\text { des Gesundheits- } \\
\text { fragebogens }\end{array}$ & $\begin{array}{c}\text { 1 positive } \\
\text { Diagnosefragen }\end{array}$ & 5 & 3 & 1 \\
\cline { 2 - 5 } & $\begin{array}{c}\text { keine positive } \\
\text { Diagnosefragen }\end{array}$ & $\mathbf{6}$ & - & - \\
\hline
\end{tabular}

(1) Rekrutierung der Zwillinge mittels drei RLS-Diagnosefragen aus dem Zwillingsregister von HealthTwiSt (Walters 1995; Berger et al. 2004)

(2) Telefonisches Interview mittels vier Diagnosekriterien der IRLSSG (Walters 1995; Allen et al. 2003)

\subsection{Probandenrekrutierung über Spezialambulanzen für Restless Legs Syndrom und die Deutsche Restless Legs Vereinigung, RLS e.V.}

Weitere 17 Zwillingspaare wurden über RLS-Spezialambulanzen und die Deutsche Restless Legs Vereinigung (RLS e.V.) rekrutiert und in einem standardisierten diagnostischen Telefoninterview auf das mögliche Vorhandensein eines RLS untersucht. Aus diesen 17 Zwillingspaaren konnten zwölf weitere Zwillingspaare mit einem RLS ermittelt werden. Bei fünf der untersuchten Zwillingspaare konnte kein RLS diagnostiziert werden. Innerhalb der zwölf Zwillingspaare mit RLS (N=24 Zwillingsindividuen) wurden 20 Zwillingsindividuen $(83,3 \%)$ als „,sicher RLS-positiv“ und weitere vier Zwillingsindividuen (16,7\%) als „RLSnegativ“" diagnostiziert. 


\subsection{Demographische Daten der Zwillinge}

Aus den beiden Probandenkollektiven (Zwillingsregister und RLS-Population aus Spezialambulanzen und Patientenvereinigung) wurden insgesamt 29 Zwillingspaare im Rahmen des diagnostischen Telefoninterviews mit einem RLS diagnostiziert (17 Zwillingspaare über Zwillingsregister HealthTwist; 12 Zwillingspaare über die RLSSpezialambulanzen und Patientenorganisationen). Abbildung 4 gibt eine zusammenfassende Übersicht über die Diagnosestellung eines RLS mittels diagnostischem Telefoninterview bei allen Zwillingspaaren aus den beiden Probandenkollektiven.

Abb. 4: Diagnosesicherung im diagnostischen Telefoninterview in der Übersicht

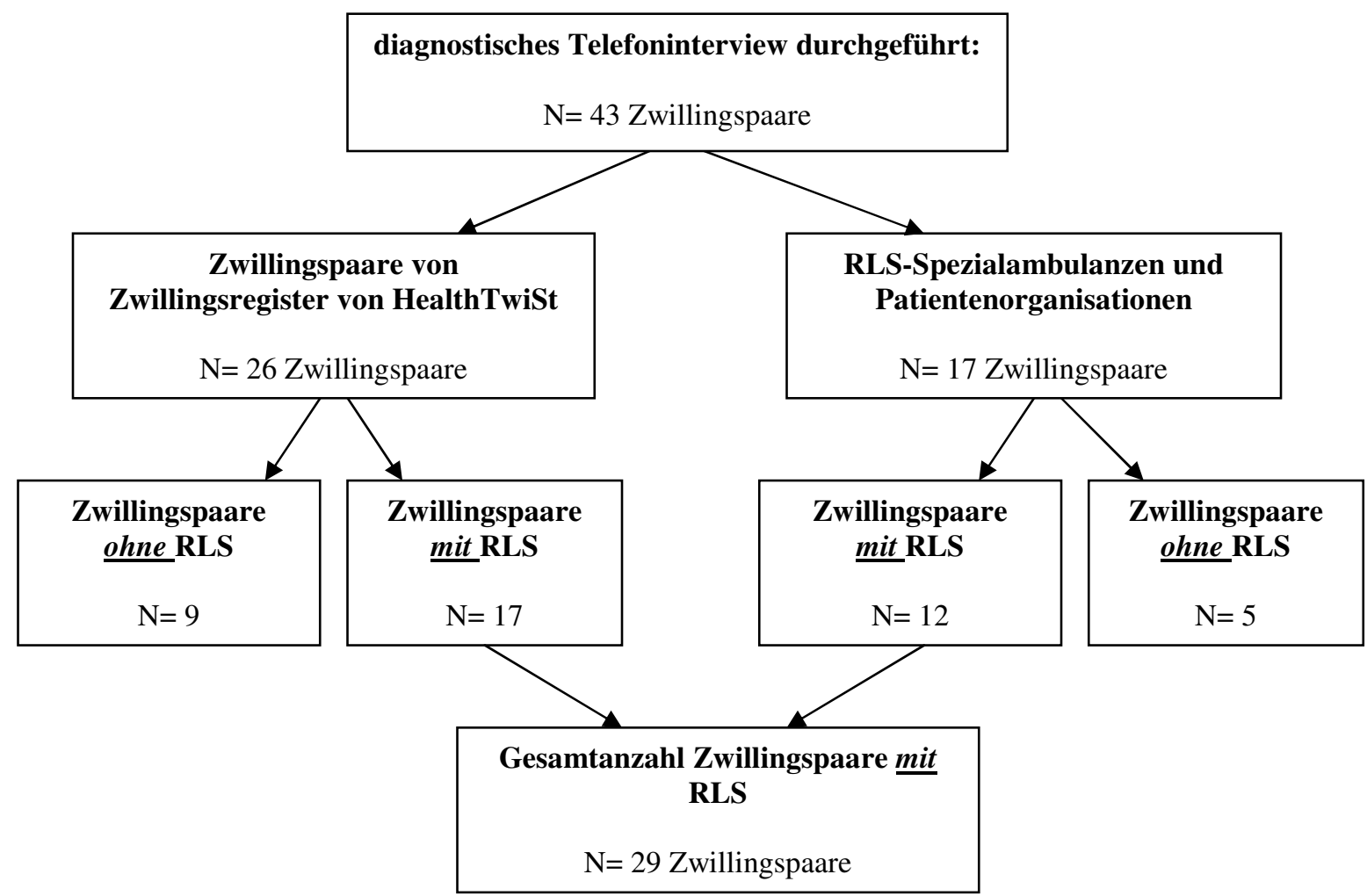

Innerhalb dieser diagnostizierten 29 Zwillingspaare $(\mathrm{N}=58$ Zwillingsindividuen) haben 48 Zwillingsindividuen Symptome eines RLS angegeben (Gesamtübersicht Tabelle 9). Davon wurden nach Auswertung der Diagnosekriterien 13 Zwillingsindividuen (27,1\%) mit der Diagnoseziffer „1“ bewertet, da vier Diagnosekriterien erfüllt waren und die Diagnose durch das Ansprechen auf eine dopaminerge Therapie unterstützt wurde. Ebenfalls alle vier Diagnosekriterien haben weitere 31 Zwillingsindividuen (64,6\%) erfüllt. Diese erhielten jedoch wegen unbekannter Wirkung einer dopaminergen Medikation die Diagnoseziffer „2“. 
Somit konnten 44 Individuen (91,7\%) als „,sicher RLS-positiv“ (Diagnoseziffer „1“ oder „2“) klassifiziert werden. Weitere vier Individuen $(8,3 \%)$ erhielten die Diagnoseziffer „3“ (drei Diagnosekriterien erfüllt) und galten somit als „wahrscheinlich RLS-positiv“ (Tabelle 7).

Tab. 7: Zwillingsindividuen mit RLS, N= 48

\begin{tabular}{|c|c|c|}
\hline \multicolumn{2}{|c|}{$\begin{array}{l}\text { „sicher RLS-positiv“6 } \\
\text { N= Zwillingsindividuen }\end{array}$} & $\begin{array}{c}\text { „wahrscheinlich RLS-positiv“ } \\
\text { N= Zwillingsindividuen }\end{array}$ \\
\hline $\begin{array}{l}\text { Vier Diagnosekriterien + } \\
\text { Zusatzkriterium (DZ „,1“) }\end{array}$ & $\begin{array}{l}\text { Vier Diagnosekriterien } \\
\left(\mathrm{DZ}, 2^{*}\right)\end{array}$ & $\begin{array}{l}\text { Drei Diagnosekriterien } \\
\left(\mathrm{DZ}, 3^{*}\right)\end{array}$ \\
\hline $13(27,1 \%)$ & $31(64,6 \%)$ & $4(8,3 \%)$ \\
\hline \multicolumn{2}{|c|}{$44(91,7 \%)$} & $4(8,3 \%)$ \\
\hline
\end{tabular}

DZ: Diagnoseziffer (Definition siehe 3.2.1., Tabelle Nr. 4)

Das durchschnittliche Alter aller RLS-betroffenen Zwillinge beträgt bei Diagnoseerhebung 50,4 Jahre (SD +/-13,12 Jahre) mit einer Alterspanne von 21 bis 67 Jahren (Tabelle 8).

Tab. 8: Alters-, Geschlechtsverteilung der Zwillingsindividuen mit RLS, N= 48

\begin{tabular}{|c|c|c|c|c|}
\hline & & $\mathbf{N}$ & & $\%$ \\
\hline \multirow[t]{2}{*}{ Geschlecht } & Frauen & 32 & \multicolumn{2}{|r|}{66,7} \\
\hline & Männer & 16 & \multicolumn{2}{|r|}{33,3} \\
\hline \multirow[t]{4}{*}{ Altersgruppe } & $21-40$ & 12 & \multicolumn{2}{|r|}{25,0} \\
\hline & $41-50$ & 10 & \multicolumn{2}{|r|}{20,8} \\
\hline & $51-60$ & 13 & \multicolumn{2}{|r|}{27,1} \\
\hline & $61-70$ & 13 & \multicolumn{2}{|r|}{27,1} \\
\hline Alter bei & Mittel & SD & Min & $\operatorname{Max}$ \\
\hline Untersuchung & 50,4 & 13,3 & 21 & 67 \\
\hline
\end{tabular}

Mittel: Durchschnittsalter in Jahren

SD: Standardabweichung in Jahren

Min/Max: Minimalalter/Maximalalter der Zwillinge in Jahren 
Tab. 9: Gesamtübersicht ausgewertete Zwillinge, $\mathrm{N}=58$ ( $\mathrm{N}=48$ RLS-positiv, $\mathrm{N}=10$ RLS-negativ)

\begin{tabular}{|c|c|c|c|c|c|c|c|}
\hline Zwilling & $\begin{array}{c}\text { Alter bei } \\
\text { Daten- } \\
\text { erhebung }\end{array}$ & Geschl & Zygotie & RLS & $\begin{array}{l}\text { Alter bei } \\
\text { Symptom- } \\
\text { beginn }\end{array}$ & $\begin{array}{l}\text { Familien- } \\
\text { anamnese }\end{array}$ & $\begin{array}{c}\text { Schwere- } \\
\text { grad }\end{array}$ \\
\hline $002-A$ & 37 & q & $\mathrm{MZ}$ & ja & 18 & positiv & 12 \\
\hline 002-B & 37 & q & $\mathrm{MZ}$ & ja & 22 & positiv & 14 \\
\hline 003-A & 55 & $\lambda$ & $\mathrm{MZ}$ & nein & I & positiv & I \\
\hline 003-B & 55 & $0^{\lambda}$ & $\mathrm{MZ}$ & ja & 54 & positiv & 27 \\
\hline 004-A & 55 & q & $\mathrm{MZ}$ & ja & 50 & positiv & 22 \\
\hline 004-B & 55 & q & $\mathrm{MZ}$ & ja & 25 & positiv & 20 \\
\hline 005-A & 42 & q & $\mathrm{MZ}$ & möglich & 38 & positiv & 0 \\
\hline 005-B & 42 & q & $\mathrm{MZ}$ & nein & 1 & positiv & 1 \\
\hline 006-A & 66 & o & $\mathrm{MZ}$ & ja & 50 & positiv & 6 \\
\hline 006-B & 66 & $\pi$ & $\mathrm{MZ}$ & ja & 50 & positiv & 6 \\
\hline 007-A & 52 & q & $\mathrm{DZ}$ & ja & 1 & positiv & 7 \\
\hline 007-B & 52 & $\hat{0}$ & DZ & ja & 20 & positiv & 13 \\
\hline 008-A & 32 & $0^{\lambda}$ & $\mathrm{MZ}$ & ja & 28 & positiv & 8 \\
\hline 008-B & 32 & $\hat{0}$ & $\mathrm{MZ}$ & möglich & 20 & positiv & 8 \\
\hline 009-A & 56 & q & $\mathrm{DZ}$ & möglich & 21 & negativ & 21 \\
\hline 009-B & 56 & $q$ & $\mathrm{DZ}$ & nein & I & negativ & 1 \\
\hline 010-A & 37 & $\lambda^{\lambda}$ & $\mathrm{MZ}$ & ja & 20 & negativ & 23 \\
\hline 010-B & 37 & 1 & $\mathrm{MZ}$ & nein & I & negativ & 1 \\
\hline 011-A & 65 & q & DZ & ja & 60 & positiv & 21 \\
\hline 011-B & 65 & 우 & DZ & ja & 60 & positiv & 19 \\
\hline 013-A & 53 & q & $\mathrm{MZ}$ & ja & 44 & negativ & 32 \\
\hline 013-B & 53 & q & $\mathrm{MZ}$ & nein & 1 & negativ & 1 \\
\hline 014-A & 21 & q & $\mathrm{DZ}$ & ja & 15 & negativ & 14 \\
\hline 014-B & 21 & $0^{\lambda}$ & DZ & nein & 1 & negativ & 1 \\
\hline 015-A & 66 & q & $\mathrm{DZ}$ & ja & 59 & positiv & 1 \\
\hline 015-B & 66 & q & DZ & ja & 62 & positiv & 21 \\
\hline 016-A & 54 & q & $\mathrm{MZ}$ & nein & I & negativ & I \\
\hline 016-B & 54 & q & $\mathrm{MZ}$ & ja & 47 & negativ & 21 \\
\hline 017-A & 25 & q & $\mathrm{MZ}$ & ja & 13 & positiv & 0 \\
\hline 017-B & 25 & 우 & $\mathrm{MZ}$ & ja & 4 & positiv & 0 \\
\hline 018-A & 50 & q & $\mathrm{MZ}$ & ja & 30 & positiv & 19 \\
\hline 018-B & 50 & q & $\mathrm{MZ}$ & $\mathrm{ja}$ & 15 & positiv & 19 \\
\hline 019-A & 40 & q & $\mathrm{MZ}$ & ja & 10 & positiv & 29 \\
\hline 019-B & 40 & q & $\mathrm{MZ}$ & ja & 10 & positiv & 24 \\
\hline 022-A & 67 & $\hat{0}$ & $\mathrm{MZ}$ & ja & 50 & positiv & 21 \\
\hline 022-B & 67 & $\hat{0}$ & $\mathrm{MZ}$ & ja & 40 & positiv & 24 \\
\hline
\end{tabular}


Fortsetzung Tab. 9:

\begin{tabular}{|c|c|c|c|c|c|c|c|}
\hline Zwilling & $\begin{array}{l}\text { Alter bei } \\
\text { Daten- } \\
\text { erhebung }\end{array}$ & Geschl & Zygotie & RLS & $\begin{array}{c}\text { Alter bei } \\
\text { Symptom- } \\
\text { beginn }\end{array}$ & $\begin{array}{l}\text { Familien- } \\
\text { anamnese }\end{array}$ & $\begin{array}{c}\text { Schwere- } \\
\text { grad }\end{array}$ \\
\hline 023-A & 65 & 우 & $\mathrm{DZ}$ & ja & 20 & positiv & 18 \\
\hline 023-B & 65 & q & DZ & nein & I & positiv & I \\
\hline 024-A & 66 & q & $\mathrm{MZ}$ & ja & 35 & positiv & 8 \\
\hline 024-B & 67 & q & $\mathrm{MZ}$ & ja & 57 & positiv & 11 \\
\hline 025-A & 42 & q & $\mathrm{MZ}$ & ja & 35 & positiv & 9 \\
\hline 025-B & 42 & q & $\mathrm{MZ}$ & ja & 36 & positiv & 7 \\
\hline 026-A & 27 & స & DZ & ja & 18 & positiv & 14 \\
\hline 026-B & 27 & 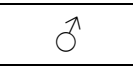 & $\mathrm{DZ}$ & $\mathrm{ja}$ & 13 & positiv & 10 \\
\hline 027-A & 54 & $\hat{0}$ & $\mathrm{MZ}$ & $\mathrm{ja}$ & 40 & positiv & 8 \\
\hline 027-B & 54 & $\hat{0}$ & $\mathrm{MZ}$ & ja & 30 & positiv & 0 \\
\hline 028-A & 52 & $q$ & $\mathrm{MZ}$ & ja & 44 & positiv & 10 \\
\hline 028-B & 52 & q & $\mathrm{MZ}$ & ja & 49 & positiv & 0 \\
\hline 029-A & 58 & 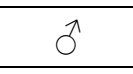 & DZ & $\mathrm{ja}$ & 25 & positiv & 0 \\
\hline 029-B & 58 & 0 & DZ & nein & 1 & positiv & 1 \\
\hline 030-A & 60 & 0 & DZ & ja & 50 & positiv & 1 \\
\hline 030-B & 60 & q & DZ & nein & 1 & positiv & 1 \\
\hline 031-A & 65 & q & $\mathrm{MZ}$ & ja & 45 & positiv & 34 \\
\hline 031-B & 65 & q & $\mathrm{MZ}$ & ja & 45 & positiv & 33 \\
\hline 032-A & 46 & q & $\mathrm{MZ}$ & ja & 20 & positiv & 10 \\
\hline 032-B & 46 & $q$ & $\mathrm{MZ}$ & ja & 29 & positiv & 2 \\
\hline 033-A & 52 & $\hat{0}$ & $\mathrm{DZ}$ & ja & 32 & positiv & 38 \\
\hline 033-B & 52 & q & $\mathrm{DZ}$ & ja & 40 & positiv & 28 \\
\hline
\end{tabular}

MZ: monozygot; DZ: dizygot

: : weiblich $\delta^{\top}:$ männlich

Geschl: Geschlecht

Schweregrad: Punktewert der Schweregrad-Skala

Familienanamnese:

positiv $=$ bei mindestens einem weiteren Familienmitglied, inklusive dem Zwillingspartner, bestand ebenfalls eine diagnostizierte RLS-Symptomatik, oder konnte diese aufgrund geäußerter typischer Beschwerden ohne bisher gesichterte Diagnose angenommen werden.

negativ $=$ es waren keine weiteren Familienmitglieder bekannt, bei denen ein RLS diagnostiziert wurde oder bei denen Symptome eines RLS ohne bisherige Diagnosestellung bestanden. 


\subsection{Zygotie und Geschlechtsverteilung innerhalb der Zwillingspaare}

Die Genotypisierung zum Nachweis der Zygotie wurde bei 25 gleichgeschlechtlichen Zwillingspaaren durchgeführt. Gegengeschlechtliche Zwillingspaare wurden ohne genetischen Zygotienachweis der Gruppe der DZ Zwillingspaare zugeordnet. Nach der Auswertung mit Hilfe des Programms GeneMapper Version 3.5, konnten die diagnostizierten Zwillingspaare in $19 \mathrm{MZ}$ und sechs DZ Zwillingspaare klassifiziert werden. Zusätzliche vier Zwillingspaare wurden aufgrund ihrer Gegengeschlechtlichkeit als DZ klassifiziert. Somit wurden in dieser Studie insgesamt 19 MZ und zehn DZ Zwillingspaare identifiziert. Bei zwei Zwillingspaaren (006-A/B; 018-A/B) konnte jeweils ein hochpolymorpher Mikrosatellitenmarker nicht ausgewertet werden, sieben Mikrosatellitenmarker zeigten identische Tetranukleotidrepeatfrequenzen. Diese Zwillingspaare wurden als MZ klassifiziert, da eine Treffsicherheit von mindestens $99 \%$ bereits bei der Auswertung von fünf Mikrosatellitenmarkern in einer früheren Studie gezeigt werden konnte (Becker et al. 1997). Die Tabelle 10 zeigt alle ausgewerteten 29 Zwillingspaare und die „Repeatfrequenzen“ der beiden Allele für die acht im Methodenteil unter Punkt 3.3.2 aufgeführten hochpolymorphen Mikrosatellitenmarker. In der Abbildung 5 und 6 ist die Auswertung für den Mikrosatellitenmarker D8S1179 für jeweils ein MZ und DZ Zwillingspaar im Vergleich dargestellt. 
Tab. 10: Auswertung Fragmentanalyse, $N=25$ gleichgeschlechtliche Zwillingspaare

\begin{tabular}{|c|c|c|c|c|c|c|c|c|c|c|c|c|c|c|c|c|c|}
\hline & \multicolumn{16}{|c|}{ Mikrosatellitenmarker } & \multirow{3}{*}{$\frac{\text { Zygotie }}{\text { MZ }}$} \\
\hline ID & \multicolumn{2}{|c|}{ D8S1179 } & \multicolumn{2}{|c|}{ D13S317 } & \multicolumn{2}{|c|}{ D5S818 } & \multicolumn{2}{|c|}{ D16S539 } & \multicolumn{2}{|c|}{ D3S1358 } & \multicolumn{2}{|c|}{ D21S11 } & \multicolumn{2}{|c|}{ D18S51 } & \multicolumn{2}{|c|}{ D7S820 } & \\
\hline \multirow{2}{*}{$\begin{array}{l}002-A \\
002-B\end{array}$} & 176 & 184 & 186 & 190 & 148 & 152 & 148 & 160 & 129 & 137 & 228 & 238 & 290 & 294 & 210 & 214 & \\
\hline & 176 & 184 & 186 & 190 & 148 & 152 & 148 & 160 & 129 & 137 & 228 & 238 & 290 & 294 & 210 & 214 & MZ \\
\hline \multirow{2}{*}{$\begin{array}{l}003-A \\
003-B\end{array}$} & 184 & 184 & 174 & 178 & 152 & 152 & 160 & 160 & 129 & 133 & 214 & 230 & 294 & 298 & 206 & 218 & \multirow[t]{2}{*}{$\mathrm{MZ}$} \\
\hline & 184 & 184 & 174 & 178 & 152 & 152 & 160 & 160 & 129 & 133 & 214 & 230 & 294 & 298 & 206 & 218 & \\
\hline \multirow{2}{*}{$\begin{array}{l}\text { 004-A } \\
\text { 004-B }\end{array}$} & 180 & 184 & 190 & 198 & 148 & 152 & 148 & 160 & 133 & 137 & 214 & 218 & 290 & 294 & 218 & 218 & \multirow[t]{2}{*}{ MZ } \\
\hline & 180 & 184 & 190 & 198 & 148 & 152 & 148 & 160 & 133 & 137 & 214 & 218 & 290 & 294 & 218 & 218 & \\
\hline \multirow{2}{*}{$\begin{array}{l}005-A \\
005-B\end{array}$} & 172 & 180 & 174 & 186 & 144 & 156 & 156 & 164 & 121 & 129 & 230 & 238 & 278 & 294 & 222 & 222 & \multirow{2}{*}{$\begin{array}{l}\text { MZ } \\
M Z\end{array}$} \\
\hline & 172 & 180 & 174 & 186 & 144 & 156 & 156 & 164 & 121 & 129 & 230 & 238 & 278 & 294 & 222 & 222 & \\
\hline \multirow{2}{*}{$\begin{array}{l}\text { 006-A } \\
\text { 006-B }\end{array}$} & & & 186 & 194 & 152 & 152 & 156 & 160 & 121 & 137 & 226 & 234 & 278 & 298 & 210 & 210 & \multirow{2}{*}{$\begin{array}{l}\mathrm{MZ} \\
\mathrm{MZ}\end{array}$} \\
\hline & 168 & 168 & 186 & 194 & 152 & 152 & 156 & 160 & 121 & 137 & 226 & 234 & 278 & 298 & 210 & 210 & \\
\hline 007-A & \multirow{2}{*}{\multicolumn{16}{|c|}{ Keine Fragmentanalyse, da Zwillingspaar gegengeschlechtlich }} & \\
\hline & & & & & & & & & & & & & & & & & \\
\hline \multirow{2}{*}{$\begin{array}{l}\text { 008-A } \\
\text { 008-B }\end{array}$} & 184 & 184 & 186 & 190 & 148 & 156 & 156 & 164 & 129 & 133 & 222 & 226 & 282 & 290 & 214 & 214 & \multirow{2}{*}{$\begin{array}{l}\mathrm{MZ} \\
\mathrm{MZ}\end{array}$} \\
\hline & 184 & 184 & 186 & 190 & 148 & 156 & 156 & 164 & 129 & 133 & 222 & 226 & 282 & 290 & 214 & 214 & \\
\hline \multirow{2}{*}{$\begin{array}{l}009-A \\
009-B\end{array}$} & 184 & 188 & 174 & 182 & 148 & 160 & 152 & 160 & 125 & 137 & 226 & 230 & 298 & 302 & 214 & 226 & \multirow{2}{*}{$\begin{array}{l}\mathrm{DZ} \\
\mathrm{DZ}\end{array}$} \\
\hline & 184 & 188 & 174 & 194 & 156 & 160 & 148 & 160 & 133 & 137 & 218 & 222 & 298 & 302 & 214 & 214 & \\
\hline \multirow{2}{*}{$\begin{array}{l}010-\mathrm{A} \\
010-\mathrm{B} \\
\end{array}$} & 176 & 180 & 186 & 186 & 152 & 164 & 156 & 160 & 137 & 137 & 214 & 238 & 290 & 306 & 218 & 218 & MZ \\
\hline & 176 & 180 & 186 & 186 & 152 & 164 & 156 & 160 & 137 & 137 & 214 & 238 & 290 & 306 & 218 & 218 & MZ \\
\hline 011-A & 180 & 180 & 178 & 186 & 144 & 152 & 156 & 164 & 133 & 137 & 218 & 222 & 282 & 302 & 214 & 222 & DZ \\
\hline 011-B & 168 & 188 & 178 & 190 & 144 & 156 & 156 & 156 & 125 & 133 & 222 & 226 & 282 & 302 & 214 & 222 & DZ \\
\hline 013-A & 184 & 196 & 186 & 190 & 148 & 148 & 148 & 156 & 129 & 133 & 222 & 222 & 286 & 294 & 214 & 214 & MZ \\
\hline 013-B & 184 & 196 & 186 & 190 & 148 & 148 & 148 & 156 & 129 & 133 & 222 & 222 & 286 & 294 & 214 & 214 & MZ \\
\hline $\begin{array}{l}\text { 014-A } \\
014-B\end{array}$ & & & & eine $\mathrm{F}$ & ragme & ntan & lyse, c & $\mathrm{a} \mathrm{Zw}$ & Illings & paar & segen & geschl & tli & & & & $\begin{array}{l}\mathrm{DZ} \\
\mathrm{DZ}\end{array}$ \\
\hline 015-A & 180 & 184 & 190 & 190 & 148 & 152 & 156 & 160 & 125 & 137 & 222 & 222 & 290 & 294 & 218 & 218 & DZ \\
\hline 015-B & 176 & 188 & 174 & 190 & 148 & 152 & 156 & 160 & 125 & 133 & 218 & 238 & 282 & 286 & 210 & 218 & DZ \\
\hline 016-A & 180 & 184 & 186 & 186 & 148 & 152 & 156 & 156 & 125 & 125 & 222 & 222 & 290 & 302 & 214 & 218 & MZ \\
\hline 016-B & 180 & 184 & 186 & 186 & 148 & 152 & 156 & 156 & 125 & 125 & 222 & 222 & 290 & 302 & 214 & 218 & $\mathrm{MZ}$ \\
\hline 017-A & 180 & 180 & 186 & 186 & 148 & 156 & 160 & 164 & 129 & 133 & 218 & 238 & 286 & 290 & 218 & 218 & MZ \\
\hline 017-B & 180 & 180 & 186 & 186 & 148 & 156 & 160 & 164 & 129 & 133 & 218 & 238 & 286 & 290 & 218 & 218 & $\mathrm{MZ}$ \\
\hline
\end{tabular}


Fortsetzung Tab. 10:

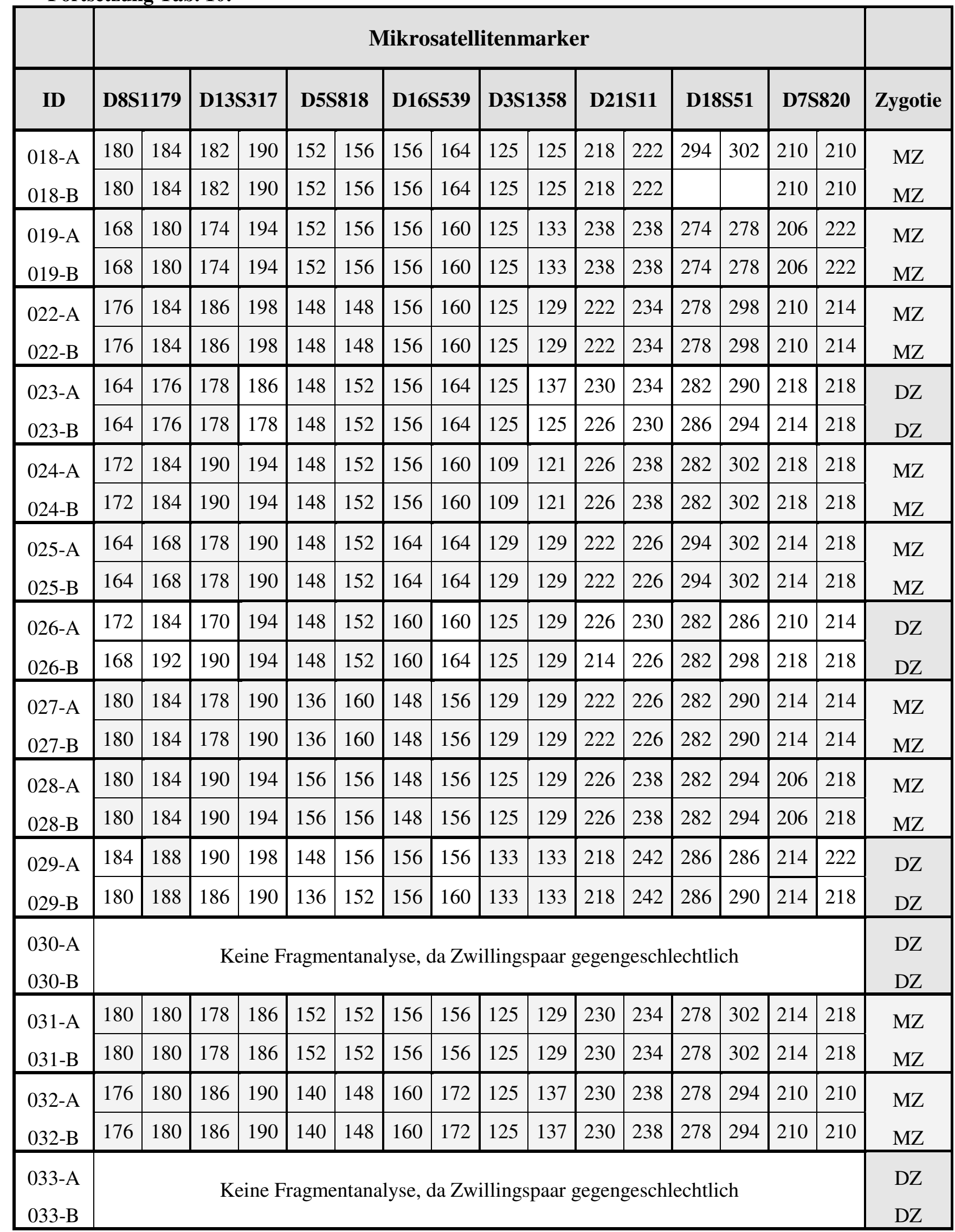

MZ: monozygot, DZ dizygot 
Abb. 5: Fragmentanalyse Zwillingspaar 002-A/B, MZ, Marker D8S1179
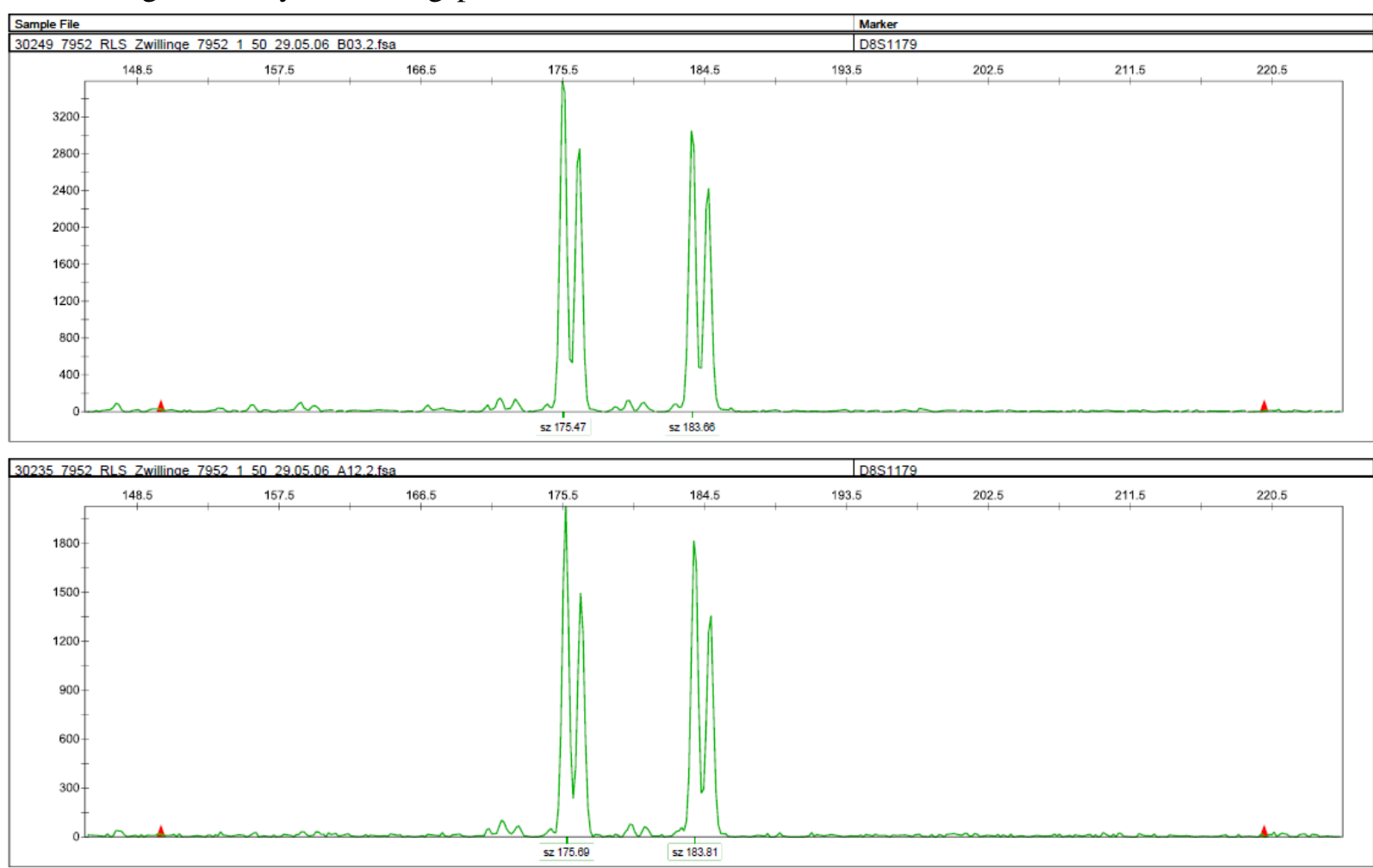

Abb. 6: Fragmentanalyse Zwillingspaar 015-A/B, DZ, Marker D8S1179
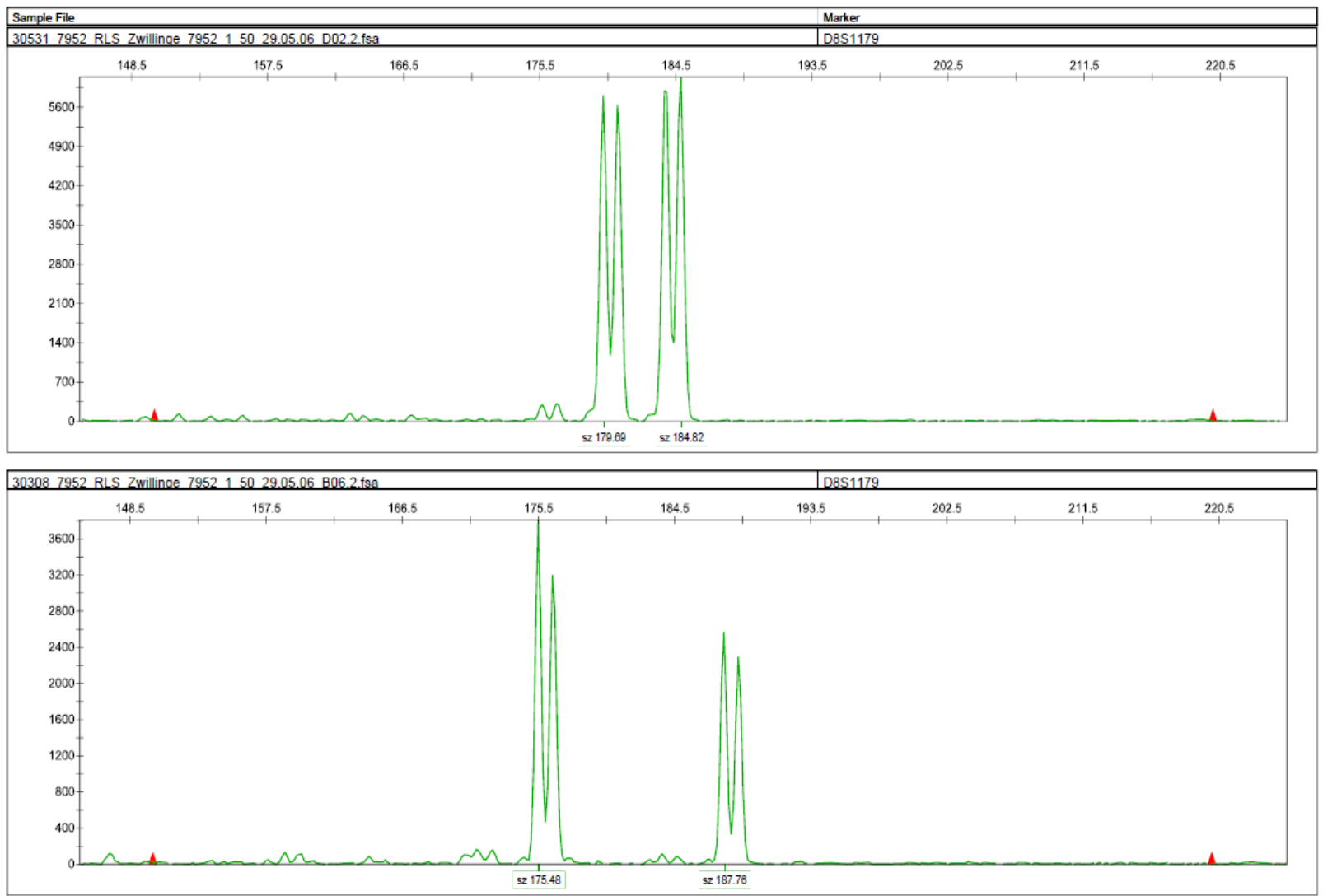
Der Anteil der weiblichen Zwillingsindividuen war mit 65,5\% ( $\mathrm{N}=38)$ größer als der Anteil der männlichen Zwillingsindividuen mit 34,5\% ( $\mathrm{N}=20)$. Dreizehn MZ Zwillingspaare waren weiblich und sechs MZ Zwillingspaare männlich. Unter den DZ Zwillingspaaren waren vier Zwillingspaare gleichgeschlechtlich weiblich, zwei Zwillingspaare gleichgeschlechtlich männlich und weitere vier Zwillingspaare waren gegengeschlechtlich. Insgesamt waren 17 MZ und DZ Zwillingspaare (59,6\%) gleichgeschlechtlich weiblich und acht MZ und DZ Zwillingspaare (27,6\%) gleichgeschlechtlich männlich. Die gegengeschlechtlichen Zwillingspaare ( $\mathrm{N}=4$ Zwillingspaare) nahmen an der Gesamtmenge einen Anteil von 13,8 \% ein (Tabelle 11).

Tab. 11: Zygotie und Geschlechtsverteilung Zwillingspaare mit RLS, $\mathrm{n}=29$

\begin{tabular}{|c|c|c|c|}
\hline & \multicolumn{3}{|c|}{ N= Zwillingspaare } \\
\hline Geschlecht & MZ & DZ & Gesamt (\%) \\
weiblich/weiblich & 13 & 4 & $17(59,6)$ \\
männlich/männlich & 6 & 2 & $8(27,6)$ \\
weiblich/männlich & $/$ & 4 & $4(13,8)$ \\
\hline Gesamt & 19 & 10 & $29(100)$ \\
\hline
\end{tabular}

\subsection{Berechnung der Konkordanzen}

Insgesamt waren $14 \mathrm{MZ}$ und fünf DZ Zwillingspaare konkordant und fünf $\mathrm{MZ}$ und fünf $\mathrm{DZ}$ Zwillingspaare diskordant für ein RLS. Es ergaben sich hieraus Paarweise Konkordanzen (pairwise concordance, PWC) von 73,68\% für MZ und 50,0\% für DZ Zwillingspaare und Probandenweise Konkordanzen (casewise concordance, CWC) von 84,84\% für MZ und 66,67\% für DZ Zwillingspaare. Das Relative Risiko (RR) für einen nicht betroffenen Zwilling an einem RLS zu erkranken, wenn sein Zwillingsgeschwister von dieser Erkrankung betroffen ist war bezogen auf die Paarweise Konkordanz (PWC) 1,47, bezogen auf die Probandenweise Konkordanz (CWC) 1,27. Bezogen auf die Paarweise Konkordanz (PWC) hat ein Zwilling ein mehr als 50\% erhöhtes Risiko ein RLS zu entwickeln, wenn sein Zwillingspartner bereits unter der Erkrankung leidet. Tabelle 12 zeigt eine Übersicht über die Ergebnisse der Konkordanzberechnungen und der Berechnung des Relativen Risikos. 
Tab.12: Konkordanzen (PWC, CWC), Relatives Risiko (RR)

\begin{tabular}{|l|c|c|}
\hline & \multicolumn{2}{|c|}{ RLS ,sicher + wahrscheinlich““ } \\
\hline & MZ & DZ \\
\hline konkordant & 14 & 5 \\
\hline diskordant & 5 & 5 \\
\hline PWC & $\mathbf{7 3 , 6 8 \%}$ & $\mathbf{5 0 , 0 0 \%}$ \\
\hline CWC & $\mathbf{8 4 , 8 4 \%}$ & $\mathbf{6 6 , 6 7 \%}$ \\
\hline RR PWC & \multicolumn{2}{|c|}{1,47} \\
\hline RR CWC & \multicolumn{2}{|c|}{1,27} \\
\hline
\end{tabular}

PWC: Paarweise Konkordanz (pairwise concordance)

CWC: Probandenweise Konkordanz (casewise concordance)

RR: Relatives Risiko (Risk Ratio)

\subsection{Strukturgleichungsmodell (ACE-Modell)}

Für die Tetrachorische Korrelation errechneten sich Werte von 0,984 für MZ und 0,826 für DZ Zwillinge. Ausgehend von diesen Werten wurde das Strukturgleichungsmodell angewendet. Der relative Varianzanteil der additiv-genetische Faktoren (A) bei der Entstehung eines RLS beträgt 32\%, der relative Varianzanteil der gemeinsamen Umwelteinflüsse (C) beträgt 67\%. Der geringste relative Varianzanteil wurde mit $2 \%$ für den Einfluss getrennter Umweltfaktoren (E) im ACE-Modell errechnet (Tabelle 13 und Abbildung 7).

Tab. 13: Strukturgleichungsmodell (ACE-Modell)

\begin{tabular}{|l|c|c|}
\hline & \multicolumn{2}{|c|}{ RLS ,sicher + wahrscheinlich““ } \\
\hline & MZ & DZ \\
\hline $\mathbf{r}_{\text {tet }}{ }^{(\mathbf{1})}$ & $\mathbf{0 , 9 8 4}$ & $\mathbf{0 , 8 2 6}$ \\
\hline Varianzanteil A $^{(2)}$ & \multicolumn{2}{|c|}{$\mathbf{3 2 \%}$} \\
\hline Varianzanteil C(3) $^{(3)} \mathbf{6 7 \%}$ \\
\hline Varianzanteil E $^{(4)}$ & \multicolumn{2}{|c|}{$\mathbf{2 \%}$} \\
\hline
\end{tabular}

(1) Tetrachorische Korrelation

(2) additiv-genetische Faktoren

(3) gemeinsame Umweltfaktoren

(4) getrennte Umweltfaktoren 
Abb. 7: Strukturgleichungsmodell (ACE-Modell)

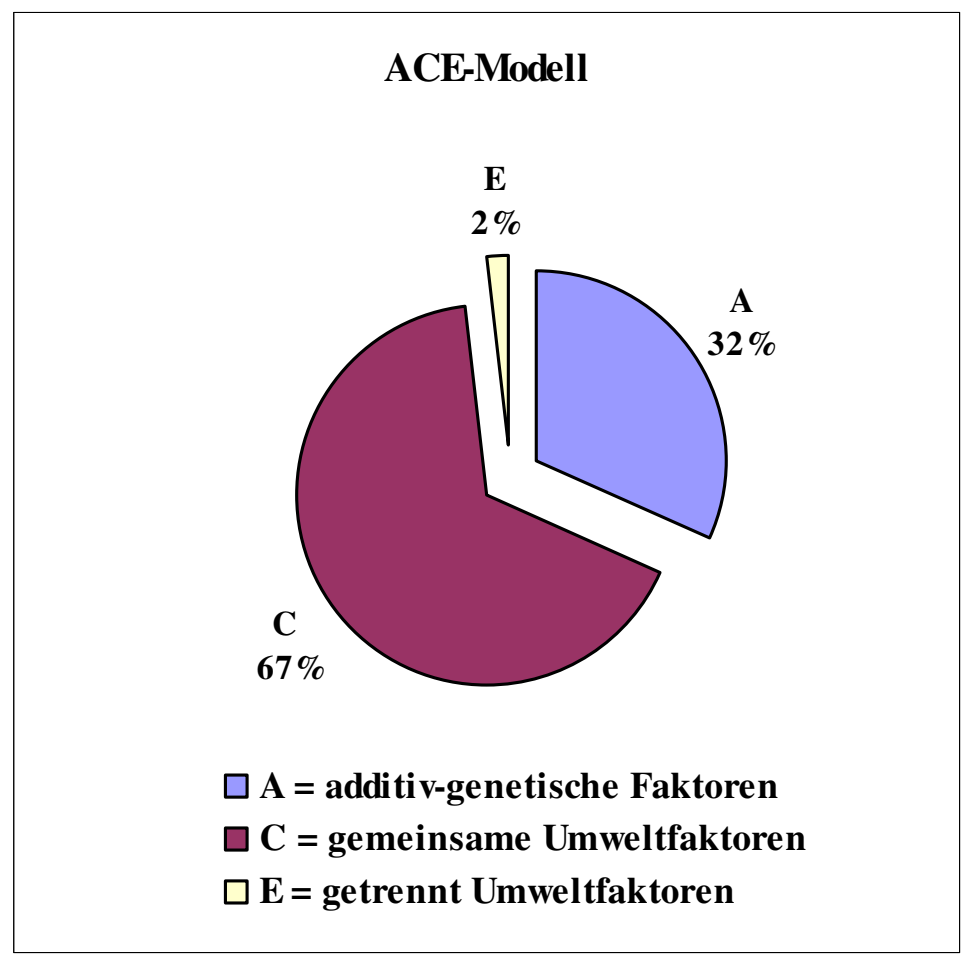

\subsection{Familienanamnese}

Von den insgesamt 48 Zwillingsindividuen mit RLS konnten 43 Individuen über eine positive Familienanamnese berichten $(89,6 \%)$, d.h., dass bei mindestens einem weiteren Familienmitglied, inklusive dem Zwillingspartner, ebenfalls eine diagnostizierte RLSSymptomatik besteht, oder diese aufgrund geäußerter Beschwerden angenommen werden könnte, jedoch bisher keine gesicherte Diagnose gestellt wurde. Bei fünf Zwillingsindividuen $(10,4 \%)$ waren keine weiteren RLS-betroffenen Familienmitglieder bekannt.

Tab. 14: Familienanamnese Zwillingsindividuen mit RLS, $N=48$

\begin{tabular}{|l|c|c|c|c|}
\hline \multirow{2}{*}{} & \multicolumn{3}{|c|}{ N= Zwillingsindividuen (\%) } \\
\hline & \multicolumn{2}{|c|}{ Positive FA } & Negative FA \\
\hline & MZ & DZ & MZ & DZ \\
\hline konkordant & $28(50,3 \%)$ & $10(20,8 \%)$ & - & - \\
\hline diskordant & $2(4,2 \%)$ & $3(6,3 \%)$ & $3(6,3 \%)$ & $2(4,2 \%)$ \\
\hline gesamt & \multicolumn{2}{|c|}{$\mathbf{4 3}(\mathbf{8 9 , 6 \%})$} & \multicolumn{2}{c|}{$\mathbf{5 ( 1 0 , 4 \% )}$} \\
\hline $\begin{array}{l}\text { Alter bei } \\
\text { Symptombeginn }\end{array}$ & 34,5 Jahre (SD +/- 16,1 Jahre) & 29,4 Jahre (SD +/- 14,9 Jahre) \\
\hline
\end{tabular}

FA: Familienanamnese 
Bei allen 38 Zwillingsindividuen $(79,2 \%)$ aus den 19 konkordanten Zwillingspaaren (14 MZ/5 DZ Zwillingspaare) konnte eine positive Familienanamnese bestätigt werden, da der jeweilige Zwillingspartner ebenfalls betroffen war. Innerhalb der zehn diskordanten Zwillingspaare berichteten zwei MZ und drei DZ Zwillingsindividuen mit RLS (10,4\%) über weitere betroffene Familienmitglieder, drei MZ und zwei DZ diskordante Zwillingsindividuen $(10,4 \%)$ mit RLS berichteten über eine negative Familienanamnese. Das durchschnittliche Alter bei Symptombeginn lag bei Zwillingen mit positiver Familienanamnese mit 34,5 Jahren (SD +/- 16,1 Jahre) über dem durchschnittlichen Alter bei Symptombeginn bei negativer Familienanamnese mit 29,4 Jahren (SD +/- 14,9 Jahre) (Tabelle 14).

\subsection{Klinische Symptomatik des Restless Legs Syndrom bei den betroffenen Zwillingsindividuen}

\section{Alter bei Symptombeginn}

Das Alter bei Symptombeginn betrug bei den Zwillingen mit RLS durchschnittlich 34,0 Jahre (SD +/- 15,9 Jahre), mit Altersangaben zwischen 4 und 62 Jahren (Tabelle 15).

Tab. 15: Alter bei Symptombeginn bei Zwillingsindividuen mit RLS, N=47*

\begin{tabular}{|l|lllc|}
\hline & \multicolumn{4}{|c|}{$\mathbf{N}$} \\
\hline Zwillinge* & Zwillingsindividuen & 47 & & Max \\
\hline Alter bei & Mean & SD & Min & 62,0 \\
Symptombeginn & 34,0 & 15,9 & 4,0 & \\
\hline
\end{tabular}

*die Angabe zum Alter bei Symptombeginn von einem Zwillingsindividuum fehlte.

Bei neun $(50,0 \%)$ der insgesamt 18 auswertbaren konkordanten Zwillingspaaren lag die Differenz des Alters bei Symptombeginn innerhalb des Zwillingspaares unter fünf Jahren, d.h. die Zwillingspartner berichteten über einen zeitnahen Beginn ihrer RLS-Beschwerden. Vier Zwillingspaare $(22,2 \%)$ gaben identische Alter bei Symptombeginn an. Ein Drittel der Zwillingspaare $(33,3 \% ; \mathrm{N}=6)$ berichtet über eine Differenz zwischen fünf und zehn Jahren. Drei Zwillingspaare $(16,7 \%)$ berichteten über eine Differenz von >10 Jahren (Tabelle 16). 
Tab. 16: Differenz Alter bei Symptombeginn bei konkordanten Zwillingspaaren, $N=18$

\begin{tabular}{|cccc|}
\hline & $\begin{array}{c}\text { Individuen gesamt } \\
\mathbf{N}(\mathbf{\%})\end{array}$ & \multicolumn{2}{c|}{$\begin{array}{c}\text { Zwillingspaare } \\
\mathbf{N}(\%)\end{array}$} \\
\hline Differenz & & $\mathbf{M Z}$ & $\mathbf{D Z}$ \\
\hline Alter bei Symptombeginn & & $6(42,9 \%)$ & $3(75,0 \%)$ \\
$\leq 5$ Jahre & $18(50,0 \%)$ & $5(35,7 \%)$ & $1(25,0 \%)$ \\
$>5 \leq 10 \mathrm{Jahre}$ & $12(33,3 \%)$ & $3(21,4)$ & $0(0 \%)$ \\
$>$ 10 Jahre & $6(16,7 \%)$ & $\mathbf{1 4}(\mathbf{1 0 0 \%})$ & $\mathbf{4} *(\mathbf{1 0 0 \%})$ \\
\hline Gesamt & $\mathbf{3 6}(\mathbf{1 0 0 \%})$ &
\end{tabular}

*es wurden nur insgesamt 18 konkordante Zwillingspaare (14 MZ/4 DZ) ausgewertet, da die Angaben eines Zwillingspartners innerhalb eines konkordanten Paares fehlten.

\section{Frequenz des Restless Legs Syndroms}

Insgesamt gaben 62,5\% ( $\mathrm{N}=30)$ der 48 RLS-betroffenen Zwillingsindividuen an, dass mehrmals in der Woche RLS-Beschwerden bei ihnen auftreten. $25 \% \quad(\mathrm{~N}=12$ Zwillingsindividuen) gaben an, nur einmal im Monat an RLS-Symptomen zu leiden. Einmalige oder sehr seltene (weniger als einmal pro Jahr) Symptome eines RLS hatten 8,3\% $(\mathrm{N}=4)$ der betroffenen Zwillingsindividuen (Tabelle 17).

Tab. 17: Häufigkeit des Auftretens der RLS-Symptome bei Zwillingsindividuen mit RLS, N= 48

\begin{tabular}{|l|c|c|}
\hline \multirow{2}{*}{$\begin{array}{c}\text { Häufigkeit des Auftretens der } \\
\text { RLS-Symptome }\end{array}$} & N & Zwillingsindividuen \\
\cline { 2 - 3 } 6-7 x wöchentlich & 15 & 31,2 \\
4-5 x wöchentlich & 2 & 4,2 \\
2-3 x wöchentlich & 13 & 27,1 \\
2-4 x monatlich & 7 & 14,6 \\
1 x monatlich & 5 & 10,4 \\
mind. 1 x jährlich & 3 & 6,2 \\
weniger als einmal jährlich & 1 & 2,1 \\
keine Angaben* & 2 & 4,2 \\
\hline Gesamt & 48 & 100,0 \\
\hline
\end{tabular}

* die Angaben von zwei Zwillingsindividuen mit RLS aus zwei unterschiedlichen Zwillingspaaren fehlten.

Von den 19 konkordanten Zwillingspaaren konnten nur 17 konkordante Paare bezüglich der Häufigkeit des Auftretens der RLS-Symptome ausgewertet werden, da bei zwei Zwillingspaaren die Angaben des Zwillingspartners fehlten (siehe Tabelle 17 und 18). Die konkordanten MZ und DZ Zwillingspaare unterschieden sich hinsichtlich der Frequenz des Auftretens der RLS-Symptome. Bei den MZ Zwillingspaaren waren 66,7\% (N=8 Zwillingspaare) diskordant in Bezug auf die Frequenz ihrer RLS-Beschwerden. Bei den DZ 
Zwillingspaaren waren 80,0\% ( $\mathrm{N}=4$ Zwillingspaare $)$ diskordant. Es zeigte sich kein signifikanter Unterschied in Bezug auf die Frequenz der RLS-Symptome innerhalb konkordanter MZ Zwillingspaare und DZ Zwillingspaare (Fisher-Test, p = 1,000) (Tabelle $18)$.

Tab. 18: Konkordanzen in Bezug auf Frequenz der RLS-Symptome bei konkordanten Zwillingspaaren, $\mathrm{N}=17$ *

\begin{tabular}{|c|c|c|c|}
\hline & \multicolumn{2}{|c|}{ N=Zwillingspaare (\%) } & \multirow{2}{*}{ p-Wert $\dagger$} \\
\hline konkordant & MZ & DZ & \multirow{2}{*}{1,000} \\
\cline { 1 - 3 } diskordant & $8(33,3 \%)$ & $4(20,0 \%)$ & \\
\hline Gesamt & $12(100,0 \%)$ & $5(100,0 \%)$ & \\
\hline
\end{tabular}

*zwei konkordante Zwillingspaare nicht auswertbar, da Angaben vom jeweiligem Zwillingspartner fehlten $\dagger$ Fisher-Test, $\mathrm{p}>0,05$ nicht signifikant

\section{Schweregrad des Restless Legs Syndroms}

Der durchschnittliche Schweregrad aller betroffener Zwillinge, erhoben mittels der RLSSchweregrad-Skala (Walters et al. 2003), betrug 15,1 (SD +/- 10,1), im Punktebereich von 1 bis maximal 37 Punktewerten. Es zeigte sich bei 19 Zwillingen (39,6\%) eine milde Schwere ihrer Symptomatik mit einem Punktewert im Bereich von 1-10. Bei jeweils zwölf Zwillingsindividuen $(25,0 \%)$ wurde ein mittelgradiges (Punktewert-Intervall 11-20) und schweres (Punktewert-Intervall 21-30) RLS ermittelt. Eine sehr schwere Ausprägung der Beschwerden (Punktewert-Intervall 31-40) konnte bei vier Zwillingsindividuen (8,3\%) erhoben werden (Tabelle 19).

Tab. 19: Auswertung Punktewert-Intervall der RLS Schweregrad-Skala bei Zwillingsindividuen, $\mathrm{N}=48$

\begin{tabular}{|c|c|c|c|c|}
\hline & & $\mathbf{N}$ & & $\%$ \\
\hline Gesamtzahl & & 48 & & \\
\hline \multirow{5}{*}{$\begin{array}{l}\text { Punktewert- } \\
\text { Intervall }\end{array}$} & 1-10 mildes RLS & 19 & & 39,6 \\
\hline & 11-20 mittelgradiges RLS & 12 & & 25,0 \\
\hline & 21-30 schweres RLS & 12 & & 25,0 \\
\hline & 31-40 sehr schweres RLS & 4 & & 8,3 \\
\hline & k.A. & 1 & & 2,1 \\
\hline \multirow{2}{*}{ Punktewert } & Mean & & Min & Max \\
\hline & 15,1 & & 0 & 37 \\
\hline
\end{tabular}


Beim Vergleich der Schweregrad-Skalen innerhalb der 18 konkordanten Zwillingspaaren (ein Zwillingspaar nicht auswertbar, wegen unvollständiger Daten) zeigte sich bei allen Zwillingspaaren $(\mathrm{N}=18)$ ein maximaler Unterschied von 10 Punktewerten. Zwölf Zwillingspaare $(66,7 \%)$ wurden in identische Schweregrad-Kategorien eingeteilt, da ihre Punktewerte innerhalb des gleichen Punktewerte-Intervalls (Tabelle 20) lagen. Sechs Zwillingspaare $(33,3 \%)$ wurden in unterschiedliche Schweregrad-Kategorien eingeteilt, ihre Punktewerte lagen in verschiedenen Punktewert-Intervallen.

Tab. 20: Kategorien der Schweregrad-Skala nach Punktewerten

\begin{tabular}{|cc|}
\hline Punktewert Intervall & Schweregrad-Kategorie \\
\hline $1-10$ & mildes RLS \\
$11-20$ & mittelgradiges RLS \\
$21-30$ & schweres RLS \\
$31-40$ & sehr schweres RLS \\
\hline
\end{tabular}

\section{Extremitätenlokalisation des Restless Legs Syndroms}

Darüber hinaus waren bei mehr als der Hälfte $(52,1 \% ; \mathrm{N}=25)$ der insgesamt 48 Zwillingsindividuen mit RLS die RLS-Symptome auf den Unterschenkel und Kniebereich lokalisiert, ohne Beteiligung des Oberschenkels. Bei 29,2\% (N=14) Zwillingsindividuen war der Unterschenkel und der Oberschenkel betroffen. Deutlich seltener waren ausschließlich der Fuß (2,1\%; N= 1 Zwillingsindividuum), der Oberschenkel (6,2\%; $N=3$ Zwillingindividuen) oder die oberen Extremitäten (2,1\%; N=1 Zwillingsindividuum) betroffen (Tabelle 21).

Tab. 21: Extremitätenlokalisation der RLS-Symptome bei Zwillingsindividuen mit RLS, N= 48

\begin{tabular}{|l|c|c|}
\hline \multirow{2}{*}{$\begin{array}{c}\text { Extremitäten - Lokalisation } \\
\text { der RLS-Symptome }\end{array}$} & N & Zwillingsindividuen \\
\cline { 2 - 3 } Fuß & 1 & 2,1 \\
US + Knie & 25 & 52,1 \\
OS & 3 & 6,2 \\
US + OS & 14 & 29,2 \\
UE + OE & 1 & 2,1 \\
keine Angaben & 4 & 8,3 \\
\hline Gesamt & 48 & 100,0 \\
\hline
\end{tabular}

Der Vergleich der Extremitätenlokalisation der RLS-Symptome innerhalb 17 konkordanter MZ und DZ Zwillingspaare (zwei konkordante Zwillingspaare wegen fehlender Angaben zur 
Extremitätenlokalisation nicht auswertbar) weist bei 69,2\% der MZ Zwillingspaaren (N=9) und bei 50,0\% der DZ Zwillingspaaren $(\mathrm{N}=2)$ konkordante Angaben zur Extremitätenlokalisation nach. Es zeigte sich kein signifikanter Unterschied in Bezug auf die Extremitätenlokalisation innerhalb konkordanter MZ und DZ Zwillingspaare (Fisher-Test, $\mathrm{p}=$ 0,294) (Tabelle 22).

Tab. 22: Konkordanzen der Extremitätenlokalisation der RLS-Symptome bei konkordanten Zwillingspaaren, $\mathrm{N}=17$ *

\begin{tabular}{|c|c|c|c|}
\hline & \multicolumn{2}{|c|}{$\begin{array}{c}\text { Anzahl Zwillingspaare } \\
\text { n(\%) }\end{array}$} & \multirow{2}{*}{ p-Wert $\dagger$} \\
\hline & MZ & DZ & \multirow{2}{*}{0,294} \\
\hline konkordant & $9(69,2 \%)$ & $2(50,0 \%)$ & \\
\hline diskordant & $4(30,8 \%)$ & $2(50,0 \%)$ & \\
\hline Gesamt & $13(100,0 \%)$ & $4(100,0 \%)$ & \\
\hline
\end{tabular}

* zwei konkordante Zwillingspaare nicht auswertbar, da keine Angaben von diesen Paaren gemacht wurden $\dagger$ Fisher-Test, $\mathrm{p}>0,05$ nicht signifikant

\subsection{Sekundäres Restless Legs Syndrom und assoziierte Erkrankungen}

Bei der Anamnese der Zusatzerkrankungen wurde besonders Wert auf Erkrankungen gelegt, die ein sekundäres RLS hervorrufen können oder gehäuft mit einem RLS assoziiert sind. Bei keinem der Zwillingsindividuen mit einem RLS wurde eine Dialysepflichtigkeit oder terminale Niereninsuffizienz (Urämie) anamnestiziert. Vier Zwillingsindividuen mit RLS $(8,3 \%)$ berichteten über einen Eisenmangel. Die Objektivierung eines latenten oder manifesten Eisenmangels war wegen fehlender aktueller Laborwerte für Eisen und/oder Ferritin jedoch nicht möglich. Drei Zwillingsindividuen (6,3\%), die an den Symptomen eines RLS litten, berichteten als Zusatzerkrankung über einen Diabetes mellitus. Der Zwillingspartner eines dieser drei Zwillingsindividuen litt ebenfalls an einem Diabetes mellitus, verneinte jedoch jegliche RLS-Symptome und war somit konkordant für einen Diabetes mellitus und diskordant für RLS. Weitere vier Zwillingsindividuen $(8,3 \%)$ berichtet über eine Polyneuropathie, auch hier lag keine diagnostische Dokumentation verschiedener Untersuchungsverfahren zur Objektivierung des Befundes vor. Lediglich zwei Zwillingsindividuen $(4,2 \%)$ aus unterschiedlichen Zwillingspaaren gaben eine Verschlechterung der RLS-Symptomatik während der Schwangerschaft mit Besserung der Symptome nach der Geburt an. 


\section{DISKUSSION}

\subsection{Bisherige Zwillingsstudien bei Patienten mit Restless Legs Syndrom}

Es wurden bisher drei Zwillingsuntersuchungen bei RLS-Patienten durchgeführt (Ondo et al. 2000; Desai et al. 2004; Xiong et al. 2007). In der ersten Studie aus den USA wurden zwölf MZ Zwillingspaare mit einem RLS untersucht (Ondo et al. 2000). Drei MZ Zwillingspaare waren Patienten aus der eigenen Klinik des Autors, neun weitere MZ Zwillingspaare wurden über eine Zeitungsanzeige in der Patientenzeitschrift von „The Nightwalkers“, einer Patientenvereinigung für RLS-Betroffene in den USA, rekrutiert. Alle Probanden wurden zu den Symptomen eines RLS persönlich oder telefonisch befragt und die Diagnose anschließend durch Ausfüllen eines Fragebogens bestätigt. Zur Diagnosesicherung verwendete der Autor Diagnosefragen auf der Grundlage der vier essentiellen Diagnosekriterien der IRLSSG (Walters 1995). Zusätzlich beantworteten die Zwillinge einen detaillierten Fragebogen zum Schweregrad der Erkrankung und Fragen zur Ausprägung ihrer RLS-Symptomatik. Bei jedem Probanden wurde eine Laboruntersuchung der Ferritinwerte durchgeführt. Da nicht alle Ferritinproben in einem zentralen Labor analysiert werden konnten, wurde darauf geachtet, dass zumindest die Proben von beiden Zwillingspartnern eines Zwillingspaares im gleichen Labor analysiert wurden. Die Genotypisierung zur Beurteilung der Zygotie erfolgte nach DNA-Extraktion aus Blutlymphozyten mittels Fragmentanalyse von elf hochpolymorphen Mikrosatellitenmarkern (Ondo et al. 2000).

Desai et al. untersuchte $1937 \mathrm{MZ}$ und DZ Zwillingspaare ( $\mathrm{N}=3874$ Zwillinsindividuen) aus dem Britischen Zwillingsregister St. Thomas`UK Adult Twin Registry (Spector \& MacGregor 2002) hinsichtlich eines Obstruktiven Schlafapnoe Syndroms (OSA) und eines RLS. Alle untersuchten Zwillingspaare waren gleichgeschlechtlich weiblich. Die Daten wurden mittels eines per Post versendeten Fragebogens erhoben. Dieser Fragebogen enthielt zwei Diagnosefragen zur Beurteilung eines RLS, die jedoch nicht die vier essentiellen Diagnosekriterien der IRLSSG beinhalteten (Walters 1995; Allen et al. 2003). Der Zygotienachweis erfolgte anhand eines standardisierten Zygotie-Fragebogens (Martin \& Martin 1975), nur bei unklaren Fällen wurde eine Genotypisierung vorgenommen (Desai et al. 2004).

Eine dritte Zwillingsstudie, die den RLS-Phänotyp untersuchte, wurde in Kanada durchgeführt. Insgesamt wurden $272 \mathrm{MZ}$ und DZ Zwillingspaare hinsichtlich eines möglichen RLS untersucht, die über das Kanadische Zwillingsregister der Universität von British 
Columbia (UBC) sowie über Familienstudien an der Universität von Montreal rekrutiert wurden. Insgesamt wurde 600 Zwillingsindividuen aus dem kanadischen Zwillingsregister der UBC ein validierter Diagnosefragebogen zur Beurteilung eines RLS per Post zugesandt. Dieser Fragebogen wurde bereits in früheren Untersuchung von RLS-Familien verwendet (Montplaisir et al. 1997; Xiong et al. 2007). Weitere 86 Zwillingsindividuen aus der Studiendatenbank der Universität von Montreal wurden im Rahmen eines telefonischen Interviews mit Hilfe des gleichen RLS-Diagnosefragebogens untersucht. Die Bestimmung der Zygotie erfolgte bei allen Zwillingen durch einen standardisierten Zygotie-Fragebogen (Kasriel \& Eaves 1976). Anschließend wurden die betroffenen Zwillingsindividuen in „definitiv betroffen“ (alle vier Diagnosekriterien erfüllt) und „wahrscheinlich betroffen“ (drei erfüllte Diagnosekriterien $+\geq$ ein unterstützender Hinweis) eingeteilt. Als unterstützende Hinweise wurden eine positive Familienanamnese, eine dopaminerge Therapie, ein RLSSchweregrad $\geq 7$, ein Auftreten der RLS-Symptomatik $\geq 1$ Tag/Woche sowie eine Bestehen der RLS-Symptomatik seit $\geq 5$ Jahren definiert (Xiong et al. 2007).

\subsubsection{Probandenrekrutierung}

\subsubsection{Probandenkollektiv}

Das Probandenkollektiv kann erhebliche Auswirkungen auf die Auswertung verschiedener Daten haben, die im Rahmen einer Studie erhoben werden. Es muss unterschieden werden, ob es sich um ein Kollektiv aus der Allgemeinbevölkerung handelt, von dem man eine Normalverteilung für das Auftreten bestimmter Erkrankungen oder Merkmale (Prävalenz) erwartet, oder ob die Probanden einem Kollektiv entstammen, welches sich durch erhöhte Prävalenzen bezüglich spezieller Eigenschaften (z.B. Erkrankungen) von der Allgemeinbevölkerung unterscheidet. Tabelle 23 zeigt eine Übersicht über die unterschiedlichen Probandenkollektive (Population und Nationalität) und die ermittelten Prävalenzen der bisher durchgeführten RLS-Zwillingsstudien (Tabelle 23). 
Tab. 23: Zwillingspopulation und Prävalenzen bisheriger RLS-Zwillingsstudien

\begin{tabular}{|c|c|c|c|c|c|c|}
\hline Studie & Population & Nationalität & $\begin{array}{l}\text { ausge } \\
\text { Indi }\end{array}$ & $\begin{array}{l}\text { vertete } \\
\text { iduen } \\
\text { d }\end{array}$ & $\begin{array}{l}\text { Individuen } \\
\text { RLS positiv } \\
\mathbf{N}\end{array}$ & $\begin{array}{c}\text { Prävalenz } \\
\text { des RLS }\end{array}$ \\
\hline $\begin{array}{l}\text { Ondo et al. } \\
2000\end{array}$ & $\begin{array}{c}\text { RLS- } \\
\text { Klinikpopulation/ } \\
\text { Patientenorganisation }\end{array}$ & USA & \multicolumn{2}{|c|}{24} & $\begin{array}{c}22 \\
(\mathrm{~m} / \mathrm{w}: 4 / 18)\end{array}$ & N.A. ${ }^{(6)}$ \\
\hline $\begin{array}{c}\text { Desai et al. } \\
2004\end{array}$ & Zwillingsregister ${ }^{(1)}$ & $\begin{array}{c}\text { Groß- } \\
\text { Britannien }\end{array}$ & \multicolumn{2}{|c|}{$3874^{(5)}$} & $\begin{array}{c}1416 \\
(\mathrm{~m} / \mathrm{w}: 0 / 1416)\end{array}$ & $36,6 \%$ \\
\hline \multirow{2}{*}{$\begin{array}{c}\text { Xiong et al. } \\
2007\end{array}$} & Zwillingsregister ${ }^{(2)}$ & Kanada & 470 & \multirow{2}{*}{544} & \multirow{2}{*}{$\begin{array}{c}114 \\
(\mathrm{~m} / \mathrm{w}: 26 / 88)\end{array}$} & \multirow{2}{*}{$29,9 \%$} \\
\hline & Studienpopulation ${ }^{(3)}$ & Kanada & 74 & & & \\
\hline \multirow{2}{*}{$\begin{array}{l}\text { aktuelle } \\
\text { Arbeit }\end{array}$} & Zwillingsregister $^{(4)}$ & Deutschland & \multicolumn{2}{|c|}{638} & $\begin{array}{c}68 \\
\text { (m/w: } 9 / 19)\end{array}$ & $10,7 \%$ \\
\hline & $\begin{array}{c}\text { RLS- } \\
\text { Klinikpopulation/ } \\
\text { Patientenorganisation }\end{array}$ & Deutschland & \multicolumn{2}{|c|}{24} & $\begin{array}{c}20 \\
(\mathrm{~m} / \mathrm{w}: 7 / 13)\end{array}$ & N.A. ${ }^{(6)}$ \\
\hline
\end{tabular}

(1) St. Thomas`UK Adult Twin Registry, Twin Research Unit, St Thomas`Hospital, London (Spector \& MacGregor 2002; Spector \& Williams 2006)

(2) University of British Columbia Twin Projekt (Jang et al. 2002)

(3) Familienstudien der Universitè de Montreal

(4) Berliner Zwillingsregister von HealthTwiSt (Busjahn 2006)

(5) nur weibliche Individuen

(6) nicht anwendbar, da bei RLS-Patientenpopulationen keine Normalverteilung gegeben ist

Zwillingsregister können nicht uneingeschränkt als Repräsentativ für die Allgemeinbevölkerung angesehen werden. Meist werden Zwillingsregister durch die freiwillige Teilnahme von Zwillingspaaren unterschiedlicher geographischer Regionen aufgebaut, die über spezielle Medien (z.B. Rundfunk, Fernsehen und Zeitungen) rekrutiert werden. Es kann also davon ausgegangen werden, dass sich dieses Zwillingskollektiv sowohl von der Gesamtzwillingspopulation in einer Gesellschaft, als auch von der Allgemeinbevölkerung in bestimmten Eigenschaften unterscheidet. Möglicherweise sind in Zwillingsregistern Individuen niedriger Schulbildung unterrepräsentiert, da allein der Zugang $\mathrm{zu}$ den oben genannten Medien, wie auch die Aufmerksamkeit und das Interesse für Zwillingsregister sowie das Verständnis für die Vorteile dieser Institution für Wissenschaft und Forschung einen entsprechenden Intellekt voraussetzen müssen.

In der Zwillingsstudie dieser Arbeit wurden die Zwillingspaare aus zwei unterschiedlichen Populationen rekrutiert. Das Berliner Zwillingsregister von HealthTwiSt (Busjahn 2006) war dabei mit insgesamt 638 Zwillingsindividuen aus 319 Zwillingspaaren das größte 
Probandenkollektiv. Weitere Zwillingspaare konnten über RLS-Spezialambulanzen und die RLS-Patientenorganisation (Deutsche Restless Legs Vereinigung, RLS e.V.) in die Studie eingeschlossen werden. Diese Zwillingspaare repräsentieren, ähnlich wie das Gesamtkollektiv in der US-amerikanischen Zwillingsstudie (Ondo et al. 2000) und ein Teilkollektiv in der Kanadischen Zwillingsstudie (Xiong et al. 2007), eine definierte und möglicherweise sensibilisierte RLS-Patientengruppe.

Die beiden Probandenkollektive aus dieser Arbeit unterscheiden sich dahingehend, dass die Zwillinge aus dem Zwillingsregister von HealthTwiSt keine Kenntnis über die RLSErkrankung hatten. Allen Zwillingspaaren, die über die RLS-Spezialambulanzen und die RLS-Patientenorganisation ermittelt wurden, waren die Symptome eines RLS dagegen bereits bekannt. Aufgrund der uneinheitlichen Probandenkollektive (Kollektiv aus dem Zwillingsregister und RLS-Patientenkollektiv) war eine Abschätzung der Prävalenz eines RLS nur bei den Zwillingen aus dem Zwillingsregister von HealthTwiSt, nach Auswertung der RLS-Diagnosefragen des Gesundheitsfragebogens, möglich. Ein Anteil von 9,7\% der Zwillingsindividuen aus dem Zwillingsregister konnte als „RLS-verdächtig“ (mindestens eine der drei RLS-Diagnosefragen des Gesundheitsfragebogens wurden mit „Ja“ beantwortet) klassifiziert werden und sollte im Rahmen des diagnostischen Telefoninterviews bezüglich eines RLS weiter untersucht werden. Zur Abschätzung der Prävalenz eines RLS wurden im Rahmen epidemiologischer Studien bisher nur Probanden als „RLS-positiv“ bewertet, wenn diese alle drei RLS-Diagnosefragen mit „Ja“ beantwortet haben (Rothdach et al. 2000; Berger et al. 2004). In unserer Studie wurden alle drei RLS-Diagnosefragen von 5,3\% der untersuchten Zwillingsindividuen mit „Ja“ beantwortet und fallen entsprechend früherer epidemiologischer Studien somit unter die Klassifizierung „RLS-positiv“. Dieser Wert kann zur Prävalenzschätzung herangezogen werden, da ein Vergleich mit Ergebnissen aus epidemiologischen Studien möglich ist. Der in dieser Studie ermittelte Anteil von Probanden, die als „RLS-positiv“ klassifiziert wurden, liegt mit 5,3\% innerhalb des in der Literatur angegeben Prävalenzbereiches von 5-10\% in der Allgemeinbevölkerung (Phillips et al. 2000; Allen et al. 2005). Dies deutet einerseits darauf hin, dass Zwillingskollektive als Repräsentativ für die Allgemeinbevölkerung verwendet werden können, auch wenn sie sich wie bereits zuvor diskutiert in einigen Aspekten von der Allgemeinbevölkerung unterscheiden (Siribaddana et al. 2008). Andererseits wird die Validität der verwendeten RLSDiagnosefragen (Rothdach et al. 2000; Berger et al. 2004) durch ihre Reproduzierbarkeit unterstützt. Für Probanden aus den RLS-Spezialambulanzen und der RLSPatientenorganisation konnten keine Prävalenzberechnungen durchgeführt werden, da sie 
bereits eine definierte RLS-Patientengruppe darstellen. Betroffene Zwillinge aus der RLSPatientenpopulation neigen zudem möglicherweise zu einem schwerer ausgeprägten RLS, da sich diese Patienten primär mit der Frage nach einer möglichen Therapie in den Ambulanzen vorstellten. Es ist anzunehmen, dass innerhalb dieser Zwillingspaare die Konkordanzen höher liegen, als bei den Zwillingspaaren aus dem Zwillingsregister. Durch die meist schwerere Ausprägung des RLS bei Zwillingen aus dem RLS-Patientenkollektiv könnte es zu einer Steigerung des Krankheitsbewusstseins für ein RLS innerhalb dieser Familien gekommen sein. Eine Beeinflussung des Zwillingspartners durch erhöhte Aufmerksamkeit für die RLSSymptomatik bis hin zur unbewussten Nachahmung kann in dieser Arbeit daher nicht ausgeschlossen werden. Dies könnte eine Erklärung für die hohen Konkordanzen von 74\% (PWC) bei MZ und 50\% (PWC) bei DZ Zwillingspaaren sein.

In der US-amerikanischen Studie waren die eingeschlossenen Probanden entweder RLSPatienten aus der Klinik oder sie meldeten sich auf eine Anzeige in einer Zeitschrift für RLSBetroffene (Ondo et al. 2000). Es kann davon ausgegangen werden, dass bei mindestens einem Zwillingsindividuum eines jeden Zwillingspaares die Diagnose eines RLS bekannt war und die Ausprägung der Symptome bereits Krankheitswert angenommen hatten, da sonst weder eine klinische Behandlung noch eine Kontaktaufnahme des jeweiligen Zwillings zu einer Patientenvereinigung für RLS-Betroffene stattgefunden hätte. Auch in dieser Studie könnte die Kenntnis der Diagnose eines RLS in der Familie durch erhöhte Krankheitsaufmerksamkeit zu unbewusstem Nachahmen der RLS-Symptomatik innerhalb der Zwilingspaare geführt haben, was auch hier die stärkere Korrelation bezüglich der RLSSymptomatik bei den untersuchten MZ Zwillingspaaren und somit die erhöhten Konkordanzen bewirkt haben könnte.

Das Probandenkollektiv aus der Britischen Zwillingsstudie entstammt dagegen einem Zwillingsregister (St. Thomas`UK Adult Twin Registry), welches durch die freiwillige Teilnahme von Zwillingen seit 1993 aufgebaut wurde und überwiegend Daten zu gleichgeschlechtlich weiblichen MZ und DZ Zwillingspaaren beinhaltet (Spector \& MacGregor 2002; Spector \& Williams 2006). Eine erhöhte Aufmerksamkeit bezüglich eines RLS ist bei den Zwillingsindividuen im Gegensatz zur RLS-Klinikpopulation unwahrscheinlich. Ob die Ergebnisse zu den Prävalenzberechnungen in der Britischen Zwillingsstudie auf die Allgemeinbevölkerung übertragen werden können, bleibt umstritten. Wie bereits weiter oben erwähnt, zeigen sich Unterschiede zwischen Zwillingskollektiven und der Allgemeinbevölkerung, wodurch eine uneingeschränkte Gleichstellung beider Kollektive nicht möglich ist (Siribaddana et al. 2008). Im Gegensatz hierzu kam eine Studie zu dem 
Schluss, dass die Ergebnisse aus der Britischen Zwillingsstudie repräsentativ für die Allgemeinbevölkerung angesehen werden (Andrew et al. 2001). Die Autoren vergleichen die Prävalenzen bezüglich bestimmter Erkrankungen und Eigenschaften (z.B. Osteoporose, Arthritis, Hytertonie, Anamnese einer Hysterektomie oder Ovarektomie, Größe, Gewicht, Menopausenstatus) sowie bezüglich Charakteristika des Lebensstils (z.B. Alkohol- und Tabakkonsum) bei den weiblichen Zwillingen aus dem Britischen Zwillingsregister (St. Thomas`UK Adult Twin Registry) mit den Prävalenzen bei Nicht-Zwillingen aus der Allgemeinbevölkerung. Lediglich bezüglich des Gewichtes fand sich ein Unterschied zwischen Zwillingen und Nicht-Zwillingen, wobei MZ Zwillinge leichter waren und im Gewicht weniger voneinander abwichen, als DZ Zwillinge und Nicht-Zwillinge (Andrew et al. 2001). Ausschlaggebender für die eingeschränkte Aussagekraft der Prävalenzberechnung in der Britischen Zwillingsstudie ist der Aspekt, dass in dieser Studie nur weibliche Zwillinge eingeschlossen wurden. Innerhalb der weiblichen Bevölkerung wurden mit altersabhängigen Prävalenzen von bis $15 \%$ in zahlreichen Studien etwa doppelt so hohe Werte, wie in der männlichen Bevölkerung dokumentiert (Rothdach et al. 2000; Ulfberg et al. 2001a; Ulfberg et al. 2001b; Berger et al. 2004; Allen et al. 2005). Dieser Umstand könnte mitunter einen geringen Beitrag zu der hohen RLS-Prävalenz von 36,6\% in der Britischen Zwillingsstudie leisten, kann jedoch aufgrund der großen Differenz zwischen beiden Prävalenz-Werten nicht als einzige Ursache hierfür angenommen werden. Diese Prävalenz der Britischen Studie liegt etwa dreifach höher im Vergleich zu anderen epidemiologischen Studien in der kaukasischen Bevölkerung, die eine altersabhängige RLS-Prävalenz von bis $\mathrm{zu} 10 \%$ in der Allgemeinbevölkerung > 65 Jahren ermittelt haben (Rothdach et al. 2000; Phillips et al. 2000; Berger et al. 2004; Hogl et al. 2005). Erhöhte Prävalenzen könnten zu höheren Konkordanzen bezüglich eines RLS bei den MZ und DZ Zwillingspaaren führen. Nach Angaben des Autors war die Erkrankung den Probanden in der Britischen RLS-Zwillingsstudie nicht bekannt, wodurch eine Sensibilisierung für ein RLS bei den Zwillingen unwahrscheinlich erscheint (Desai et al. 2004).

In der Kanadischen Zwillingsstudie wurde der größte Anteil der eingeschlossenen Zwillingspaare $(\mathrm{N}=272)$ über das kanadische Zwillingsregister der UBC rekrutiert. Dieses begann 1991 mit der Rekrutierung von Zwillingspaaren aus der Allgemeinbevölkerung über Medienaufrufe (Rundfunk, Fernsehen, Zeitungen) (Jang et al. 2002). Weitere 37 Zwillingspaare wurden in einer Patientendatenbank ausfindig gemacht, die an der Universität von Montreal für Familienstudien angelegt wurden. Die erhöhte RLS-Prävalenz von 20,9\%, die in der Kanadischen Zwillingsstudie ermittelt wurde, könnte auf das Probandenkollektiv 
aus den Familienstudien der Universität von Montreal, die möglicherweise eine RLSPatientenpopulation definiert, zurückzuführen sein. Angaben, ob es sich bei den Familien aus der Datenbank der Universität von Montreal nur um RLS-Familien handelt, wurden nicht gemacht (Xiong et al. 2007). Die deutlich niedrigeren Konkordanzen (MZ: CWC 53,5\%, PWC 36,6\%; DZ: CWC 15,4\%, PWC 8,3\%) sowohl bei MZ als auch bei DZ Zwillingen lassen sich hierdurch jedoch nicht erklären (Xiong et al. 2007).

Darüber hinaus spielt die Größe der Probandenpopulationen bei der Auswertung der erhobenen Daten und der Beurteilung der Ergebnisse eine entscheidende Rolle. Je größer eine Probandenanzahl ist, desto genauer können Prävalenzen und Konkordanzen bei Zwillingen berechnet und klinische Charakteristika in einem repräsentativen Populationsquerschnitt beurteilt werden. Sowohl in der US-amerikanischen, als auch in der Kanadischen Zwillingsstudie finden sich kleine Studienpopulationen (Ondo et al. 2000; Xiong et al. 2007). In der Britischen Zwillingsstudie wurde eine weitaus größere Anzahl von Zwillingspaaren rekrutiert, eingeschränkt durch den Aspekt, dass es sich nur um weibliche Probanden handelt sowie durch die ungenaue Diagnosestellung mit nur zwei Diagnosefragen (Desai et al. 2004).

\subsubsection{Diagnose des Restless Legs Syndroms}

Die Anwendung der Diagnosekriterien der IRLSSG (Walters 1995; Allen et al. 2003) ermöglicht einen Vergleich der Ergebnisse aus unterschiedlichen RLS-Studien. In den bisher publizierten RLS-Zwillingsstudien wurden unterschiedliche Methoden zur Diagnosestellung eines RLS verwendet (Tabelle 24).

Die Identifizierung „möglicher RLS-betroffener“ Zwillingspaare aus dem Berliner Zwillingsregister von HealthTwiSt erfolgte in dieser Arbeit mittels drei RLS-Diagnosefragen (Rothdach et al. 2000; Berger et al. 2004) auf der Grundlage der Diagnosekriterien der IRLSSG von 1995 (Walters 1995). Gesichert wurde die Diagnose eines RLS bei allen Zwillingen im Rahmen eine diagnostischen Telefoninterviews durch einen speziell geschulten Untersucher mittels der überarbeiteten Diagnosekriterien der IRLSSG von 2003 (Walters 1995; Allen et al. 2003).

In der Kanadischen Zwillingsstudie wurde die RLS-Diagnose ebenfalls mittels der überarbeiteten Diagnosekriterien der IRLSSG gestellt (Walters 1995; Allen et al. 2003), jedoch im Rahmen eines Selbstbeurteilungsfragebogens (Xiong et al. 2007). Unklare RLSDiagnosen ließen sich in der Studie aus dieser Arbeit durch gezielte Fragen innerhalb des diagnostischen Telefoninterviews möglicherweise besser beurteilen, als in der Kanadischen 
Zwillingsstudie. Leider war es auch uns in den meisten Fällen nicht möglich, die Patienten persönlich zu untersuchen, die Diagnose durch den Nachweis von PLM in der Polysomnographie zu objektivieren oder Differentialdiagnosen mittels elektrophysiologischer Untersuchungen abzuklären. Fehldiagnosen sind daher auch in dieser Arbeit letztendlich nicht auszuschließen. Mögliche Auswirkungen auf Konkordanzen und Prävalenzen mit Verschiebungen zu sowohl falsch erhöhten, als auch zu falsch erniedrigten Werten könnten die Folge sein.

Tab. 24: Diagnosemethoden bisheriger RLS-Zwillingsstudien im Vergleich

\begin{tabular}{|c|c|c|c|c|}
\hline \multirow[b]{2}{*}{ Studie } & \multirow[b]{2}{*}{ Probandenkollektiv } & \multirow[b]{2}{*}{$\begin{array}{l}\text { Zwillingspaare } \\
(\mathrm{N})\end{array}$} & \multicolumn{2}{|l|}{ Diagnose } \\
\hline & & & Methode & Kriterien \\
\hline $\begin{array}{l}\text { Ondo et } \\
\text { al. } 2000\end{array}$ & $\begin{array}{c}\text { RLS- } \\
\text { Klinikpopulation/ } \\
\text { Patientenorganisation }\end{array}$ & $12^{(9)}$ & $\begin{array}{c}\text { Erste Diagnose: } \\
\text { telefonisches/persönliches } \\
\text { Interview } \\
\text { Diagnosebestätigung: } \\
\text { Selbstbeurteilungfragebogen }\end{array}$ & $\begin{array}{l}\text { IRLSSG von } \\
\qquad 1995^{(6)} \\
\begin{array}{l}1995^{(6)} \\
\text { IRLSSG von }\end{array}\end{array}$ \\
\hline $\begin{array}{l}\text { Desai et } \\
\text { al. } 2004\end{array}$ & Zwillingsregister $^{(1)}$ & $1937^{(10)}$ & Selbstbeurteilungfragebogen ${ }^{(5)}$ & keine $^{(7)}$ \\
\hline \multirow{2}{*}{$\begin{array}{l}\text { Xiong et } \\
\text { al. } 2007\end{array}$} & Zwillingsregister ${ }^{(2)}$ & 235 & Selbstbeurteilungfragebogen ${ }^{(5)}$ & $\begin{array}{l}\text { IRLSSG von } \\
2003^{(8)}\end{array}$ \\
\hline & Studienpopulation ${ }^{(3)}$ & 37 & telefonisches Interview & $\begin{array}{l}\text { IRLSSG von } \\
2003^{(8)}\end{array}$ \\
\hline \multirow[t]{2}{*}{$\begin{array}{c}\text { aktuelle } \\
\text { Arbeit }\end{array}$} & Zwillingsregister ${ }^{(4)}$ & 319 & $\begin{array}{c}\text { Erste Diagnose: } \\
\text { Selbstbeurteilungfragebogen } \\
\\
\text { Diagnosebestätigung: } \\
\text { telefonisches Interview }\end{array}$ & $\begin{array}{l}\text { IRLSSG von } \\
\qquad 1995^{(6)} \\
\text { IRLSSG von } \\
2003^{(8)}\end{array}$ \\
\hline & $\begin{array}{c}\text { RLS- } \\
\text { Klinikpopulation/ } \\
\text { Patientenorganisation }\end{array}$ & 17 & $\begin{array}{l}\text { telefonisches/persönliches } \\
\text { Interview }\end{array}$ & $\begin{array}{l}\text { IRLSSG von } \\
2003^{(8)}\end{array}$ \\
\hline
\end{tabular}

(1) Britisches Zwillingsregister der Twin Research Unit des St Thomas Hospital in London

(2) Kanadisches Zwilingsregister der University of British Columbia (UBC) (Jang et al. 2002)

(3) Probandenpopulation aus Familienstudien der Université de Montreal in Quebec

(4) Berliner Zwillingsregister von HealthTwiSt GmbH (Busjahn 2006)

(5) Fragebogen vom Probanden eigenständig ausgefüllt, kein telefonischen/persönlichen Interview

(6) Diagnosekriterien der IRLSSG von 1995 (Walters 1995)

(7) zwei Fragen, unabhängig von Diagnosekriterien der IRLSSG von 1995/2003 (Walters 1995; Allen et al. 2003)

Frage 1: ...,,ever experience an urge to move (their) legs during the night to relieve tingling or numbness."

Frage 2: ....,ever find (their) legs jerk involuntarily during the night."

(8) Diagnosekriterien der IRLSSG von 2003 (Allen et al. 2003)

(9) nur MZ Zwillingspaare

(10) nur gleichgeschlechtlich weibliche MZ und DZ Zwillingspaare 
In der US-amerikanischen Zwillingsstudie wurde die Diagnose anhand der Diagnosekriterien der IRLSSG (Walters 1995) im Rahmen eines standardisierten telefonischen oder persönlichen Interviews durch einen speziell geschulten Untersucher gestellt (Ondo et al. 2000).

In der Britischen Zwillingsstudie war die Diagnosestellung dagegen unsicher. Lediglich zwei RLS-Diagnosefragen, die unabhängig von den Diagnosekriterien der IRLSSG (Walters 1995; Allen et al. 2003) erstellt wurden, wurden zur Diagnosestellung herangeszogen (Tabelle 25).

Tab. 25: RLS-Diagnosefragen aus der Studie von Desai et al. (Desai et al. 2004)

\section{Diagnosefragen (Desai et al. 2004)}

Frage A: ,haben Sie jemals in der Nacht einen Drang die Beine zu bewegen verspürt, um dadurch ein Kribbeln und Taubheitsgefühl zu bessern?“

Frage B: ,haben Sie jemals ein unwillkürliches Zucken Ihrer Beine in der Nacht erlebt?“

Im Gegensatz zu den essentiellen Diagnosekriterien der IRLSSG wurden in den beiden RLSDiagnosefragen der Britischen Studie die klinischen Charakteristika eines RLS nicht konkret abgefragt. Der abgefragte „Bewegungsdrang“ aus Frage A der Britischen Studie bezieht sich nur auf die Nacht, und nicht auf Ruhesituationen und/oder sonstige Phasen motorischer Inaktivität, wie es im zweiten Diagnosekriterium der IRLSSG formuliert ist (Walters 1995; Allen et al. 2003). Auch der charakteristische Rhythmus der RLS-Beschwerden, mit einer Verschlechterung der Symptome abends und nachts (viertes Diagnosekriterium der IRLSSG), wird in den beiden RLS-Diagnosefragen (Tabelle 25) nicht herausgearbeitet. Der Bewegungsdrang, der oftmals mit Missempfindungen einhergeht, wird in Frage A als „Kribbeln oder Taubheitsgefühl“ abgefragt. Oftmals können die Sensationen im Rahmen eines RLS von betroffenen Patienten nur als „unangenehm“ und „unbeschreibbar“ definiert werden. Die genaue Vorgabe der Empfindung in Frage A schränkt somit die Antwortfreiheit von RLS-Patienten deutlich ein. Das erste Diagnosekriterium der IRLSSG bezieht sich dagegen auf eine allgemeine Formulierung der Sensationen und bezeichnet diese als „unbehagliche und unangenehme Empfindungen“, was die Empfindungen von RLS-Patienten meist deutlicher trifft und somit einfacher bestätigt werden kann. Darüber hinaus wird das Phänomen der Besserung der Symptome durch motorische Aktivität und/oder Bewegung der betroffenen Extremität, zumindest für den Zeitraum der Aktivität (drittes Diagnosekriterium der IRLSSG), in den beiden RLS-Diagnosefragen der Britischen Studie ebenfalls nicht konkretisiert. Die Frage B (Tabelle 25) der Britischen Zwillingsstudie bezieht sich auf das 
Auftreten „Periodischer Beinbewegungen während des Schlafes“ (PLMS), die bei etwa 85\% der RLS-Patienten auftreten (Montplaisir et al. 1997). Die IRLSSG klassifiziert „Periodische Beinbewegungen im Wachen und/oder im Schlaf“ (PLMW/PLMS) als „Supportives Diagnosekriterium“, das die Diagnose eines RLS weiter unterstützen soll (Allen et al. 2003). Das Auftreten von PLMs soll von den Zwillingsindividuen der Britischen Studie subjektiv beurteilt werden, wobei der Begriff PLM`s nur ungenau als „Zucken der Beine in der Nacht“ umschrieben wurde. Eine objektive Beurteilung (z.B. Polysomnographie) wurde nicht durchgeführt, Differentialdiagnosen (z.B. Einschlafmyoklonien) konnten somit nicht abgegrenzt werden. Diese RLS-Diagnosefragen waren Teil eines Selbstbeurteilungsfragebogens. Eine Befragung im Rahmen eines persönlichen oder telefonischen Interviews wurde nicht durchgeführt. Unklare Fälle konnte hierdurch nicht individuell beurteilt werden (Desai et al. 2004). Hier kann es zu erheblichen Differenzen gekommen sein, die durch telefonischen oder persönlichen Kontakt mit einem geschulten Untersucher möglicherweise hätten abgeschwächt werden können. Im Rahmen dieser unvollständigen und unsicheren Diagnostik in der Britischen Studie muss davon ausgegangen werden, dass „falsch-positive“ RLS-Patienten eingeschlossen wurden. Ebenso ist es möglich, dass einige RLS-Patienten nicht identifiziert werden konnten und somit als „falsch-negative“ RLS-Patienten ausgewertet wurden. Die hohe Prävalenz des RLS mit 36,6\% deutet auf den Einschluss „falsch positiver“ RLS-Patienten hin. Diese haben zwar die ungenauen RLS-Diagnosefragen positiv beantwortet, die Ursache hierfür war aber nicht ein zugrunde liegendes RLS, sondern möglicherweise eine andere Erkrankung. Die Fehlermöglichkeit des Einschlusses „falsch negativer" Probanden scheint eine untergeordnete Rolle zu spielen. Dieser Fehler würde zu „falsch niedrigen“ Prävalenzen führen und steht somit im Widerspruch $\mathrm{zu}$ der hohen Prävalenz von 36,6\% in der Britischen Zwillingsstudie stehen (Desai et al. 2004). Auswirkungen auf die Konkordanzen bei MZ und DZ Zwillingspaaren sind durch die Fehler bei der Diagnosestellung in beide Richtungen zu erwarten. Die niedrigen Konkordanzen bei MZ (CWC 61,0\%, PWC 43,6\%) und DZ Zwillingspaaren (CWC 45,0\%, PWC 29,0\%) deutet ebenfalls auf den Einschluss „falsch positiver“ RLS-Patienten hin (Desai et al. 2004). „Falsch positive" RLS-Diagnosen aufgrund von anderen Erkrankungen wie z.B. eine periphere Arterielle Verschlusskrankheit oder eine Polyneuropathie, sind meist nicht in beiden Zwillingsindividuen $\mathrm{zu}$ finden, wodurch eine Korrelation bezüglich dieser durch andere Erkrankungen ,imitierten“ RLS-Symptome innerhalb eines solchen Zwillingspaares nicht zu erwarten ist. Die Kanadische Zwillingsstudie verwendete zur RLS-Diagnosesicherung die überarbeiteten Diagnosekriterien der IRLSSG von 2003 (Allen et al. 2003). Eine 
Vergleichbarkeit mit der US-Amerikanischen Zwillingsstudie und der Studie aus dieser Arbeit ist auf der Ebene der Diagnosestellung daher möglich. Die Konkordanzen bei den MZ (CWC 53,7\%, PWC 36,6\%) und DZ (CWC 15,4\%, PWC 8,3\%) Zwillingspaaren weichen deutlich von der hohen PWC von 83,3\% aus der US-Amerikanischen Zwillingsstudie ab (Ondo et al. 2000), liegen sogar noch niedriger, als die Konkordanzen aus der Britischen Zwillingsstudie (MZ: CWC 61,0\%, PWC 43,6\% und DZ: CWC 45,0\%, PWC 29,0\%) (Desai et al. 2004). Eine Erklärung für die niedrigen Konkordanzergebnissen ist möglicherweise nicht bei den verwendeten Diagnosekriterien zu suchen. Vielmehr könnte der zusätzliche Einschluss von Patienten mit sekundärem RLS diese Berechnungen in gegebenem Ausmaß beeinflusst haben, was unter Punkt 5.1.5 nochmals genauer diskutiert wird (Xiong et al. 2007). Dagegen ermittelt die Kanadische Zwillingsstudie eine relativ hohe Prävalenz von 20,9\% (definitives + mögliches RLS). Auch hier könnte der Einschluss sekundärer RLSPatienten einen erheblichen Beitrag zu einer „falsch hohen“ Prävalenz beigetragen haben.

\subsubsection{Zygotie der Zwillinge}

Eine korrekt determinierte Zygotie ist die Voraussetzung zur Anwendung der klassischen Zwillingsmethode, mit der Berechnung der Konkordanzen bei MZ und DZ Zwillingspaaren sowie dem aussagefähigen Konkordanzvergleich zwischen beiden Zygotiegruppen. Hierfür stehen verschiedene Methoden zur Verfügung. Zum einen besteht die Möglichkeit, die Zygotie mittels validierter und standardisierter Fragebögen zu bestimmen. Im Rahmen verschiedener Studien wurden Zygotiefragebögen erstellt, die von erwachsenen oder jugendlichen bzw. kindlichen Zwillingen selbst und/oder von deren Eltern ausgefüllt werden mussten. Die Ergebnisse wurden anschließend anhand biologischer Verfahren (Blutgruppenserologie, Genotypisierung von Mikrosatellitenmarkern) geprüft. Die Genauigkeit der Methode der Zygotiefragebögen schwankte in den Studien zwischen 91-98\% (Cederlof et al. 1961; Nichols \& Bilbro, Jr. 1966; Torgersen 1979; Jackson et al. 2001; Christiansen et al. 2003). Die Fragebögen beinhalten Fragen zur ,allgemeinen Ähnlichkeit“ der Zwillinge zueinander, zur Verwechslungshäufigkeit durch dritte Personen sowie zu bestimmten physischen Merkmalen (Haarfarbe, Haarform, Augenfarbe usw.).

Eine weitere Methode ist die Genotypisierung von Mikrosatellitenmarkern. Bei der Verwendung von fünf Mikrosatellitenmarkern liegt die Wahrscheinlichkeit für eine korrekt bestimmte Zygotie bei 99\% (Becker et al. 1997). In den bisher veröffentlichten RLSZwillingsstudien wurden beide Verfahren zur Zygotiebestimmung verwendet (Tabelle 26). 
Für die Zygotiebestimmung in dieser Arbeit wurden acht hochpolymorphe TetranukleotidMikrosatellitenmarker genotypisiert. Mikrosatelliten sind kurze, sich oft wiederholende DNASequenzen an bestimmten Loci innerhalb des Genoms, mit einer Basenlänge von zwei bis vier Nukleotiden, die keine kodierenden Informationen enthalten. Die Wahrscheinlichkeit der korrekt determinierten Zygotie liegt in dieser Arbeit bei der Auswertbarkeit von mindestens sieben der acht verwendeten Mikrosatellitenmarkern bei >99\% (Becker et al. 1997).

Tab. 26: Methode der Zygotiebestimmung der bisherigen RLS-Zwillingsstudien im Vergleich

\begin{tabular}{|c|c|c|c|}
\hline \multirow[b]{2}{*}{ Studie } & \multicolumn{3}{|c|}{ Zygotiebestimmung } \\
\hline & Methode & klassifiz & ngspaare \\
\hline & & MZ & DZ \\
\hline Ondo et al. 2000 & Genotypisierung $^{(1)}$ & $\mathrm{N}=12$ & - \\
\hline Desai et al. 2004 & $\begin{array}{c}\text { Stufe 1: } \\
\text { Zygotiefragebogen } \\
\text { Stufe 2:(3) } \\
\text { Genotypisierung }\end{array}$ & $\mathrm{N}=933$ & $\mathrm{~N}=1004$ \\
\hline Xiong et al. 2007 & Zygotiefragebogen $^{(4)}$ & $\mathrm{N}=140$ & $\mathrm{~N}=132$ \\
\hline aktuelle Arbeit & Genotypisierung $^{(5)}$ & $\mathrm{N}=19$ & ${ }^{(6)} \mathrm{N}=10$ \\
\hline
\end{tabular}

(1) Genotypisierung von elf hochpolymorpher Mikrosatellitenmarker

(2) Stufe 1: alle Zwillinge erhielten einen standardisierten Zygotiefragebogen (Martin \& Martin 1975).

(3) Stufe 2: Zwillinge mit unklarem Zygotiefragebogen wurden durch Genotypisierung klassifiziert. Anzahl der genotypisierten Zwillingspaare und Methode unbekannt.

(4) standardisierter Zygotiefragebogen (Kasriel \& Eaves 1976)

(5) Genotypisierung von acht hochpolymorpher Mikrosatellitenmarker bei allen gleichgeschlechtlichen Zwillingspaaren.

(6) Vier Paare gegengeschlechtlich, keine Genotypisierung

Die US-amerikanische Zwillingsstudie bestätigte bei allen zwölf Zwillingspaaren die „Monozygotie“ durch Genotypisierung von elf hochpolymorphen Mikrosatellitenmarkern, ausgewählt aus dem CHLC Human Screening Set/Version 8 (Research Genetics) (Ondo et al. 2000). In der Britischen Studie wurde die Zygotie mittels eines standardisierten Fragebogens bestimmt. Detaillierte Angaben über die darin enthaltenen Fragen werden nicht gemacht, es findet sich jedoch der Verweis auf den ersten Teil einer Zwillingsstudie von 1975 zur Beurteilung der Vererbung schulischer Fähigkeiten innerhalb einer Auswahl von Zwillingen (Martin \& Martin 1975). Diese Studie beurteilt die Zygotie durch Fragen zur Ähnlichkeit des äußeren Erscheinungsbilds sowie zur Verwechslungshäufigkeit durch externe Personen, die auf der Grundlage bereits getesteter Zygotie-Fragebögen, für die eine > 90\% Korrektheit nachgewiesen werden konnte (Cederlof et al. 1961; Nichols \& Bilbro, Jr. 1966), basieren. Darüber hinaus wurden Personen des täglichen Umfelds der Zwillinge (z.B. Schuldirektoren) 
von den Autoren zu ihrer Meinung in Bezug auf die Zygotie der jeweiligen Zwillingspaare befragt. Diese Ergebnisse wurden bei 47 Zwillingspaaren durch serologische Verfahren kontrolliert und in $100 \%$ bestätigt (Martin \& Martin 1975). Unklare Ergebnisse aus den Fragebögen wurden in der Britischen Zwillingsstudie durch zusätzliche Genotypisierung geklärt (Desai et al. 2004). Die Kanadische RLS-Zwillingsstudie verwendet zur Zygotiebestimmung ebenfalls einen standardisierten Fragebogen. Auch hier finden sich keine konkreten Angaben zu den verwendeten Fragen. Die Autoren verweisen hier auf eine Studie, bei der die Zygotiebeurteilung aus einem Fragebogen mit zwei Fragen zur äußerlichen Ähnlichkeit und zur Verwechslungshäufigkeit von 178 Zwillingspaaren mit den Analyseergebnissen der jeweiligen Blutgruppenmarker verglichen wurden und nur bei sieben Zwillingspaaren von 178 abwich (Kasriel \& Eaves 1976; Xiong et al. 2007). Eine Fremdbeurteilung der Zygotie durch die Eltern und/oder dritte Personen aus dem Umfeld der Zwillinge sowie eine zusätzliche Beurteilung anhand von Fotos beider Zwillingspartner, wurde nach Angaben der Autoren weder in der Britischen, noch in der Kanadischen Zwillingsstude durchgeführt (Desai et al. 2004; Xiong et al. 2007).

Da die Wahrscheinlichkeit korrekter Zygotie-Bestimmung nach Literaturangaben bei Verwendung von Mikrosatellitenmarkern größer ist (Becker et al. 1997), als bei der Verwendung von Zygotie-Fragebögen (Cederlof et al. 1961; Nichols \& Bilbro, Jr. 1966; Torgersen 1979; Christiansen et al. 2003), wird das Ausmaß falscher Zygotie-Bestimmung in dieser Arbeit geringer eingeschätzt, als in der Britischen und Kanadischen RLSZwillingsstudie (Desai et al. 2004; Xiong et al. 2007).

Sowohl in der Britischen, als auch in der Kanadischen RLS-Zwillingsstudie ist aufgrund der Zygotiebeurteilung mittels Fragebögen eine ungenaue Einteilung in MZ oder DZ Zwillingspaare nicht auszuschließen. DZ Zwillingspaare, die äußerlich sehr ähnlich sind, könnten nach Ausfüllen der Fragebögen fälschlicherweise als MZ klassifiziert worden sein. $\mathrm{Da}$ in der Regel die Konkordanzen bei DZ Zwillingspaaren in Bezug auf ein RLS niedriger sind, würden diese „falsch MZ“ klassifizierten Zwillingspaare die Konkordanzen der MZ Zwillinge erniedrigen. In der Britischen und Kanadischen Zwillingsstudie finden wir im Vergleich zur US-Amerikanischen Studie und zu der aktuellen Arbeit deutlich erniedrigte Konkordanzen für MZ Zwillinge. Die Möglichkeit der falschen Klassifikation DZ Zwillingspaare als MZ bei der Verwendung von Zygotie-Fragebögen, könnte eine Erklärung für die in der Britischen und Kanadischen Zwillingsstudie niedrigen Konkordanzergebnissen sein. Der umgekehrte Fall, d.h. die falsche Einteilung MZ Zwillingspaare in die Gruppe der 
DZ Zwillinge, erklärt die niedrigen Konkordanzen aus den Studien jedoch nicht, da diese Fehlermöglichkeit eher zu „falsch hohen“ Konkordanzen bei den DZ Zwillingen führen würde (Desai et al. 2004; Xiong et al. 2007).

\subsubsection{Konkordanzen, deren beeinflussende Faktoren und Strukturgleichungsmodell (ACE-Modell)}

Ekbom berichtete über ein MZ Zwillingspaar unter seinen Patienten, das in Bezug auf die Symptome eines RLS konkordant war (Ekbom 1960). Beide Zwillingspartner verspürten nur eine leichte RLS-Symptomatik, während ihre Mutter an einem schweren RLS litt. Unklar bleibt jedoch, ob es sich wirklich um ein MZ Zwillingspaar handelte, da über einen Zygotienachweis mittels Fragebogen oder Blutgruppenserologie keine Angaben gemacht werden. Eine Genotypisierung der Zwillinge auf molekulargenetischer Basis kann in Anbetracht des Publikationsdatums (1960) als ausgeschlossen angesehen werden (Ekbom 1960). Eine familiäre Häufung des RLS ist seit dieser Beschreibung in zahlreichen Studien mit unterschiedlichen Prävalenzen von 30\% bis zu 92\% gezeigt worden (Ekbom 1960; Ondo \& Jankovic 1996; Walters et al. 1996; Montplaisir et al. 1997; Winkelmann et al. 2000; Allen et al. 2003). Die Konkordanzraten aus den bisher veröffentlichten Zwillingsuntersuchungen konnten die Vermutung eines starken genetischen Einflusses auf die Entstehung eines RLS und die dadurch bedingte familiäre Aggregation ebenfalls erhärten (Ondo et al. 2000; Desai et al. 2004; Xiong et al. 2007). Hierbei muss jedoch beachtet werden, dass im Rahmen dieser Studien unterschiedliche Konkordanzraten berechnet wurden, entweder die „Paarweise Konkordanz“(PWC) oder die „Probandenweise Konkordanz“(CWC).

In der vorliegenden Arbeit wurde eine PWC von 73,7\% für MZ und 50\% für DZ Zwillingspaare und eine CWC von 84,8\% für MZ und 66,7\% für DZ Zwillingspaare errechnet.

In der US-amerikanischen Zwillingsstudie wurde die Paarweise Konkordanz (PWC) berechnet (Ondo et al. 2000), die Britische und Kanadische Zwillingsstudie berechneten dagegen die Probandenweise Konkordanz (CWC) (Desai et al. 2004; Xiong et al. 2007). In dieser Arbeit wurden beide Konkordanzen (PWC und CWC) berechnet. Um die bisherigen RLS-Zwillingsstudien besser vergleichen zu können, wurden die Konkordanzen aus diesen Studien rechnerisch angepasst. Von den zwölf MZ Zwillingspaaren aus der USamerikanischen Zwillingsstudie waren zehn Zwillingspaare konkordant für ein RLS, woraus eine PWC von 83,3\% errechnet wurde, was einer CWC von 90,1\% entspricht (Ondo et al. 
2000). Die Britische Zwillingsstudie diagnostizierte 493 betroffene MZ und 549 betroffene DZ Zwillingspaare und bestimmte eine CWC von $61 \%$ für $\mathrm{MZ}$ und $45 \%$ für $\mathrm{DZ}$ Zwillingspaare. Diese Ergebnisse entsprechen einer PWC von 43,6\% für MZ und 29,0\% für DZ Zwillingspaare (Desai et al. 2004). In der Kanadischen Zwillingsstudie wurden 30 betroffene MZ Zwillingspaare diagnostiziert, von denen elf Zwillingspaare konkordant und 19 Zwillingspaare diskordant waren. Hieraus wurde eine CWC von 53,7\% berechnet $(\triangleq \mathrm{PWC}$ 36,6\%). Zusätzlich wurden 24 DZ Zwillingspaare diagnostiziert (zwei Zwillingspaare konkordant; 22 Zwillingspaare diskordant), woraus eine CWC von 15,4\% (^ $\mathrm{PWC} 8,3 \%$ ) berechnet wurde (Xiong et al. 2007). Tabelle 27 zeigt die abweichenden Ergebnisse der Konkordanzberechnung (PWC und CWC) aus den bisher veröffentlichten RLSZwillingsstudien und der aktuellen Studie (Ondo et al. 2000; Desai et al. 2004; Xiong et al. 2007) (Tabelle 27).

Tab. 27: Konkordanzen (PWC, CWC) der bisherigen RLS-Zwillingsstudien im Vergleich

\begin{tabular}{|c|c|c|c|c|c|c|}
\hline Studie & \multicolumn{2}{|c|}{$\begin{array}{c}\text { Anzahl } \\
\text { Zwillingspaare (n) }\end{array}$} & \multicolumn{2}{c|}{ PWC (\%) } & \multicolumn{2}{c|}{ CWC (\%) } \\
\hline & MZ & DZ & MZ & DZ & MZ & DZ \\
\hline Ondo et al. 2000 & 12 & $/$ & $83,3 \%$ & $/$ & $90,1 \%$ & $/$ \\
\hline Desai et al. 2004 & 493 & 549 & $43,6 \%$ & $29,0 \%$ & $61,0 \%$ & $45,0 \%$ \\
\hline Xiong et al. 2007 & 30 & 24 & $36,6 \%$ & $8,3 \%$ & $53,7 \%$ & $15,4 \%$ \\
\hline $\begin{array}{c}\text { aktuelle Studie dieser } \\
\text { Arbeit }\end{array}$ & 19 & 10 & $73,7 \%$ & $50,0 \%$ & $84,8 \%$ & $66,7 \%$ \\
\hline
\end{tabular}

PWC: „Pairwise Concordance“ = Paarweise Konkordanz:

Anzahl der konkordanten Zwillingspaare (C) geteilt durch die Summe aus konkordanten und diskordanten

Zwillingspaaren $(\mathrm{C}+\mathrm{D})$, wobei $\mathrm{C}$ die Anzahl der konkordanten Zwillingspaare und D die Anzahl der

diskordanten Zwillingspaare sind $(\mathrm{C} / \mathrm{C}+\mathrm{D})$

CWC: „Casewise Concordanz“ = Probandweise Konkordanz:

Anzahl der konkordanten Zwillingsindividuen (2C) geteilt durch die Summe aus konkordanten Zwillingsindividuen und diskordanten Zwillingspaare $(2 \mathrm{C}+\mathrm{D})$, wobei $\mathrm{C}$ die Anzahl der konkordanten Zwillingspaare und $\mathrm{D}$ die Anzahl der diskordanten Zwillingspaare sind $(2 \mathrm{C} / 2 \mathrm{C}+\mathrm{D})$

Die in der US-amerikanischen Zwillingsstudie ermittelte hohe Konkordanz für MZ Zwillingspaare (Ondo et al. 2000) konnte in der Britischen und Kanadischen Zwillingsstudie nicht verifiziert werden (Desai et al. 2004; Xiong et al. 2007). In den vorherigen Abschnitten wurden bereits einigen Faktoren diskutiert, die die Konkordanzen in den jeweiligen Zwillingsstudien beeinflussen und zu den divergenten Ergebnissen führen. Die PWC von 73,7\% für MZ Zwillingspaare aus der Studie dieser Arbeit nähern sich am ehesten der Konkordanz, die in der US-amerikanischen Zwillingsstudie ermittelt wurde (PWC 83,3\%) 
(Ondo et al. 2000). Ein Vergleich der US-amerikanischen und dieser Studie ist nur bei den MZ Zwillingspaaren möglich, da in der US-amerikanischen Zwillingsstudie keine DZ Zwillingspaare rekrutiert wurden (Ondo et al. 2000). Auch in dieser Arbeit kann die hohe Konkordanz bei MZ und DZ Zwillingen dadurch bedingt sein, dass ein Teil der Zwillingspaare über eine RLS-Klinikpopulation rekrutiert wurde. Es kann davon ausgegangen werden, dass diese Zwillinge, wie möglicherweise auch in der US-amerikanischen Studie, an einer schwereren Form des RLS litten, wodurch eine gesteigerte Aufmerksamkeit für die RLS-Symptomatik innerhalb des Zwillingspaares nicht auszuschließen ist. Dieser Effekt, der zu höheren Konkordanzen führen könnte, wird bei unserer Untersuchung dadurch etwas abgeschwächt, dass der größere Anteil der Zwillingspaare aus einem Zwillingsregister, mit einer RLS-Prävalenz ähnlich der Allgemeinbevölkerung, rekrutiert wurde. Zudem waren alle Zwillingspaare aus dem Zwillingsregister in Unkenntnis über den Hintergrund der Untersuchung, oftmals war der Begriff „RLS“ innerhalb dieses Kollektivs sogar unbekannt. Die intensive Diagnosesicherung durch einen geschulten Interviewer hat möglicherweise verhindert, Probanden mit leichter RLS-Symptomatik ohne Krankheitscharakter als „falschnegativ“ zu diagnostizieren. Somit konnte die Fehlerwahrscheinlichkeit einer „falsch-niedrig“ ermittelten Konkordanz aufgrund nicht identifizierter RLS-Fälle limitiert werden. Diese Vermutung kann dadurch bekräftigt werden, dass oftmals zu Beginn des Interviews ein RLS verneint wurde, bei genauer Befragung der Probanden aber eine RLS-Diagnose bestätigt werden konnte. Im Laufe ihres Lebens hatten diese Probanden zwar bereits die Erfahrung einer RLS-Symptomatik in speziellen Situationen gemacht, aufgrund der geringen Frequenz und Ausprägung wurde den Symptomen jedoch kein Krankheitswert zugeordnet.

Die geringe Probandenzahl stellt in dieser Arbeit einen limitierenden Faktor dar, wodurch die Aussagekraft der Konkordanzen zusätzlich eingeschränkt wird. Eine Interpretation der ermittelten Konkordanzen sollte daher möglichst unter kritischer Betrachtung aller Einflussfaktoren durchgeführt werden, um falsche Schlussfolgerungen zu vermeiden.

Die Berechnung der Heritabilität bzw. Erblichkeit des RLS im Rahmen von Zwillingsstudien erfordert den Vergleich der Konkordanzen zwischen MZ und DZ Zwillingspaaren. Da MZ Zwillinge genetisch identisch sind, DZ Zwillinge dagegen wie normale Geschwister nur die Hälfte ihrer genetischen Information teilen, wird vermutet, dass die Konkordanz in Bezug auf die Ausprägung eines RLS bei MZ Zwillingspaaren höher ist, als bei DZ Zwillingspaaren. Die Heritabilität ist als der Anteil der genetischen Varianz an der phänotypischen Varianz definiert (Murken et al. 2006). Sie lässt sich in diesem Fall als die Differenz der 
Konkordanzen von MZ und DZ Zwillingen multipliziert mit dem Faktor 2 errechnen (Tabelle 29) (Boomsma et al. 2002). Zusätzlich können auch Umweltfaktoren die Ausprägung eines RLS beeinflussen und tragen somit ebenfalls zur phänotypischen Varianz bei. Der Anteil der Varianz, die durch die Faktoren aus der Umwelt bedingt ist, errechnet sich als Differenz aus der Gesamtkonkordanz minus dem Anteil, der durch die Heritabilität bedingt ist, jeweils für MZ und DZ Zwillinge (Tabelle 28) (Boomsma et al. 2002).

Tab. 28: Formelübersicht $h^{2},\left(V_{E}\right)$

\begin{tabular}{|l|l|}
\hline \multicolumn{1}{|c|}{ Variable } & \multicolumn{1}{c|}{ Formel } \\
\hline Heritabilität $\mathrm{h}^{2}$ & $\mathrm{~h}^{2}=2^{*}\left(\mathrm{r}_{\mathrm{MZ}}-\mathrm{r}_{\mathrm{DZ}}\right)$ \\
\hline Umweltbedingter Varianzanteil $\left(\mathrm{V}_{\mathrm{E}}\right)$ & $\begin{array}{l}\mathrm{MZ}: \mathrm{r}_{\mathrm{MZ}}-\mathrm{h}^{2} \\
\mathrm{DZ}: \mathrm{r}_{\mathrm{DZ}}-\mathrm{h}^{2} / 2\end{array}$ \\
\hline
\end{tabular}

$\mathrm{r}_{\mathrm{MZ}}$ Konkordanz (Korrelation) MZ Zwillinge in Bezug auf ein Merkmal

$\mathrm{r}_{\mathrm{DZ}}$ Konkordanz (Korrelation) DZ Zwillinge in Bezug auf ein Merkmal

Eine weitere Möglichkeit den Anteil genetischer und nicht-genetischer Einflussfaktoren auf die Ätiologie und phänotypische Ausprägung komplexer Erkrankungen im Rahmen der Zwillingsforschung abzuschätzen, bietet die Anwendung des Strukturgleichungsmodells (structural equation modelling, SEM). Mittels dieses Modells können die Anteile additivgenetischer (A) und dominant-genetischer (D) Faktoren sowie die Anteile geteilter (C) und getrennter (E) Umweltfaktoren bestimmt werden, die an der Pathogenese des RLS beteiligt sind. Unter geteilten (gemeinsamen) Umweltfaktoren versteht man nicht-genetische Faktoren aus der Umwelt, die auf beide Zwillingsindividuen während des gemeinsamen Aufwachsens einwirken (z.B. Erkrankung der Mutter während der Schwangerschaft, spezielle innerfamiliäre Noxen, prä- und/oder postnatale Mangelversorgung, klimatische Besonderheiten, usw.). Nichtgeteilte (getrennte) Umweltfaktoren (E) bezeichnen dagegen nicht-genetische Faktoren aus der Umwelt, die nur auf einen Zwillingspartner innerhalb eines Paares einwirken und meist zu deren Unterschiedlichkeit beitragen (z.B. Unfälle, erworbene Erkrankungen, usw.). Zudem lässt sich die Interaktion zwischen genetischen Faktoren und Umweltfaktoren durch dieses Modell ebenfalls abschätzen. Diese Gen-Umwelt-Interaktion überschreitet die additiven Effekte der jeweiligen Einzelfaktoren. Es kommt zu einer gegenseitigen Beeinflussung, wie z.B. der Änderung der Genexpression, bedingt durch bestimmte Umweltfaktoren. Spezielle statistische Programme wurden zur Berechnung dieses Modells entwickelt. In dieser Arbeit wurde die Software Mx, die von Neale entwickelt wurde, zur Berechnung des Strukturgleichungsmodell verwendet (Neale et al. 2002; Boomsma et al. 2002). 
In der Britischen RLS-Zwillingsstudie wurde ebenfalls das Strukturgleichungsmodell angewendet (Desai et al. 2004). In dieser Studie wurden die Varianzanteile der Einflussfaktoren A, D, C, und E, die an der Pathogenese des RLS beteiligt sind, in verschiedenen Kombinationen berechnet (ADCE-Modelle). Nach der Analyse dieser verschiedenen Modelle schloss der Autor einen signifikanten Einfluss gemeinsamer Umweltfaktoren (C) sowie dominant-genetischer Faktoren (D) bei der Entstehung des RLS aus. Den größten Einfluss auf die Varianz der RLS-Symptome innerhalb der Studienpopulation zeigten die additiv-genetischen Faktoren (A) mit 54\% ( $\triangleq$ Heritabilität) sowie die getrennten Umweltfaktoren (E) mit 46\%. Er begrenzte sich daher auf die Darstellung der Varianzanteile mittels AE-Modell (Desai et al. 2004).

In der Zwillingsstudie aus dieser Arbeit haben wir uns für die Anwendung des Strukturgleichungsmodells trotz kleiner Probandenzahl entschlossen. Verschiedene Kombinationen der relativen Varianzanteile additiv- (A) und dominant- (D) genetischer Faktoren sowie gemeinsamer (C) und getrennter (E) Umweltfaktoren wurden getestet. Hier konnte für das Modell mit Berechnung der Komponenten A, C, und E (ACE-Modell) die besten Ergebnisse für die Varianzanteile ermittelt werden. Es zeigte sich, dass der Anteil additiv-genetischer Faktoren (A) mit 32\% deutlich niedriger als in der Britischen Zwillingsstudie $(\mathrm{A}=54 \%)$ ausfällt. Während der Autor in der Britischen Zwillingsstudie den Varianzanteil der gemeinsamen Umweltfaktoren (C) wegen zu schwachem Effekt aus seiner Berechnung ausgeschlossen hat, bildete dieser in unserer Studie den Hauptvarianzanteil von 67\%. Kontroverse Ergebnisse finden sich in den beiden Studien auch bezüglich der Anteile der getrennten Umweltweinflüsse (E), die in der Studie aus dieser Arbeit mit $2 \%$ nur einen unwesentlichen Beitrag zur Ausprägung eines RLS leisten, in der Britischen Zwillingsstudie dagegen mit 46\% einen starken Varianzanteil einnehmen (Desai et al. 2004) (Abbildung 8). 
Abb. 8: Vergleich ACE-Modell Desai et al. versus aktuelle Studie

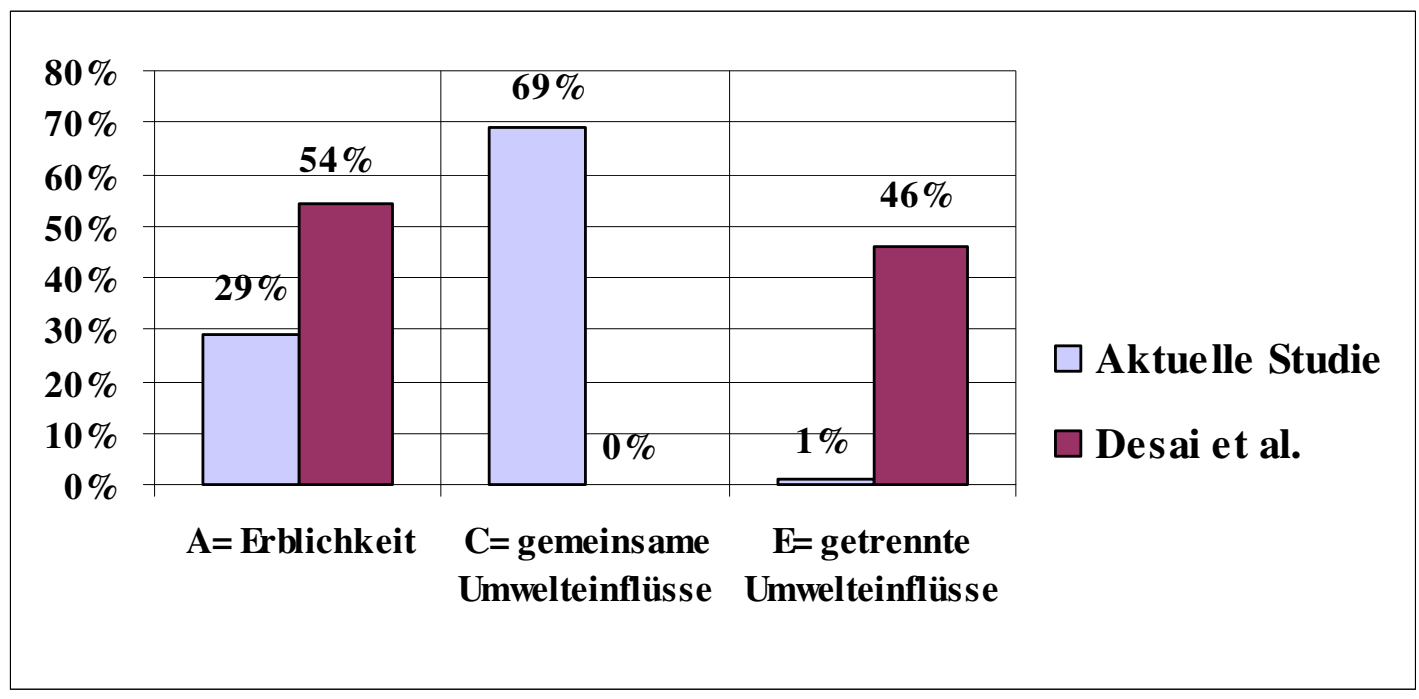

Aufgrund der geringen Anzahl an Probanden wurde in der Kanadischen RLS-Zwillingsstudie auf die Anwendung dieses Modells verzichtet (Xiong et al. 2007). Da ein Vergleich der Korrelationen zwischen MZ und DZ Zwillingspaaren die Voraussetzung für die Anwendung des Strukturgleichungsmodells ist, in der US-amerikanischen RLS-Zwillingsstudie jedoch nur MZ Zwillingspaare untersucht wurden, konnte in dieser Studie das Strukturgleichungsmodell nicht angewendet werden (Ondo et al. 2000).

Die Ergebnisse in dieser Arbeit weisen darauf hin, dass bei der Entstehung eines RLS auch nicht-genetische Faktoren bzw. Umweltfaktoren beteiligt sind. Genetische Faktoren sind relevant, spielen aber möglicherweise eine geringere Rolle als bisher angenommen. Dieses Modell könnte daher ebenfalls eine Erklärung für RLS-Familienstammbäume mit einer hohen Anzahl ( $>50 \%)$ betroffener Nachkommen sein. Gemeinsame Umwelteinflüsse $(\mathrm{C})$ verlieren sich bei Zwillingspaaren mit steigendem Lebensalter, ihr Haupteffekt ist daher in der frühen Entwicklung zu suchen, d.h. diese nicht-genetischen Faktoren bzw. Umweltfaktoren können innerfamiliäre Einflüsse sein. Bereits während der Embryonalentwicklung können gemeinsamen Umweltfaktoren zum Tragen kommen und sollten daher nicht nur in der postnatalen Entwicklungsphase der Individuen gesucht werden. Dabei könnte es sich auch um epigenetische Effekte handeln. Das bedeutet, Umweltfaktoren beeinflussen die Expression und Regulation bestimmter Gene durch Veränderungen der DNA, die nicht auf Sequenzebene (abweichende Abfolge der Basensequenz) lokalisiert sind, sondern sich in der Methylierung von Cytosin-Basen oder durch Histon-Acetylierung manifestieren und so bei identischem Genotypen zu phänotypischen Unterschieden führen können. DNA-Methylierungen führen zu Veränderungen der Chromatinstruktur, wodurch bestimmte DNA-Abschnitte für Transkriptionsfaktoren nicht mehr zugänglich sind und die Genexpression gehemmt wird. 
Von Bedeutung sind hierbei insbesondere Regionen unterschiedlicher Basenlänge im Promotorbereich von Genen, mit einem erhöhten Gehalt an CG-Dinukleotiden, die durch einen Phosphodieseter miteinander verbunden sind (sog. CpG-Inseln). Diese CpG-Inseln liegen, im Gegensatz zu Cytosin-Basen in den übrigen Regionen des Genoms, in der Regel in nicht-methylierter Form vor. Eine Methylierung der Cytosin-Basen innerhalb der CpG-Inseln führt durch Inaktivierung des zugehörigen Gens zu einer reduzierten Genexpression (De Sario 2009).

Epigenetische Mechanismen könnten sich somit hinter dem im ACE-Modell errechneten Anteil von $67 \%$ für die gemeinsamen Umweltfaktoren (C) verbergen. Da sich epigenetische Veränderungen im Laufe des gesamten Lebens manifestieren, können sie somit sowohl durch gemeinsame Umweltfaktoren (C), als auch durch getrennte Umweltfaktoren (E) ausgelöst werden. Es hat sich gezeigt, dass durch epigenetische Effekte bedingte Veränderungen der DNA innerhalb MZ Zwillinge mit zunehmendem Alter stärker voneinander differieren (Fraga et al. 2005). Bei dieser Untersuchung wurde beispielsweise der Gesamtgehalt der methylierten Cytosin-Basen in der DNA und die Histon H3- und H4-Acetylierung quantifiziert sowie genomweit Loci mit abweichenden DNA-Methylierungen identifiziert. Hieraus wurde eine Erklärung für die phänotypische Varianz bestimmter Merkmale und Erkrankungen bei identischem Genotypen innerhalb MZ Zwillinge abgeleitet (Fraga et al. 2005). Da frühe gemeinsame Umweltfaktoren (C) auf beide Zwillinge eines MZ und DZ Paares in ähnlichem Ausmaß einwirken, dürften MZ und DZ Zwillingspaare in jungen Jahren nur geringe epigenetische Unterschiede innerhalb der jeweiligen Paare aufweisen. Man erwartet daher sowohl bei jungen MZ, als auch bei jungen DZ Zwillingspaaren eine hohe Konkordanz bezüglich epigenetisch geprägter Eigenschaften mit geringer Differenz zwischen MZ und DZ Zwillingen. Ist der Einfluss der späten, getrennten Umweltfaktoren (E) größer, so erwartet man durch stärker differierende epigenetische Muster sowohl bei älteren MZ, als auch bei älteren DZ Zwillingen eine abweichende Genexpression innerhalb der jeweiligen Zwillingspaare, was zu reduzierten Konkordanzen in beiden Gruppen (MZ und DZ) führen könnte. Daher könnte auch das Strukturgleichungsmodell der Britischen Zwillingsstudie, mit einem hohen Varianzanteil für getrennte Umweltfaktoren $(E=46 \%)$ durch den Einfluss epigenetischer Effekte bedingt sein (Desai et al. 2004). Der späte Effekt epigenetischer Faktoren wäre zusätzlich eine Erklärung dafür, dass das idiopathische RLS eine Erkrankung des höheren Alters ist, mit den höchsten Prävalenzen um das 60.-70. Lebensjahr (Rothdach et al. 2000; Nichols et al. 2003; Berger et al. 2004; Allen et al. 2005; Hogl et al. 2005). Das 
Phänomen der abnehmenden Prävalenz nach dem 70. Lebensjahr lässt sich mittels Epigenetik nicht erklären.

Der Varianzanteil E (getrennte Umweltfaktoren) führt in Zwillingspaaren zu unterschiedlicher Ausprägung des Phänotyps und somit zu einer geringeren Übereinstimmung (Konkordanz). Dagegen trägt der Varianzanteil C (gemeinsame Umweltfaktoren) in Zwillingspaaren zu einer Übereinstimmung bezüglich eines Phänotyps und somit zu höheren Konkordanzen bei. Dies entspricht einerseits den Ergebnissen der Britischen Zwillingsstudie mit niedrigen Konkordanzen von 43,6\% (PWC) bei MZ und 29,0\% (PWC) bei DZ Zwillingen bei hohem Einfluss von E und niedrigem Einfluss von C. Andererseits lassen sich auch in der vorliegenden Zwillingsstudie die höheren Konkordanzen bei MZ (PWC 73,7\%) und DZ (PWC 50,0\%) durch den hohen Einfluss von C und bei niedrigem Einfluss von E erklären. Die geringen Konkordanzunterschiede zwischen MZ und DZ Zwillingen $\left(\mathrm{r}_{\mathrm{DZ}}>0,5 * \mathrm{r}_{\mathrm{MZ}}\right)$ in beiden Studien deuten wiederum darauf hin, dass Umweltfaktoren insgesamt bei der Pathogenese des RLS einen bedeutenden Einfluss haben, der den der genetischen Faktoren übertreffen könnte (Boomsma et al. 2002).

Die abweichenden Ergebnisse bei der Berechnung der Strukturgleichungsmodelle in der Britischen Zwillingsstudie und in dieser Arbeit (siehe Abbildung Nr. 8) sind möglicherweise auf die ungenaue RLS-Diagnostik und den Einschluss sekundärer RLS-Fälle in der Britischen Zwillingsstudie zurückzuführen. Erkrankungen oder Bedingungen, die einem sekundären RLS zugrunde liegen, könnten als nichtgeteilte Umweltfaktoren (d.h. Faktoren, die nur auf einen Zwillingspartner einwirken) identifiziert werden, und somit diesen Varianzanteil (E) beeinflusst haben (Desai et al. 2004).

\subsubsection{Zusammenhang zwischen ACE-Modell und der aktuellen genetischen Grundlage des Restless Legs Syndrom}

Die bisher identifizierten sechs Kopplungsregionen (RLS-Loci) auf den Chromosomen 12q, 14q, 9p, 2p, 20p, und 16p (Desautels et al. 2001; Bonati et al. 2003; Chen et al. 2004; Pichler et al. 2006; Levchenko et al. 2006; Levchenko et al. 2008) sowie der Hinweis auf eine siebte Kopplungsregion auf Chromosom 19p (Kemlink et al. 2008), deuten auf eine Locusheterogenität hin. Das bedeutet, dass möglicherweise mehrere Mutationen innerhalb verschiedener Genen oder innerhalb verschiedener genregulatorischer Regionen, auch unabhängig voneinander, ein RLS auslösen können. Die Kopplungsergebnisse wurden in unterschiedlichen Populationen ermittelt. Tabelle 29 gibt einen Überblick über alle bisher 
identifizierten RLS-Loci (Pichler et al. 2008). Einige dieser Kopplungssignale (Chromosom 12q, 14q, 9p) ließen sich auch in unabhängigen Familien anderer Herkunft bestätigen (Winkelmann et al. 2006; Liebetanz et al. 2006; Kemlink et al. 2007). Das Kopplungssignal auf Chromosom 12q konnte jedoch in drei Familien aus Südtirol nicht bestätigt werden (Kock et al. 2002; Vogl et al. 2006). Die variablen Ergebnisse aus Kopplungsstudien in Familien unterschiedlicher Herkunft deuten auf eine genetische Komplexität des RLS hin.

Tab. 29: RLS-Loci in Abwandlung nach Pichler (Pichler et al. 2008)

\begin{tabular}{|c|c|c|c|c|c|}
\hline $\begin{array}{l}\text { RLS- } \\
\text { Locus }\end{array}$ & Chromosom & Erbgang & Diagnose & Population & Quelle \\
\hline RLS1 & $12 q 22-23.3$ & $\begin{array}{l}\text { AR, } \\
\text { pseudodominant }\end{array}$ & $\begin{array}{l}\text { IRLSSG-Kriterien von } \\
1995^{(1)}\end{array}$ & $\begin{array}{l}\text { Französisch- } \\
\text { kanadisch }\end{array}$ & $\begin{array}{l}\text { (Desautels et } \\
\text { al. 2001) }\end{array}$ \\
\hline RLS2 & $14 q 13-22$ & $\mathrm{AD}$ & $\begin{array}{l}\text { IRLSSG-Kriterienvon } \\
1995^{(1)}\end{array}$ & Italien & $\begin{array}{l}\text { (Bonati et } \\
\text { al. 2003) }\end{array}$ \\
\hline RLS3 & $9 p 24-22$ & $\mathrm{AD}$ & $\begin{array}{l}\text { IRLSSG-Kriterien von } \\
1995^{(1)}\end{array}$ & USA & $\begin{array}{l}\text { (Chen } \text { et al. } \\
\text { 2004) }\end{array}$ \\
\hline RLS4 & $2 q 33$ & $\mathrm{AD}$ & $\begin{array}{l}\text { Stufe 1: } \\
\text { IRLSSG-Kriterien von } \\
1995^{(1)} \\
\text { Stufe 2: } \\
\text { IRLSSG-Kriterien von } \\
2003^{(2)}\end{array}$ & $\begin{array}{l}\text { Südtirol, } \\
\text { Italien }\end{array}$ & $\begin{array}{l}\text { (Pichler et } \\
\text { al. 2006) }\end{array}$ \\
\hline RLS5 & 20p13 & $\mathrm{AD}$ & $\begin{array}{l}\text { IRLSSG-Kriterien von } \\
2003^{(2)}\end{array}$ & $\begin{array}{l}\text { Französisch- } \\
\text { kanadisch }\end{array}$ & $\begin{array}{l}\text { (Levchenko } \\
\text { et al. 2006) }\end{array}$ \\
\hline- & $16 \mathrm{p} 12.1$ & $\mathrm{AD}$ & $\begin{array}{l}\text { IRLSSG-Kriterien von } \\
2003^{(2)}\end{array}$ & $\begin{array}{l}\text { Französisch- } \\
\text { kanadisch }\end{array}$ & $\begin{array}{l}\text { (Levchenko } \\
\text { et al. 2008) }\end{array}$ \\
\hline
\end{tabular}

AD: autosomal dominat;

AR: autosomal recessi

IRLSSG: Internationale Restless Legs Syndrome Study Group

(1) Diagnosekriterien der IRLSSG von 1995 (Walters 1995)

(2) Modifizierte Diagnosekriterien der IRLSSG von 2003 (Allen et al. 2003)

Die in zwei Assoziationsstudien identifizierten genetischen Varianten in den Genen MEIS1, BTBD9, LBXCOR1/MAP2K5 und PTPRD (Winkelmann et al. 2007; Stefansson et al. 2007; Schormair et al. 2008), die mit einem erhöhten Risiko für die Entstehung eines RLS einhergehen, verdeutlichen ebenfalls die Komplexität dieser Erkrankung (Tabelle 30). 
Tab. 30: RLS-assoziierte Genvarianten, Funktion und möglicher Zusammenhang mit RLS, in Abwandlung nach Mignot (Mignot 2007)

\begin{tabular}{|c|c|c|c|}
\hline Gen & Funktion & $\begin{array}{c}\text { möglicher } \\
\text { Zusammenhang } \\
\text { mit RLS }\end{array}$ & Referenz \\
\hline $\begin{array}{l}\text { MEIS1 } \\
\text { (Homöobox-Gen, } \\
\text { Transkriptionsfaktor) } \\
\text { Locus: 2p14-p13 }\end{array}$ & $\begin{array}{l}\text { Entwicklung der proximodistalen } \\
\text { Extremitäten (Zellspezifizierung und } \\
\text { Determinierung der Strukturen } \\
\text { entlang der proximodistalen } \\
\text { Extremitätenachse) und der } \\
\text { Neuralleiste, Expression in } \\
\text { dopaminergen Neuronen der } \\
\text { Substantia nigra. }\end{array}$ & $\begin{array}{l}\text { Bewegungsdrang, } \\
\text { PLM }\end{array}$ & $\begin{array}{l}\text { (Mercader et } \\
\text { al. } 1999 ; \\
\text { Winkelmann } \\
\text { et al. } 2007 \text { ) }\end{array}$ \\
\hline $\begin{array}{l}\text { BTBD9 } \\
\text { (Locus: } 6 p 21\end{array}$ & $\begin{array}{l}\text { unbekannt; bei Drosophila Einfluss } \\
\text { auf Extremitätenentwicklung während } \\
\text { der Embryogenese. }\end{array}$ & PLM & $\begin{array}{l}\text { (Winkelmann } \\
\text { et al. 2007; } \\
\text { Stefansson } \text { et } \\
\text { al. 2007) }\end{array}$ \\
\hline $\begin{array}{l}\text { MAP2K5 } \\
\text { (Kinase) } \\
\text { Locus: } 15 q 23\end{array}$ & $\begin{array}{l}\text { Beteiligung bei Wachstumsfaktor- } \\
\text { stimulierter Proliferation und } \\
\text { Differenzierung von Muskelzellen }\end{array}$ & unbekannt & $\begin{array}{l}\text { (Winkelmann } \\
\text { et al. 2007) }\end{array}$ \\
\hline $\begin{array}{l}\text { LBXCOR1 } \\
\text { (Corepressor für den } \\
\text { Transkriptionsfaktor } \\
\text { LBX1) } \\
\text { Locus: } 15 q 23\end{array}$ & $\begin{array}{l}\text { Einfluss auf Differenzierung von } \\
\text { GABAergen Interneuronen im } \\
\text { dorsalen Rückenmark während der } \\
\text { Embryonalentwicklung }\end{array}$ & $\begin{array}{l}\text { sensible Symptome, } \\
\text { Missempfindung } \\
\text { und/oder Schmerz- } \\
\text { empfindung }\end{array}$ & $\begin{array}{l}\text { (Mizuhara et } \\
\text { al. 2005; } \\
\text { Cheng } \text { et al. } \\
\text { 2005; } \\
\text { Winkelmann } \\
\text { et al. 2007) }\end{array}$ \\
\hline $\begin{array}{l}\text { PTPRD } \\
\text { (Signaltrans- } \\
\text { duktionsmolekül) } \\
\text { Locus: 9p23-p24.3 }\end{array}$ & $\begin{array}{l}\text { Regulation von Neuronen- und } \\
\text { Axonwachstum; möglicherweise } \\
\text { Beeinflussung der embryonalen } \\
\text { Motoneuronenentwicklung }\end{array}$ & $\begin{array}{l}\text { Motorische } \\
\text { Komponente des } \\
\text { RLS }\end{array}$ & $\begin{array}{l}\text { (Schormair } e t \\
\text { al. 2008) }\end{array}$ \\
\hline
\end{tabular}

Dabei konnte lediglich die genetische Variante im Gen PTPRD der Kopplungsregion auf Chromosom 9p23-24 zugeordnet werden (Schormair et al. 2008). Die übrigen drei genetischen Varianten liegen außerhalb der bisher identifizierten Kopplungsregionen.

$\mathrm{Ob}$ es sich bei den vier identifizierten Assoziationssignalen im genomischen Intronbereich der Gene MEIS1; BTBD9, LBXCOR1/MAP2K5 und PTPRD (Winkelmann et al. 2007; Stefansson et al. 2007; Schormair et al. 2008) um Varianten in der DNA-Sequenz handelt, oder ob diese auf Genregulationsebene zum Tragen kommen, ist nicht geklärt. Auch epigentische Veränderungen, z.B. durch Modifikationen von Histon-Proteinen oder durch DNA-Methylierung, dürfen nicht ausgeschlossen werden. Die Ergebnisse aus den Kopplungsund Assoziationsstudien widersprechen somit keinesfalls der Möglichkeit, dass gemeinsame Umweltfaktoren (C) über die Initiierung epigenetischer Effekte einen bedeutenden Einfluss auf die Entstehung eines RLS haben können. Um welche Faktoren aus der Umwelt es sich 
dabei handelt und auf welcher Ebene diese Umweltfaktoren wirken, lässt sich zum gegebenen Zeitpunkt nicht abschätzen. In Anbetracht der diskutierten genetischen Studien scheint eine Wirkung spezifischer Umweltfaktoren auf genomischer Ebene, möglicherweise durch epigenetische Effekte, jedoch durchaus denkbar und sollten zukünftig neue Forschungsansätze liefern, die das pathophysiologischen Verständnis des RLS erweitern könnten.

Die Ergebnisse aus den Berechnungen des Strukturgleichungsmodells dieser Arbeit müssen aufgrund der geringen Probandenzahl vorsichtig interpretiert werden. Sie sollten eher eine Tendenz anzeigen, die Anleitung zur Entwicklung neuer Forschungs- und Denkansätzen liefern soll und nicht als Absolutwerte angesehen werden.

\subsubsection{Familienanamnese}

In dieser Arbeit konnte bei insgesamt 43 Zwillingsindividuen (89,6\%) eine positive Familienanamnese erhoben werden. 38 dieser Individuen stammten aus konkordanten Zwillingspaaren (14 MZ/5DZ Zwillingspaare). Zusätzlich berichteten fünf Zwillingsindividuen aus diskordanten Paaren (2 MZ/3 DZ Zwillingspaare) bei nicht-betroffenem Zwillingsgeschwister über weitere betroffene Familienmitglieder. In bisherigen Studien zeigte sich, dass das durchschnittliche „Alter bei Symptombeginn“ bei Patienten mit einer positiven Familienanamnese jünger ist, als bei Patienten mit negativer Familienanamnese (Walters et al. 1996; Winkelmann et al. 2000; Tison et al. 2005).

In der vorliegenden Arbeit konnte dieses Ergebnis nicht verifiziert werden. Das durchschnittliche „Alter bei Symptombeginn“ lag bei Patienten mit positiver Familienanamnese mit 34,5 Jahren (SD +/- 16,1 Jahre) über dem der Patienten mit negativer Familienanamnese (29,4 Jahre, SD +/- 14,9 Jahre). Allerdings ist das Erkankungsalter bei positiver Familienanamese (34,5 Jahren, SD +/- 16,1 Jahre) mit dem früherer Studien $(35,45$ Jahre, SD +/- 1,83) vergleichbar (Winkelmann et al. 2000). Aufgrund der Größendifferenz der beurteilten Untergruppen (positive Familienanamense: $\mathrm{N}=43$ vs. negative Familienanamnese: $\mathrm{N}=5$ ) ist in dieser Arbeit das „Alter bei Symptombeginn“ möglicherweise nicht zu vergleichen. Das Kollektiv von fünf Patienten zur genauen Beurteilung des Erkankungsalters bei negativer Familienanamnese ist zu niedrig um aussagekräftige Durchschnittswerte zu ermitteln. Aufgrund der Differenz und schlechten Vergleichbarkeit der beiden Gruppen (34,5 Jahre bei positiver Familienanamnese, N= 43 vs. 29,4 Jahre bei negativer Familienanamnese, $\mathrm{N}=5$ ) haben wir auf einen Signifikanztest verzichtet. 
In der US-amerikanischen Zwillingsstudie konnten bei allen zehn konkordanten MZ Zwillingspaaren und insgesamt bei elf $(91,7 \%)$ der untersuchten zwölf MZ Zwillingspaare weitere Familienmitglieder mit einem sicheren oder fraglichen RLS identifiziert werden. Der Zusammenhang von Alter bei Symptombeginn und Familienanamnese wurde vom Autor bei den zwölf MZ Zwillingspaaren nicht ausgewertet (Ondo et al. 2000). Sowohl die Britische, als auch die Kanadische Zwillingsstudie erhob keine Daten zur Familienanamnese (Desai et al. 2004; Xiong et al. 2007).

Durch die geringe Probandenzahl und das besondere Kollektiv aus MZ und DZ Zwillingen sowie die verwendete Definition einer positiven Familienanamnese bereits bei betroffenem Zwillingspartner lassen sich die Ergebnisse der aktuellen Arbeit nicht uneingeschränkt auf die früheren epidemiologischen Studien (Walters et al. 1996; Winkelmann et al. 2000; Allen et al. 2002) und die US amerikanische Zwillingsstudie übertragen (Ondo et al. 2000).

\subsubsection{Klinische Daten zum Restless Legs Syndrom}

Oftmals zeigt sich eine phänotypisch stark variable klinische Ausprägung des RLS bei mehreren betroffenen Mitgliedern innerhalb einer Familie. Das Alter bei Symptombeginn kann dabei in der betroffenen Familie variieren. In zwei Studien zeigte sich die Tendenz eines früheren Beginn der Symptomatik in den nachfolgenden Generationen (Trenkwalder et al. 1996; Lazzarini et al. 1999). Zusätzlich konnten im Rahmen mehrerer Familienuntersuchungen unterschiedliche Penetranzen in den verschiedenen Familien beobachtet werden (Lazzarini et al. 1999). Auch dieser Aspekt lässt wiederum eine GenUmwelt-Interaktion vermuten, was mit Hilfe des Zwillingsmodells gut zu beurteilen ist. Aus diesem Grund bietet sich besonders innerhalb konkordanter Zwillingspaare ein Vergleich der klinischen Charakteristika des RLS an.

In der Studie aus dieser Arbeit lag bei 50\% der Zwillingspaare die Differenz des Alters bei Symptombeginn unter fünf Jahren, mit einem Maximalwert von 25 Jahren bei nur einem MZ Zwillingspaar. Ähnlichkeiten fanden sich auch im Schweregrad der Erkrankung. Die ermittelten Werte der Schweregrad-Skala, mit zu erreichenden Punktewerten von 1-40 (Kategorie-Intervall: 1-10 leicht, 11-20 mittel, 21-30 stark, 31-40 sehr stark) wichen bei allen Zwillingspaaren nicht mehr als 10 Punkte (max. 25\%) voneinander ab, wodurch die Zwillinge sich maximal um eine Schweregrad-Kategorie unterschieden. Durchschnittlich erreichten die betroffenen Zwillinge einen Schweregrad von 15,1 (SD +/- 10,1). Die Klinische Ausprägung des RLS in Bezug auf Häufigkeit des Auftretens der Symptome $(p=1,0)$ sowie der 
Extremitätenlokalisation $(\mathrm{p}=0,294)$ zeigte keine signifikant höheren Korrelationen bei MZ Zwillingen gegenüber DZ Zwillingen. Die in dieser Arbeit ermittelten p-Werte für die Signifikanz der beiden klinischen Ausprägungen entstehen möglicherweise aufgrund der geringen Anzahl an Zwillingspaaren und lassen sich daher nicht abschließend interpretieren. Zusammengefasst konnten wir keine deutlichen Korrelationen im Krankheitsverlauf erkennen und fanden ebenso wenig signifikante Unterschiede beim Vergleich zwischen MZ und DZ Zwillingspaaren.

In der US-amerikanischen und Kanadischen Zwillingsstudie zeigten sich diesbezüglich innerhalb aller konkordanten Zwillingspaare widersprüchliche Ergebnisse (Ondo et al. 2000; Xiong et al. 2007). Trotz einer hohen Konkordanzrate fanden sich in der US-amerikanischen Studie deutliche Unterschiede im Alter bei Symptombeginn sowie in der Ausprägung bzw. Beschreibung der RLS-Symptomatik innerhalb der konkordanten Zwillingspaare (Ondo et al. 2000). Dagegen berichtet die Kanadische Zwillingsstudie, bei insgesamt niedrigeren Konkordanzen, von einem scheinbar ähnlichen Krankheitsverlauf innerhalb der konkordanten Zwillingspaare, mit einer hohen Korrelation in Bezug auf das Alter bei Symptombeginn und den Schwergrad der Symptome (Xiong et al. 2007). Das niedrigste durchschnittliche Alter bei Symptombeginn wurde in der US-amerikanischen Studie mit 21,5 Jahre (SD +/- 16,0 Jahre) ermittelt. Die Kanadische Studie ermittelte ein durchschnittliches Alter bei Symptombeginn für „definitives RLS“ von 30,7 Jahren (SD +/- 18,3 Jahre) und für „,wahrscheinliches RLS“ von 25,9 Jahren (SD +/- 19,0 Jahre) (Xiong et al. 2007). Die Britische Zwillingsstudie macht keine Angaben zum Alter bei Symptombeginn bei betroffenen Zwillingsindividuen (Desai et al. 2004). In der Studie aus dieser Arbeit findet sich das bisher im Rahmen von Zwillingsstudien ermittelte höchste durchschnittliche Alter bei Symptombeginn von 34,0 Jahren (SD +/- 15,9 Jahre). Gründe für die unterschiedlichen Alter bei Symptombeginn innerhalb der RLS-Zwillingsstudien sind im Probandenkollektiv $\mathrm{zu}$ suchen. Alle Zwillingspaare aus der US-amerikanischen Studie entstammen einer RLS-Klinikpopulation (Ondo et al. 2000). Es kann davon ausgegangen werden, dass Probanden aus einer RLSKlinikpopulation bereits länger und schwerer an einem RLS leiden, da erst ab einem gewissen Leidensdruck eine Arztkonsultation mit medikamentöser Behandlung der Beschwerden in Betracht gezogen wird. In der Kanadischen Studie und der Studie dieser Arbeit wurde nur der kleinere Anteil der Probanden aus einer RLS-Klinikpopulation, der größte Anteil dagegen aus Zwillingsregistern rekrutiert (Xiong et al. 2007). Bei Probanden aus Zwillingsregistern erwartet man eine mildere Ausprägung und einen späteren Beginn der RLS-Symptome. Der Effekt des zugrunde liegenden Probandenkollektivs lässt sich auch auf den durchschnittlichen 
Schweregrad der RLS-Symptome übertragen. Höchste durchschnittliche SchweregradPunktewerte finden sich mit 23,0 (SD +/- 8,2) Punktewerten in der US-amerikanischen Studie innerhalb der RLS-Klinikpopulation (Ondo et al. 2000). Die ermittelten durchschnittlichen Schweregrade aus dem Mischkollektiv einer Klinikpopulation und eines Zwillingsregisters aus der Kanadischen Studie (,definitives RLS“: 13,0 SD +/- 6,1 Punktewerte; „wahrscheinliches RLS“: 14,4 SD +/- 7,7 Punktewerte) und der aktuellen Studie dieser Arbeit (15,1 SD +/- 10,1 Punktewerte) sind deutlich niedriger und in beiden Studien fast identisch (Xiong et al. 2007).

In der Britischen Zwillingsstudie wurden keine weiteren Daten zur RLS-Symptomatik bei betroffenen Zwillingsindividuen erhoben, eine Analyse der klinischen Ausprägung des RLS innerhalb konkordanter Zwillingspaare konnte daher nicht durchgeführt werden (Desai et al. 2004).

Somit konnten in der Zwillingsstudie aus dieser Arbeit die Erkenntnisse aus der Kanadischen Zwillingsstudie bezüglich der klinischen Ausprägung der Symptome und des Krankheitsverlaufs innerhalb der konkordanten Zwillingspaare nicht reproduziert werden (Xiong et al. 2007), tendieren dagegen in Richtung der Ergebnissen der US-amerikanischen Studie (Ondo et al. 2000). Wie jedoch bereits erwähnt, schränken die niedrigen Probandenzahlen die Aussagefähigkeit der Ergebnisse ein. Die Ursache der widersprüchlichen Ergebnisse aus den Zwillingsstudien lässt sich an dieser Stelle nicht abschließend erörtern. Gerade in der US-amerikanischen Zwillingsstudie würde man aufgrund des RLS-Patientenkollektivs mit möglicher Beeinflussung der Zwillingspartner stärkere Korrelationen bezüglich der klinischen Charakteristika des RLS erwarten, was jedoch nicht bestätigt werden konnte (Ondo et al. 2000).

\subsubsection{Sekundäres Restless Legs Syndrom}

Ein sekundäres RLS entsteht auf der Basis einer Erkrankung oder Veränderung des Körpers, wie z.B. Niereninsuffizienz, Schwangerschaft oder Eisenmangel. Ob die Prädisposition zur Entstehung eines sekundären RLS wie beim primären RLS genetisch determiniert ist, konnte bisher nicht geklärt werden. Aus diesem Grund sollten Familien- und Zwillingsuntersuchungen sowie molekulargenetische Untersuchungen, die dazu dienen die Erblichkeit der Erkrankung abzuschätzen und mögliche Genvarianten zu identifizieren, nur bei Patienten mit primärem RLS durchgeführt werden. Hierdurch sollen abschwächende 
Effekte auf genetische Untersuchungsergebnisse, die beim Vermischen primärer und sekundärer RLS-Phänotypen zustande kommen können, vermieden werden.

Der Einschluss sekundärer RLS-Fälle kann in der Studie aus dieser Arbeit nicht ausgeschlossen werden. Serumeisen und Serumferritinwerte, sowie Ferritin im Liquor wurden bei keinem der Zwillinge bestimmt. Anamnestisch lag bei keinem der engeschlossenen Zwillinge eine terminale Niereninsuffizienz mit Dialysepflicht vor. Diabetes mellitus und Polyneuropathie wurde in $6,3 \%$ bzw. $8.3 \%$ der RLS-Fälle anamnestiziert, eine kausale Assoziation zur RLS-Symptomatik konnte in diesen Fällen jedoch nicht beurteilt werden. Die Konkordanzraten, die in dieser Arbeit ermittelt wurden, könnten durch den Einschluss nicht diagnostizierter sekundärer RLS-Fälle, sowohl bei den $\mathrm{MZ}$ als auch bei den DZ Zwillingspaaren „falsch niedrige“ Werte annehmen, wodurch Aussagen über die Erblichkeit eines RLS beeinflusst werden.

Der Autor der US-amerikanischen RLS-Zwillingsstudie schließt ebenfalls nicht aus, in seiner Studie nicht erkannte sekundäre RLS-Fälle eingeschlossen zu haben. Ein sekundäres RLS aufgrund eines manifesten Eisenmangels scheint unwahrscheinlich, da bei keinem Zwillingsindividuum erniedrigte Werte für Ferritin im Serum nachgewiesen werden konnten (Ondo et al. 2000). Allerdings kann dies nicht sicher ausgeschlossen werden, da der Ferritinwert des Liquors nicht bestimmt wurde (Ondo et al. 2000). Ein zerebraler Eisenmangel kann somit nicht ausgeschlossen werden. Es konnte nachgewiesen werden, dass trotz normaler Serum-Ferritinwerte der Ferritinwert im Liquor erniedrigt und mit einem RLS assoziiert sein kann (Mizuno et al. 2005a).

Auch in der Britischen RLS-Zwillingsstudie können die Studienergebnisse durch nicht identifizierte sekundäre RLS-Fälle beeinflusst worden sein und müssen daher kritisch betrachtet werden. Eine genaue Differenzierung zwischen primärem und sekundärem RLS wurde in dieser Studie nicht durchgeführt (Desai et al. 2004). Der Einschluss sekundärer RLS-Fälle kann einerseits zu erhöhten Prävalenzen eines RLS führen, die in der Britischen Zwillingsstudie mit 36,6\% deutlich über der in zahlreichen epidemiologischen Studien gezeigten Prävalenz von etwa 10\% liegt (Rothdach et al. 2000; Phillips et al. 2000; Berger et al. 2004; Hogl et al. 2005). Möglicherweise führt der Einschluss sekundärer RLS-Zwillinge zu falsch niedrigen Konkordanzen bei den Zwillingspaaren, da in diesen Fällen eher eine nicht-erblich bedingte Grunderkrankung, und nicht eine genetische Prädisposition als Auslöser des RLS in Betracht kommt (Desai et al. 2004). Die Kanadische Zwillingsstudie gibt keine Auskunft über den definitiven Ausschluss sekundärer RLS-Fälle (Xiong et al. 
2007). Aus diesem Grund kann in dieser Zwillingsstudie eine Beeinflussung der Konkordanz $\mathrm{zu}$ niedrigeren Werten nicht ausgeschlossen werden. Trotzdem wurden Daten zu fünf Erkrankungen, die häufig mit einem RLS assoziiert sind, beziehungsweise Ursache eines sekundären RLS sein können, erhoben. Die Pävalenzen dieser RLS-assozieerten Erkrankungen wurden im Vergleich zur Prävalenz des RLS bei den 272 untersuchten Zwillingspaaren aufgeführt, mit dem Ergebnis, dass eine Anämie bzw. ein Eisenmangel (Prävalenz 22,64\%) sowie eine Arthritis (Prävalenz 22,37\%) zusammen mit einem „definitiven RLS“ (Prävalenz 12,25\%) die drei häufigsten Erkrankungen innerhalb der untersuchten 272 Zwillingspaare waren. Darüber hinaus konnte in der Kanadischen Zwillingsstudie gezeigt werden, dass ein „definitives RLS“ in hohem Maß mit dem Auftreten einer Anämie und Arthritis assoziiert ist, unabhängig von der Zygotie der untersuchten Zwillingspaare. Anhand dieser Ergebnisse stellten sich eine Anämie (RR 2,51) und Arthritis (RR 2,57) als signifikante Risikofaktoren für die Ausbildung eines RLS innerhalb des Probandenkollektives heraus, das bedeutet, dass alle Zwillinge aus der Kanadischen Zwillingsstudie ein etwa 2,5fach erhöhtes Risiko aufweisen an einem „definitiven RLS“ zu erkranken, sofern sie entweder anämisch sind oder an einer Arthritis leiden. Über die Assoziation von RLS mit einer Urämie (Pävalenz 1,08\%), einem Diabetes mellitus (Pävalenz 3,58\%) oder einer Polyneuropathie (Pävalenz 0,65\%) innerhalb des Probandenkollektives wurden keine weiteren Aussagen gemacht (Xiong et al. 2007). Es wird daher angenommen, dass keine auffälligen Risikoprofile zur Ausbildung eines RLS bei Probanden mit diesen Erkrankungen in der Kanadischen Zwillingsstudie ermittelt werden konnten.

\subsection{Vergleich mit Zwillingsstudien zu anderen neurologischen Erkrankungen}

Nachfolgend wird auf Studien mit Zwillingen bei anderen neurologischen Erkrankungen wie Morbus Parkinson, Essentieller Tremor, Narkolepsie und Tourette Syndrom eingegangen. In Tabelle 31a-d sind einige Zwillingsstudien bezüglich der zuvor erwähnten neurologischen Erkrankungen mit den entsprechenden Konkordanzen aufgeführt.

Zwillingsstudien beim Parkinson-Syndrom zeigen uneinheitliche Ergebnisse für Konkordanzen bei MZ und DZ Zwillingen. Diese schwanken bei den in der Tabelle 32a zitierten Studien zwischen 0\% - 33,3\% für MZ und 0\% - 25\% für DZ Zwillingspaare (Ward et al. 1983; Marsden 1987; Marttila et al. 1988; Vieregge et al. 1992; Tanner et al. 1999; 
Vieregge et al. 1999; Wirdefeldt et al. 2004). Schon der geringe Unterschied der Konkordanzen zwischen MZ und DZ Zwillingspaaren deutet eher auf den Einfluss von Umweltfaktoren auf die Pathopysiologie eines Parkinson-Syndroms hin, als auf eine starke genetische Komponente (Ward et al. 1983; Boomsma et al. 2002; Wirdefeldt et al. 2004) (Tabelle 31a).

Tab. 31a: Zwillingsstudien bei Morbus Parkinson

\begin{tabular}{|c|c|c|c|c|c|c|}
\hline \multicolumn{7}{|c|}{ Morbus Parkinson in MZ und DZ Zwillingspaaren } \\
\hline \multirow[t]{2}{*}{ Studie } & \multicolumn{2}{|c|}{$\begin{array}{c}\text { Eingeschlossene } \\
\text { Zwillingspaare (N) }\end{array}$} & \multicolumn{2}{|c|}{$\begin{array}{c}\text { Konkordante } \\
\text { Zwillingspaare (N) }\end{array}$} & \multicolumn{2}{|c|}{$\operatorname{PWC}(\%)$} \\
\hline & MZ & $\mathbf{D Z}$ & MZ & DZ & MZ & DZ \\
\hline Ward et al. 1983 & 43 & 19 & 1 & 0 & $2,3 \%$ & $0 \%$ \\
\hline Marsden et al. 1987 & 11 & 11 & 1 & 1 & $9,1 \%$ & $9,1 \%$ \\
\hline Marttila et al. 1988 & 18 & 14 & 0 & 1 & $0 \%$ & $7,1 \%$ \\
\hline Vieregge et al. 1992 & 9 & 12 & 3 & 3 & $33,3 \%$ & $25,0 \%$ \\
\hline $\begin{array}{l}\text { Vieregge et al. } 1999 \\
\text { Follow-Up von } 1992\end{array}$ & 9 & 14 & 3 & 6 & $33,3 \%$ & $42,9 \%$ \\
\hline Tanner et al. 1999 & 71 & 90 & 11 & 10 & $15,5 \%$ & $11,1 \%$ \\
\hline \multirow{3}{*}{$\begin{array}{l}\text { Wirdefeldt et al. } 2004 \\
\text { mögliches Parkinson- } \\
\text { Syndrom } \\
\text { V.a. Parkinsonismus oder } \\
\text { Bewegungsstörung }\end{array}$} & & & & & & \\
\hline & 33 & 80 & 0 & 2 & $0 \%$ & $2,5 \%$ \\
\hline & 101 & 182 & 6 & 8 & $5,9 \%$ & $4,4 \%$ \\
\hline
\end{tabular}

Hohe Konkordanzen bei MZ Zwillingspaaren finden sich für das Auftreten eines Essentiellen Tremors (ET). In zwei Studien konnten fast identische Konkordanzen (PWC) von 60\% (Tanner et al. 2001) und 63\% (Lorenz et al. 2004) ermittelt werden. Die Konkordanzen für DZ Zwillingspaare waren in beiden Studien weniger als die Hälfte der Konkordanzen für MZ Zwillingspaaren (PWC DZ 27\% und PWC DZ 14\%) (Tanner et al. 2001; Lorenz et al. 2004). Das weist auf eine deutliche hereditäre Komponente beim Essentiellen Tremor hin, an deren phänotypischer Ausprägung möglicherweise zusätzliche Umwelteffekte beteiligt sind (Tanner et al. 2001)(Tabelle 31b). 
Tab. 31b: Zwillingsstudien bei Essentiellem Tremor

\begin{tabular}{|c|c|c|c|c|c|c|}
\hline \multicolumn{6}{|c|}{ Essentieller Tremor (ET) in MZ und DZ Zwillingspaaren } \\
\hline & \multicolumn{2}{|c|}{$\begin{array}{c}\text { Eingeschlossene } \\
\text { Zwillingspaare (N) }\end{array}$} & $\begin{array}{c}\text { Konkordante } \\
\text { Zwillingspaare (N) }\end{array}$ & \multicolumn{2}{c|}{ PWC (\%) } \\
\hline Studie & MZ & DZ & MZ & DZ & MZ & DZ \\
\hline Tanner et al. 2001 & 5 & 11 & 3 & 3 & $60 \%$ & $27 \%$ \\
\hline $\begin{array}{c}\text { Lorenz et. al. 2004 } \\
\text {,definitive ET-Diagnose“ }\end{array}$ & 8 & 14 & 5 & 2 & $63 \%$ & $14 \%$ \\
\hline
\end{tabular}

Es gibt nur sehr wenige Untersuchungen zur Narkolepsie bei Zwillingen. Eine größere Narkolepsie-Zwillingsstudie ermittelte Konkordanzen von 15,5\% (PWC) für MZ und 12,4\% (PWC) für DZ Zwillingspaare. Hublin et al. konnte lediglich drei DZ Zwillingspaare mit Narkolepsie aus dem Finnischen Zwillingsregister ermitteln, die zudem alle diskordant waren (Hublin et al. 1994). Die meisten Berichte beschränken sich auf Fallbeschreibungen einzelner MZ Zwillingspaare (Imlah 1961; Montplaisir \& Poirier 1987; Douglass et al. 1989; Honda et al. 2001; Dauvilliers et al. 2004). Bis zum Jahr 2004 waren in der Literatur 17 MZ Zwillingspaare mit Narkolepsie beschrieben, sechs Paare waren wahrscheinlich konkordant (Khatami et al. 2004). Kaprio et al. vermutet, dass genetische Faktoren eher die Schlafkomponenten beeinflussen, während die Ausprägung der Kataplexie-Symptome möglicherweise in stärkerem Ausmaß durch Umweltfaktoren bedingt ist (Kaprio et al. 1996) (Tabelle 31c).

Tab. 31c: Zwillingsstudien bei Narkolepsie

\begin{tabular}{|c|c|c|c|c|c|c|}
\hline \multicolumn{6}{|c|}{ Narkolepsie in MZ und DZ Zwillingspaaren } \\
\hline & \multicolumn{2}{|c|}{$\begin{array}{c}\text { Eingeschlossene } \\
\text { Zwillingspaare (N) }\end{array}$} & $\begin{array}{c}\text { Konkordante } \\
\text { Zwillingspaare (N) }\end{array}$ & \multicolumn{2}{c|}{ PWC (\%) } \\
\hline Studie & MZ & DZ & MZ & DZ & MZ & DZ \\
\hline Kaprio et al. 1996 & 348 & 631 & 54 & 78 & $15,5 \%$ & $12,4 \%$ \\
\hline Hublin et al. 1994 & 0 & 3 & 0 & 0 & $0 \%$ & $0 \%$ \\
\hline
\end{tabular}

Ebenso selten finden sich Konkordanzstudien bei MZ und DZ Zwillingen mit einem TouretteSyndrom (TS) innerhalb großer Studienpopulationen. Price et al. ermittelte bei $30 \mathrm{MZ}$ und 13 DZ Zwillingspaaren eine Konkordanz für ein Tourette-Syndrom von 53\% (PWC) bei MZ und 8\% (PWC) bei DZ Paaren. Weitet der Autor die Diagnosekriterien zum Einschluss zusätzlicher Tic-Erkrankungen etwas aus, so erhöhen sich die Konkordanzen auf 77\% (PWC) 
bei MZ und 23\% (PWC) bei DZ Zwillingen. Anhand dieser Zahlen wird deutlich, dass beim Tourette-Syndrom eine deutliche genetische Komponente vorhanden ist. Die erhebliche Differenz zwischen den Konkordanzraten der MZ $\left(\mathrm{r}_{\mathrm{MZ}}\right)$ und DZ ( $\left.\mathrm{r}_{\mathrm{DZ}}\right)$ Zwillingspaare, mit einer mehr als doppelt so hohen Konkordanz für MZ im Vergleich zur DZ Zwillinge ( $\mathrm{r}_{\mathrm{MZ}}>$ 2* $\mathrm{r}_{\mathrm{DZ}}$ ), deutet auf einen geringen Einfluss umweltbedingter Faktoren hin (Boomsma et al. 2002). Dieser kann jedoch nicht ausgeschlossen werden, da MZ Zwillinge keine 100\%ige Konkordanz zeigen (Price et al. 1985). Zusätzlich zu den in der Tabelle 32d aufgeführten Untersuchungen bei MZ Zwillingen durch Hyde et al. und Randolph et al., mit der Intention die Korrelationen in Bezug auf Charakteristika und Ausprägung der Erkrankung zu untersuchen (Hyde et al. 1992; Randolph et al. 1993), finden sich noch zahlreiche Fallbeschreibungen MZ konkordanter Zwillingspaare in der Literatur (Jenkins \& Ashby 1983; Waserman et al. 1983; Vieregge 1987; Goetz \& Tanner 1990) (Tabelle 31d).

Tab. 31d: Zwillingsstudien bei Tourette-Syndrom

\begin{tabular}{|c|c|c|c|c|c|c|}
\hline \multicolumn{7}{|c|}{ Tourette-Syndrome (TS) in MZ und DZ Zwillingspaaren } \\
\hline \multirow[b]{2}{*}{ Studie } & \multicolumn{2}{|c|}{$\begin{array}{c}\text { Eingeschlossene } \\
\text { Zwillingspaare (N) }\end{array}$} & \multicolumn{2}{|c|}{$\begin{array}{c}\text { Konkordante } \\
\text { Zwillingspaare (N) }\end{array}$} & \multicolumn{2}{|c|}{ PWC (\%) } \\
\hline & MZ & DZ & MZ & $\mathbf{D Z}$ & MZ & DZ \\
\hline \multicolumn{7}{|l|}{ Price et al. 1985} \\
\hline TS & 30 & 13 & 16 & 1 & $53 \%$ & $8 \%$ \\
\hline TS und/oder Tics & 30 & 13 & 23 & 3 & $77 \%$ & $23 \%$ \\
\hline \multicolumn{7}{|l|}{ Hyde et al. 1992} \\
\hline TS & 16 & 0 & 9 & 0 & $56 \%$ & $0 \%$ \\
\hline Tic-Erkrankungen & 16 & 0 & 15 & 0 & $94 \%$ & $0 \%$ \\
\hline Randolph et al. 1993 & 12 & 0 & 11 & 0 & $91,7 \%$ & $0 \%$ \\
\hline
\end{tabular}

In Bezug auf die Chorea Huntington-Erkrankung, deren molekulargenetische Grundlage durch die Identifikation der Mutation (expandierendes CAG-Triplett-Repeat) im HuntingtonGen (HTT, Chr. 4p16.3) mittlerweile besser verstanden ist, sind bisher nur einzelne MZ Zwillingspaare bezüglich ihrer klinischen Charakteristika untersucht worden (SchiottzChristensen 1969; Bird \& Omenn 1975; Sudarsky et al. 1983; Anca et al. 2004; Friedman et al. 2005; Gomez-Esteban et al. 2007). Fallberichte MZ Zwillingspaare zeigten trotz identischer Anzahl von CAG-Triplett-Repeats eine unterschiedliche Symptomatik und/oder einen abweichenden Verlauf der Erkrankung (Georgiou et al. 1999; Anca et al. 2004; Friedman et al. 2005; Gomez-Esteban et al. 2007). Aufgrund dieser Ergebnisse kann, trotz der 
Kenntnis der Mutation, der Einfluss weiterer genetischer und/oder epigenetischer Effekte bedingt durch Umweltfaktoren auf die klinischen Ausprägung der Erkrankung nicht ausgeschlossen werden kann. 


\section{KRITISCHE BETRACHUNG DER ARBEIT}

Das grundlegende Problem dieser Studie war es, eine ausreichend große Studienpopulation zu gewinnen, die möglichst die Allgemeinbevölkerung repräsentiert. Etwa 1,2\% aller Geburten in Mitteleuropa sind Zwillingsgeburten, was der „Zwillingsprävalenz“ entspricht. Die durchschnittliche Prävalenz eines RLS wird mit 5-10\% in der Gesamtbevölkerung angegeben (Rothdach et al. 2000; Phillips et al. 2000; Berger et al. 2004; Hogl et al. 2005). Das bedeutet, das unter 10000 Individuen nur etwa 6-12 Zwillinge mit einem RLS zu finden sind. Mit Hilfe eines bestehenden Zwillingsregisters (Busjahn 2006) konnte eine Zwillingspopulation zur Verfügung gestellt werden, die annähernd als Repräsentativ für die Allgemeinbevölkerung angesehen werden kann. Wir konnten daher von einer RLS-Prävalenz von 5-10\% innerhalb des Zwillingsregisters ausgehen.

Aus verschiedenen Gründen ließen sich nur etwa 50\% der insgesamt 49 Zwillingspaare (N= 26), die durch positives Ausfüllen der RLS-Diagnosefragen des Gesundheitsfragebogens ermittelt wurden, für die weitere Untersuchung gewinnen. Die Ausbeute war demnach mit 17 auswertbaren Zwillingspaaren aus einem ursprünglichen Zwillingskollektiv von 319 Paaren entsprechend gering. Wir entschlossen uns daher, die Zahl der auswertbaren Zwillingspaare durch den Einschluss weiterer zwölf Zwillinspaare über RLS-Spezialambulanzen und Patientenorganisationen auf insgesamt 29 Zwillingspaare zu erhöhen. Die Aussagekraft der Ergebnisse aus dem RLS-Patientenkolletiv ist gegenüber dem Zwillingsregister deutlich eingeschränkt, von einer Normalverteilung eines RLS ist hier nicht auszugehen. Prävalenzberechnungen sind innerhalb dieser RLS-Patientengruppe nicht durchzuführen. Außerdem müssen wir davon ausgehen, dass die 12 Zwillingspaare aufgrund der Ausprägung eines schwereren RLS und einer möglichen innerfamiliären Sensibilisierung für die Erkrankung zu einer Verschiebung der Konkordanzen geführt haben. Ein Mischen der beiden unterschiedlichen Kollektive schränkt die Aussagekraft unserer Ergebnisse daher erheblich ein.

Darüber hinaus war es uns auch nicht möglich die Probanden persönlich zu sehen, um eine neurologische und elektrophysiologische Untersuchung durchzuführen oder die Diagnose mittels Polysomnographie zu verifizieren. Lediglich für einzelne RLS-Zwillinge aus der Klinikpopulation lagen entsprechende Befunde vor. Auch eine einheitliche 
Laboruntersuchung zum Ausschluss eines manifesten Eisenmangels oder einer Anämie wurde nicht durchgeführt. Der Einschluss möglicher sekundärer Fälle ist daher nicht auszuschließen. Unsere Diagnose stützte sich somit lediglich auf die klinische Symptomatik, die mittels der Diagnosekriterien der IRLSSG (Walters 1995; Allen et al. 2003) im Rahmen eines diagnostischen Telefoninterviews erhoben wurde.

Die errechneten Konkordanzen und Ergebnisse aus dem Strukturgleichungsmodell sind aufgrund der geringen Probandenzahl vorsichtig $\mathrm{zu}$ interpretieren. Für repräsentative Aussagen mittels des Strukturgleichungsmodells sind in der Regel weitaus größere Probandenkollektive notwendig. In Kenntnis der unsicheren Berechnungen, beabsichtigten wir jedoch mit der Anwendung des ACE-Modells eine bestimmt Ergebnisstendenz zu ermitteln, die neue Forschungsansätze liefern soll. 


\section{ZUSAMMENFASSUNG}

Das Restless Legs Syndrom (RLS) ist eine häufige neurologische Erkrankung, deren Symptomatik mit einem unbeugsamen Bewegungsdrang, insbesondere der unteren Extremitäten, verbunden mit unangenehmen Missempfindungen, einhergeht. Die Beschwerden treten vorwiegend in Ruhephasen auf und folgen typischerweise einer zirkadianen Rhythmik, mit einem Maximum am Abend und in der Nacht (Trenkwalder et al. 1999a; Hening et al. 1999b). Die familiäre Häufung (Montplaisir et al. 1997; Winkelmann et al. 2000) sowie die Ergebnisse aus drei RLS-Zwillingsstudien (Ondo et al. 2000; Desai et al. 2004; Xiong et al. 2007), deuten auf eine genetische Grundlage der Erkrankung hin. Bisher konnten häufige genetische Varianten mit schwachem Effekt auf den Phänotyp in vier Genen identifiziert werden, die mit dem Auftreten eines RLS assoziiert sind (Winkelmann et al. 2007; Stefansson et al. 2007; Schormair et al. 2008). Es ließ sich jedoch bis zum jetzigen Zeitpunkt keine seltene Genvariante mit starkem Effekt auf den RLS-Phänotyp identifizieren. Beim RLS handelt es sich um eine komplex-genetische Erkrankung, an deren Pathogenese und Ausprägung genetische und nicht-genetische Faktoren oder Umweltfaktoren beteiligt sind.

In der vorliegenden Arbeit wenden wir die Methode der Zwillingsforschung an, die sich dafür eignet, sowohl die genetischen als auch die umweltbedingten (nicht-genetischen) Komponenten einer Erkrankung abzuschätzen und das Ausmaß der Interaktion dieser Faktoren zu beurteilen.

Hierfür wurden $638 \mathrm{MZ}$ und DZ Zwillingsindividuen aus dem Berliner Zwillingsregister von HealthTwiSt (Busjahn 2006) durch drei RLS-Diagnosefragen innerhalb eines Gesundheitsfragebogens auf das mögliche Vorhandensein eines RLS untersucht. Die drei RLS-Diagnosefragen zur Beurteilung eines RLS enthalten die vier essentiellen Diagnosekriterien der IRLSSG (Walters 1995) und wurden als Selbstbeurteilungsfragebogen bereits in mehreren epidemiologischen Studien verwendet (Rothdach et al. 2000; Berger et al. 2004). Die Diagnose wurde bei allen Zwillingspaaren, die durch die drei RLS-Diagnosefragen als RLS-verdächtig ermitteltet wurden, durch ein diagnostisches Telefoninterview gesichert (Walters 1995; Allen et al. 2003). Zusätzliche 34 Zwillingsindividuen wurden aus einer 
Klinikpopulation von RLS-Patienten rekrutiert und ebenfalls in einem diagnostischen Telefoninterview auf das Vorhandensein eines RLS untersucht.

Von allen gleichgeschlechtlichen Zwillingspaaren wurde eine Blutprobe erbeten, um durch Genotypisierung von hochpolymorphen Tetranukleotid-Mikrosatellitenmarkern die Zygotie $\mathrm{zu}$ bestimmen und die Zwillingspaare als MZ oder DZ zu klassifizieren. Gegengeschlechtliche Paare wurden ohne molekulargenetischen Nachweis als DZ klassifiziert.

Insgesamt konnten $19 \mathrm{MZ}$ und $10 \mathrm{DZ}$ Zwillingspaare mit einem RLS diagnostiziert werden. Vierzehn MZ und fünf DZ Zwillinge waren konkordant für ein RLS. Die Konkordanz (PWC) bei den MZ Zwillingspaaren ergab 73,7\%. Für die DZ Zwillinge wurde eine Konkordanz (PWC) von 50\% errechnet.

Die klinische Symptomatik zeigte auch innerhalb betroffener Zwillingspaare variable Verläufe. Der Schweregrad unterschied sich um maximal zehn Punktewerte, was höchstens einer Schweregradstufe entspricht. Bei der überwiegenden Anzahl der Zwillingspaare unterschied sich das Alter bei Symptombeginn um weniger als fünf Jahre. Aufgrund der geringen Probandenzahl sind jedoch keine Aussagen über signifikanten Korrelationen innerhalb MZ und DZ Zwillingspaaren in Bezug auf die klinischen Charakteristika und den Verlauf des RLS zu treffen.

Zur Beurteilung der relativen Varianzanteile genetischer und nicht-genetischer Faktoren, die an der Pathogenese des RLS beteiligt sind, wurden mittels Strukturgleichungsmodells ideale Ergebnisse durch das ACE-Modell errechnet. Es zeigte sich, dass genetische Faktoren (A), die mit der Heritabilität gleichgesetzt werden können, mit 32\% zwar eine Rolle bei der Pathogenese eines RLS spielen, jedoch der Anteil gemeinsamer Umweltfaktoren (C) mit 67\% einen weitaus größeren Einfluss auf die Entstehung eines RLS hat, als der Anteil der genetischen Faktoren. Getrennte Umweltfaktoren (E) scheinen mit einem Varianzanteil von 2\% keinen bedeutenden Einfluss auf die Pathogenese eines RLS zu haben.

Der hohe Varianzanteil der gemeinsamen Umweltfaktoren (C) sowie die große Differenz zum Anteil der getrennten Umweltfaktoren (E) deuten darauf hin, dass es sich um sehr frühe, möglicherweise auch prä- und/oder perinatale Effekte in der Entwicklung der Zwillinge 
handelt, die zur späteren Ausprägung eines RLS führen. Da diese gemeinsamen Umweltfaktoren (C), im Gegensatz $\mathrm{zu}$ den getrennten Umweltfaktoren (E), auf beide Zwillingsindividuen gleichermaßen einwirken, tragen sie, zusätzlich zu den genetischen Faktoren (A), zu deren Gleichheit bei.

Die Ergebnisse des starken Effekts gemeinsamer Umweltfaktoren (C) dürfen wegen der geringen Probandenzahl nicht als absolute Werte missverstanden werden. Vielmehr sollten die Berechnungen richtungweisend sein und dazu führen, in der Erforschung der Ätiologie und Pathogenese des RLS neue Denkansätze zu formulieren.

Auch epigenetische Effekte könnten eine Erklärung für den hohen Varianzanteil der gemeinsamen Umweltfaktoren (C) sein. Durch epigenetische Mechanismen könnte es zu Veränderungen der Genexpression und/oder Genregulation kommen, wodurch sich die Grundlage der Pathogenese eines RLS manifestieren könnte. Es besteht die Möglichkeit den Methylierungsgrad von Cytosin-Basen innerhalb genregulatorischer Bereiche von RLSassoziierten Genen bei konkordanten und diskordanten Zwillingspaaren zu vergleichen um Aktivitätsunterschiede zu identifizieren. Darüber hinaus könnte durch genomweiten Vergleich des Methylierungsgrades der gesamten DNA und insbsondere CpG-reicher Regionen in RLSPatienten und gesunden Kontrollpersonen gewebsspezifische Unterschiede und somit weitere Risikogene für das RLS identifiziert werden (Rakyan et al. 2008).

Abschließend ist festzuhalten, dass bei der Entstehung eines RLS auch innerfamiliäre Einflüsse beteiligt sind. Genetische Faktoren sind relevant, spielen aber möglicherweise eine geringere Rolle als bisher angenommen. Dieses Ergebnis steht im Gegensatz zu bisherigen Studien, die von einer Heredität von bis zu 0,6 ausgegangen sind. Das in der vorliegenden Arbeit errechnete Strukturgleichungsmodell könnte ebenfalls eine Erklärung für RLSFamilienstammbäume mit einer hohen Anzahl (>50\%) betroffener Nachkommen sein. Adoptionsstudien und Untersuchungen von getrennt aufwachsenden diskordanten MZ und DZ Zwillingspaaren ermöglichen in Zukunft die Identifizierung spezifischer Einflussfaktoren aus der Umwelt. Qualitative und quantitative Untersuchungen epigenetischer Veränderungen, sowohl bei Zwilingen, als auch im Vergleich von betroffenen und nicht-betroffenen Probanden sollten zukünftig ebenfalls Gegenstand neuer Forschungsmodelle bei RLS sein. 


\section{LITERATURVERZEICHNIS}

Reference List

Abetz,L., Allen,R., Follet,A., Washburn,T., Earley,C., Kirsch,J. \& Knight,H. 2004.

Evaluating the quality of life of patients with restless legs syndrome. Clin.Ther., 26, 925-935.

Allen,R.P., Barker,P.B., Wehrl,F., Song,H.K. \& Earley,C.J. 2001. MRI measurement of brain iron in patients with restless legs syndrome. Neurology, 56, 263-265.

Allen,R.P.\& Earley,C.J. 1996. Augmentation of the restless legs syndrome with carbidopa/levodopa. Sleep, 19, 205-213.

Allen,R.P.\& Earley,C.J. 2000. Defining the phenotype of the restless legs syndrome (RLS) using age-of-symptom-onset. Sleep Med., 1, 11-19.

Allen,R.P., La Buda,M.C., Becker,P. \& Earley,C.J. 2002. Family history study of the restless legs syndrome. Sleep Med., 3 Suppl, S3-S7.

Allen,R.P., Picchietti,D., Hening,W.A., Trenkwalder,C., Walters,A.S. \& Montplaisi,J. 2003. Restless legs syndrome: diagnostic criteria, special considerations, and epidemiology. A report from the restless legs syndrome diagnosis and epidemiology workshop at the National Institutes of Health. Sleep Med., 4, 101-119.

Allen,R.P., Walters,A.S., Montplaisir,J., Hening,W., Myers,A., Bell,T.J. \& Ferini-Strambi,L. 2005. Restless legs syndrome prevalence and impact: REST general population study.

Arch.Intern.Med., 165, 1286-1292.

Anca,M.H., Gazit,E., Loewenthal,R., Ostrovsky,O., Frydman,M. \& Giladi,N. 2004. Different phenotypic expression in monozygotic twins with Huntington disease. Am.J.Med.Genet.A, 124A, 89-91.

Andrew,T., Hart,D.J., Snieder,H., de Lange,M., Spector,T.D. \& MacGregor,A.J. 2001. Are twins and singletons comparable? A study of disease-related and lifestyle characteristics in adult women. Twin.Res., 4, 464-477.

Beard,J.L.\& Connor,J.R. 2003. Iron status and neural functioning. Annu.Rev.Nutr., 23, 41-58.

Becker,A., Busjahn,A., Faulhaber,H.D., Bahring,S., Robertson,J., Schuster,H. \& Luft,F.C. 1997. Twin zygosity. Automated determination with microsatellites. J.Reprod.Med., 42, 260266.

Berger,K., Luedemann,J., Trenkwalder,C., John,U. \& Kessler,C. 2004. Sex and the risk of restless legs syndrome in the general population. Arch.Intern.Med., 164, 196-202.

Bird,T.D.\& Omenn,G.S. 1975. Monozygotic twins with Huntington's disease in a family expressing the rigid variant. Neurology, 25, 1126-1129.

Bjorvatn,B., Leissner,L., Ulfberg,J., Gyring,J., Karlsborg,M., Regeur,L., Skeidsvoll,H., Nordhus,I.H. \& Pallesen,S. 2005. Prevalence, severity and risk factors of restless legs 
syndrome in the general adult population in two Scandinavian countries. Sleep Med., 6, 307312.

Bonati,M.T., Ferini-Strambi,L., Aridon,P., Oldani,A., Zucconi,M. \& Casari,G. 2003. Autosomal dominant restless legs syndrome maps on chromosome 14q. Brain, 126, 1485 1492.

Boomsma,D., Busjahn,A. \& Peltonen,L. 2002. Classical twin studies and beyond. Nat.Rev.Genet., 3, 872-882.

Busjahn,A. 2006. HealthTwiSt: the Berlin Twin Registry. Twin.Res.Hum.Genet., 9, 778-782.

Cederlof,R., Friberg,L., Jonsson,E. \& Kaij,L. 1961. Studies on similarity diagnosis in twins with the aid of mailed questionnaires. Acta Genet.Stat.Med., 11, 338-362.

Cervenka,S., Palhagen,S.E., Comley,R.A., Panagiotidis,G., Cselenyi,Z., Matthews,J.C., Lai,R.Y., Halldin,C. \& Farde,L. 2006. Support for dopaminergic hypoactivity in restless legs syndrome: a PET study on D2-receptor binding. Brain, 129, 2017-2028.

Chang,C.C., Shiah,I.S., Chang,H.A. \& Mao,W.C. 2006. Does domperidone potentiate mirtazapine-associated restless legs syndrome? Prog.Neuropsychopharmacol.Biol.Psychiatry, 30, 316-318.

Chen,S., Ondo,W.G., Rao,S., Li,L., Chen,Q. \& Wang,Q. 2004. Genomewide linkage scan identifies a novel susceptibility locus for restless legs syndrome on chromosome 9p. Am.J.Hum.Genet., 74, 876-885.

Cheng,L., Samad,O.A., Xu,Y., Mizuguchi,R., Luo,P., Shirasawa,S., Goulding,M. \& Ma,Q. 2005. Lbx 1 and Tlx3 are opposing switches in determining GABAergic versus glutamatergic transmitter phenotypes. Nat.Neurosci., 8, 1510-1515.

Christiansen,L., Frederiksen,H., Schousboe,K., Skytthe,A., Wurmb-Schwark,N., Christensen,K. \& Kyvik,K. 2003. Age- and sex-differences in the validity of questionnairebased zygosity in twins. Twin.Res., 6, 275-278.

Clardy,S.L., Earley,C.J., Allen,R.P., Beard,J.L. \& Connor,J.R. 2006. Ferritin subunits in CSF are decreased in restless legs syndrome. J.Lab Clin.Med., 147, 67-73.

Connor,J.R., Boyer,P.J., Menzies,S.L., Dellinger,B., Allen,R.P., Ondo,W.G. \& Earley,C.J. 2003. Neuropathological examination suggests impaired brain iron acquisition in restless legs syndrome. Neurology, 61, 304-309.

Cuellar,N.G., Strumpf,N.E. \& Ratcliffe,S.J. 2007. Symptoms of restless legs syndrome in older adults: outcomes on sleep quality, sleepiness, fatigue, depression, and quality of life. J.Am.Geriatr.Soc., 55, 1387-1392.

Dauvilliers,Y., Maret,S., Bassetti,C., Carlander,B., Billiard,M., Touchon,J. \& Tafti,M. 2004. A monozygotic twin pair discordant for narcolepsy and CSF hypocretin-1. Neurology, 62, 2137-2138.

De Sario,A. 2009. Clinical and molecular overview of inherited disorders resulting from epigenomic dysregulation. Eur.J.Med.Genet.. 
Desai,A.V., Cherkas,L.F., Spector,T.D. \& Williams,A.J. 2004. Genetic influences in selfreported symptoms of obstructive sleep apnoea and restless legs: a twin study. Twin.Res., 7, 589-595.

Desautels,A., Turecki,G., Montplaisir,J., Sequeira,A., Verner,A. \& Rouleau,G.A. 2001. Identification of a major susceptibility locus for restless legs syndrome on chromosome 12q. Am.J.Hum.Genet., 69, 1266-1270.

Diener H-C., Putki N. \& Kommission für Leitlinien der Deutschen Gesellschaft für Neurologie 2008. Leitlinien für Diagnostik und Therapie in der Neurologie, 4., überarb. Aufl.

Djokanovic,N., Garcia-Bournissen,F. \& Koren,G. 2008. Medications for restless legs syndrome in pregnancy. J.Obstet.Gynaecol.Can., 30, 505-507.

Douglass,A.B., Harris,L. \& Pazderka,F. 1989. Monozygotic twins concordant for the narcoleptic syndrome. Neurology, 39, 140-141.

Earley,C.J.\& Allen,R.P. 1996. Pergolide and carbidopa/levodopa treatment of the restless legs syndrome and periodic leg movements in sleep in a consecutive series of patients. Sleep, 19, 801-810.

Earley,C.J., Connor,J.R., Beard,J.L., Malecki,E.A., Epstein,D.K. \& Allen,R.P. 2000. Abnormalities in CSF concentrations of ferritin and transferrin in restless legs syndrome. Neurology, 54, 1698-1700.

Earley,C.J., Heckler,D. \& Allen,R.P. 2004. The treatment of restless legs syndrome with intravenous iron dextran. Sleep Med., 5, 231-235.

Eisensehr,I., Wetter,T.C., Linke,R., Noachtar,S., von Lindeiner,H., Gildehaus,F.J., Trenkwalder,C. \& Tatsch,K. 2001. Normal IPT and IBZM SPECT in drug-naive and levodopa-treated idiopathic restless legs syndrome. Neurology, 57, 1307-1309.

Ekbom,K.A. 1960. Restless legs syndrome. Neurology, 10, 868-873.

Fraga,M.F., Ballestar,E., Paz,M.F., Ropero,S., Setien,F., Ballestar,M.L., Heine-Suner,D., Cigudosa,J.C., Urioste,M., Benitez,J., Boix-Chornet,M., Sanchez-Aguilera,A., Ling,C., Carlsson,E., Poulsen,P., Vaag,A., Stephan,Z., Spector,T.D., Wu,Y.Z., Plass,C. \& Esteller,M. 2005. Epigenetic differences arise during the lifetime of monozygotic twins. Proc.Natl.Acad.Sci.U.S.A, 102, 10604-10609.

Friedman,J.H., Trieschmann,M.E., Myers,R.H. \& Fernandez,H.H. 2005. Monozygotic twins discordant for Huntington disease after 7 years. Arch.Neurol., 62, 995-997.

Galton,F. 1876. The History of Twins, as a Criterion of the Relative Powers of Nature and Nurture. The Journal of the Antropological Institute of Great Britain and Ireland.

Garcia-Borreguero,D., Larrosa,O., de la,L.Y., Verger,K., Masramon,X. \& Hernandez,G. 2002. Treatment of restless legs syndrome with gabapentin: a double-blind, cross-over study. Neurology, 59, 1573-1579.

Gemignani,F., Brindani,F., Negrotti,A., Vitetta,F., Alfieri,S. \& Marbini,A. 2006. Restless legs syndrome and polyneuropathy. Mov Disord., 21, 1254-1257. 
Gemignani,F.\& Marbini,A. 2002. Restless legs syndrome and peripheral neuropathy. J.Neurol.Neurosurg.Psychiatry, 72, 555.

Georgiou,N., Bradshaw,J.L., Chiu,E., Tudor,A., O'Gorman,L. \& Phillips,J.G. 1999. Differential clinical and motor control function in a pair of monozygotic twins with Huntington's disease. Mov Disord., 14, 320-325.

Gigli,G.L., Adorati,M., Dolso,P., Piani,A., Valente,M., Brotini,S. \& Budai,R. 2004. Restless legs syndrome in end-stage renal disease. Sleep Med., 5, 309-315.

Goetz,C.G.\& Tanner,C.M. 1990. Gilles de la Tourette's syndrome in twins: clinical and neurochemical data. Mov Disord., 5, 173-175.

Gomez-Esteban,J.C., Lezcano,E., Zarranz,J.J., Velasco,F., Garamendi,I., Perez,T. \& Tijero,B. 2007. Monozygotic twins suffering from Huntington's disease show different cognitive and behavioural symptoms. Eur.Neurol., 57, 26-30.

Goodman,J.D., Brodie,C. \& Ayida,G.A. 1988. Restless leg syndrome in pregnancy. BMJ, 297, 1101-1102.

Guilleminault,C., Cetel,M. \& Philip,P. 1993. Dopaminergic treatment of restless legs and rebound phenomenon. Neurology, $\mathbf{4 3}, 445$.

Happe,S., Sauter,C., Klosch,G., Saletu,B. \& Zeitlhofer,J. 2003. Gabapentin versus ropinirole in the treatment of idiopathic restless legs syndrome. Neuropsychobiology, 48, 82-86.

Hening,W., Allen,R., Earley,C., Kushida,C., Picchietti,D. \& Silber,M. 1999a. The treatment of restless legs syndrome and periodic limb movement disorder. An American Academy of Sleep Medicine Review. Sleep, 22, 970-999.

Hening,W.A. 2004. Restless legs syndrome: the most common and least diagnosed sleep disorder. Sleep Med., 5, 429-430.

Hening,W.A. 2007. Current guidelines and standards of practice for restless legs syndrome. Am.J.Med., 120, S22-S27.

Hening,W.A., Allen,R.P., Earley,C.J., Picchietti,D.L. \& Silber,M.H. 2004. An update on the dopaminergic treatment of restless legs syndrome and periodic limb movement disorder. Sleep, 27, 560-583.

Hening,W.A., Walters,A., Kavey,N., Gidro-Frank,S., Cote,L. \& Fahn,S. 1986. Dyskinesias while awake and periodic movements in sleep in restless legs syndrome: treatment with opioids. Neurology, 36, 1363-1366.

Hening,W.A., Walters,A.S., Wagner,M., Rosen,R., Chen,V., Kim,S., Shah,M. \& Thai,O. 1999b. Circadian rhythm of motor restlessness and sensory symptoms in the idiopathic restless legs syndrome. Sleep, 22, 901-912.

Hogl,B., Kiechl,S., Willeit,J., Saletu,M., Frauscher,B., Seppi,K., Muller,J., Rungger,G., Gasperi,A., Wenning,G. \& Poewe,W. 2005. Restless legs syndrome: a community-based study of prevalence, severity, and risk factors. Neurology, 64, 1920-1924. 
Honda,M., Honda,Y., Uchida,S., Miyazaki,S. \& Tokunaga,K. 2001. Monozygotic twins incompletely concordant for narcolepsy. Biol.Psychiatry, 49, 943-947.

Hublin,C., Kaprio,J., Partinen,M., Koskenvuo,M., Heikkila,K., Koskimies,S. \& Guilleminault,C. 1994. The prevalence of narcolepsy: an epidemiological study of the Finnish Twin Cohort. Ann.Neurol., 35, 709-716.

Hyde,T.M., Aaronson,B.A., Randolph,C., Rickler,K.C. \& Weinberger,D.R. 1992.

Relationship of birth weight to the phenotypic expression of Gilles de la Tourette's syndrome in monozygotic twins. Neurology, 42, 652-658.

Imlah,N.W. 1961. Narcolepsy in identical twins. J.Neurol.Neurosurg.Psychiatry, 24, 158160.

Jackson,R.W., Snieder,H., Davis,H. \& Treiber,F.A. 2001. Determination of twin zygosity: a comparison of DNA with various questionnaire indices. Twin.Res., 4, 12-18.

Jang,K.L., Livesley,W.J. \& Vernon,P.A. 2002. The etiology of personality function: the University of British Columbia Twin Project. Twin.Res., 5, 342-346.

Jenkins,R.L.\& Ashby,H.B. 1983. Gilles de la Tourette's syndrome in identical twins. Arch.Neurol., 40, 249-251.

Kaprio,J., Hublin,C., Partinen,M., Heikkila,K. \& Koskenvuo,M. 1996. Narcolepsy-like symptoms among adult twins. J.Sleep Res., 5, 55-60.

Kasriel,J.\& Eaves,L. 1976. The zygosity of twins: further evidence on the agreement between diagnosis by blood groups and written questionnaires. J.Biosoc.Sci., 8, 263-266.

Kemlink,D., Plazzi,G., Vetrugno,R., Provini,F., Polo,O., Stiasny-Kolster,K., Oertel,W., Nevsimalova,S., Sonka,K., Hogl,B., Frauscher,B., Hadjigeorgiou,G.M., Pramstaller,P.P., Lichtner,P., Meitinger,T., Muller-Myshok,B., Winkelmann,J. \& Montagna,P. 2008.

Suggestive evidence for linkage for restless legs syndrome on chromosome 19p13.

Neurogenetics., 9, 75-82.

Kemlink,D., Polo,O., Montagna,P., Provini,F., Stiasny-Kolster,K., Oertel,W., de Weerd,A., Nevsimalova,S., Sonka,K., Hogl,B., Frauscher,B., Poewe,W., Trenkwalder,C.,

Pramstaller,P.P., Ferini-Strambi,L., Zucconi,M., Konofal,E., Arnulf,I., Hadjigeorgiou,G.M., Happe,S., Klein,C., Hiller,A., Lichtner,P., Meitinger,T., Muller-Myshok,B. \& Winkelmann,J. 2007. Family-based association study of the restless legs syndrome loci 2 and 3 in a European population. Mov Disord., 22, 207-212.

Khatami,R., Maret,S., Werth,E., Retey,J., Schmid,D., Maly,F., Tafti,M. \& Bassetti,C.L. 2004. Monozygotic twins concordant for narcolepsy-cataplexy without any detectable abnormality in the hypocretin (orexin) pathway. Lancet, 363, 1199-1200.

Kock,N., Culjkovic,B., Maniak,S., Schilling,K., Muller,B., Zuhlke,C., Ozelius,L., Klein,C., Pramstaller,P.P. \& Kramer,P.L. 2002. Mode of inheritance and susceptibility locus for restless legs syndrome, on chromosome 12q. Am.J.Hum.Genet., 71, 205-208.

Kraus,T., Schuld,A. \& Pollmacher,T. 1999. Periodic leg movements in sleep and restless legs syndrome probably caused by olanzapine. J.Clin.Psychopharmacol., 19, 478-479. 
Lauerma,H.\& Markkula,J. 1999. Treatment of restless legs syndrome with tramadol: an open study. J.Clin.Psychiatry, 60, 241-244.

Lavigne,G.J.\& Montplaisir,J.Y. 1994. Restless legs syndrome and sleep bruxism: prevalence and association among Canadians. Sleep, 17, 739-743.

Lazzarini,A., Walters,A.S., Hickey,K., Coccagna,G., Lugaresi,E., Ehrenberg,B.L., Picchietti,D.L., Brin,M.F., Stenroos,E.S., Verrico,T. \& Johnson,W.G. 1999. Studies of penetrance and anticipation in five autosomal-dominant restless legs syndrome pedigrees. Mov Disord., 14, 111-116.

Levchenko,A., Montplaisir,J.Y., Asselin,G., Provost,S., Girard,S.L., Xiong,L., Lemyre,E., St Onge,J., Thibodeau,P., Desautels,A., Turecki,G., Gaspar,C., Dube,M.P. \& Rouleau,G.A. 2008. Autosomal-dominant locus for restless legs syndrome in French-Canadians on chromosome 16p12.1. Mov Disord. .

Levchenko,A., Provost,S., Montplaisir,J.Y., Xiong,L., St Onge,J., Thibodeau,P., Riviere,J.B., Desautels,A., Turecki,G., Dube,M.P. \& Rouleau,G.A. 2006. A novel autosomal dominant restless legs syndrome locus maps to chromosome 20p13. Neurology, 67, 900-901.

Liebetanz,K.M., Winkelmann,J., Trenkwalder,C., Putz,B., Dichgans,M., Gasser,T. \& MullerMyhsok,B. 2006. RLS3: fine-mapping of an autosomal dominant locus in a family with intrafamilial heterogeneity. Neurology, 67, 320-321.

Lorenz,D., Frederiksen,H., Moises,H., Kopper,F., Deuschl,G. \& Christensen,K. 2004. High concordance for essential tremor in monozygotic twins of old age. Neurology, 62, 208-211.

Manconi,M.\& Ferini-Strambi,L. 2004. Restless legs syndrome among pregnant women. Sleep, 27, 350 .

Manconi,M., Ferini-Strambi,L., Filippi,M., Bonanni,E., Iudice,A., Murri,L., Gigli,G.L., Fratticci,L., Merlino,G., Terzano,G., Granella,F., Parrino,L., Silvestri,R., Arico,I., Dattola,V., Russo,G., Luongo,C., Cicolin,A., Tribolo,A., Cavalla,P., Savarese,M., Trojano,M., Ottaviano,S., Cirignottta,F., Simioni,V., Salvi,F., Mondino,F., Perla,F., Chinaglia,G., Zuliani,C., Cesnik,E., Granieri,E., Placidi,F., Palmieri,M.G., Manni,R., Terzaghi,M., Bergamaschi,R., Rocchi,R., Ulivelli,M., Bartalini,S., Ferri,R., Lo,F.S., Ubiali,E., Viscardi,M., Rottoli,M., Nobili,L., Protti,A., Ferrillo,F., Allena,M., Mancardi,G., Guarnieri,B. \& Londrillo,F. 2008. Multicenter case-control study on restless legs syndrome in multiple sclerosis: the REMS study. Sleep, 31, 944-952.

Manconi,M., Govoni,V., De Vito,A., Economou,N.T., Cesnik,E., Casetta,I., Mollica,G., Ferini-Strambi,L. \& Granieri,E. 2004. Restless legs syndrome and pregnancy. Neurology, 63, 1065-1069.

Marsden,C.D. 1987. Parkinson's disease in twins. J.Neurol.Neurosurg.Psychiatry, 50, 105106.

Martin,N.G.\& Martin,P.G. 1975. The inheritance of scholastric abilities in a sample of twins. I. Ascertainments of the sample and diagnosis of zygosity. Ann.Hum.Genet., 39, 213-218.

Marttila,R.J., Kaprio,J., Koskenvuo,M. \& Rinne,U.K. 1988. Parkinson's disease in a nationwide twin cohort. Neurology, 38, 1217-1219. 
Matalon Lagnado,L.\& Cohn Deke,S. 1994. Die Zwillinge des Dr. Mengele. Der Arzt von Auschwitz und seine Opfer.

Mercader,N., Leonardo,E., Azpiazu,N., Serrano,A., Morata,G., Martinez,C. \& Torres,M. 1999. Conserved regulation of proximodistal limb axis development by Meis1/Hth. Nature, 402, 425-429.

Merlino,G., Fratticci,L., Valente,M., Del Giudice,A., Noacco,C., Dolso,P., Cancelli,I., Scalise,A. \& Gigli,G.L. 2007. Association of restless legs syndrome in type 2 diabetes: a case-control study. Sleep, 30, 866-871.

Michaud,M., Soucy,J.P., Chabli,A., Lavigne,G. \& Montplaisir,J. 2002. SPECT imaging of striatal pre- and postsynaptic dopaminergic status in restless legs syndrome with periodic leg movements in sleep. J.Neurol., 249, 164-170.

Mignot,E. 2007. A step forward for restless legs syndrome. Nat.Genet., 39, 938-939.

Miller,C.A., III\& Costa,M. 1988. Characterization of DNA-protein complexes induced in intact cells by the carcinogen chromate. Mol.Carcinog., 1, 125-133.

Mizuhara,E., Nakatani,T., Minaki,Y., Sakamoto,Y., Ono,Y. \& Takai,Y. 2005. MAGI1 recruits Dll1 to cadherin-based adherens junctions and stabilizes it on the cell surface. J.Biol.Chem., 280, 26499-26507.

Mizuno,S., Mihara,T., Miyaoka,T., Inagaki,T. \& Horiguchi,J. 2005a. CSF iron, ferritin and transferrin levels in restless legs syndrome. J.Sleep Res., 14, 43-47.

Mizuno,S., Miyaoka,T., Inagaki,T. \& Horiguchi,J. 2005b. Prevalence of restless legs syndrome in non-institutionalized Japanese elderly. Psychiatry Clin.Neurosci., 59, 461-465.

Montplaisir,J., Boucher,S., Nicolas,A., Lesperance,P., Gosselin,A., Rompre,P. \& Lavigne,G. 1998. Immobilization tests and periodic leg movements in sleep for the diagnosis of restless leg syndrome. Mov Disord., 13, 324-329.

Montplaisir,J., Boucher,S., Poirier,G., Lavigne,G., Lapierre,O. \& Lesperance,P. 1997. Clinical, polysomnographic, and genetic characteristics of restless legs syndrome: a study of 133 patients diagnosed with new standard criteria. Mov Disord., 12, 61-65.

Montplaisir,J., Godbout,R., Poirier,G. \& Bedard,M.A. 1986. Restless legs syndrome and periodic movements in sleep: physiopathology and treatment with L-dopa.

Clin.Neuropharmacol., 9, 456-463.

Montplaisir,J.\& Poirier,G. 1987. Narcolepsy in monozygotic twins. Neurology, 37, 1089.

Murken,J., Grimm,T. \& Holinski-Feder,E. 2006. Taschenlehrbuch Humangenetik.

Nichols,D.A., Allen,R.P., Grauke,J.H., Brown,J.B., Rice,M.L., Hyde,P.R., Dement,W.C. \& Kushida,C.A. 2003. Restless legs syndrome symptoms in primary care: a prevalence study. Arch.Intern.Med., 163, 2323-2329.

Neale, M. C., Boker, S. M., Xie, G. \& Maes, H. H. Mx: Statistical Modeling 6th edn, Department of Psychiatry, VCU Box 900126, Richmond, Virginia 23298, USA. (2002). 
Nichols,R.C.\& Bilbro,W.C., Jr. 1966. The diagnosis of twin zygosity. Acta Genet.Stat.Med., 16, 265-275.

O'Keeffe,S.T., Gavin,K. \& Lavan,J.N. 1994. Iron status and restless legs syndrome in the elderly. Age Ageing, 23, 200-203.

Ohayon,M.M.\& Roth,T. 2002. Prevalence of restless legs syndrome and periodic limb movement disorder in the general population. J.Psychosom.Res., 53, 547-554.

Ondo,W.\& Jankovic,J. 1996. Restless legs syndrome: clinicoetiologic correlates. Neurology, 47, 1435-1441.

Ondo,W., Romanyshyn,J., Vuong,K.D. \& Lai,D. 2004. Long-term treatment of restless legs syndrome with dopamine agonists. Arch.Neurol., 61, 1393-1397.

Ondo,W.G., Vuong,K.D. \& Wang,Q. 2000. Restless legs syndrome in monozygotic twins: clinical correlates. Neurology, 55, 1404-1406.

Page,R.L., Ruscin,J.M., Bainbridge,J.L. \& Brieke,A.A. 2008. Restless legs syndrome induced by escitalopram: case report and review of the literature. Pharmacotherapy, 28, 271-280.

Phillips,B., Young,T., Finn,L., Asher,K., Hening,W.A. \& Purvis,C. 2000. Epidemiology of restless legs symptoms in adults. Arch.Intern.Med., 160, 2137-2141.

Pichler,I., Hicks,A.A. \& Pramstaller,P.P. 2008. Restless legs syndrome: an update on genetics and future perspectives. Clin.Genet., 73, 297-305.

Pichler,I., Marroni,F., Volpato,C.B., Gusella,J.F., Klein,C., Casari,G., De Grandi,A. \& Pramstaller,P.P. 2006. Linkage analysis identifies a novel locus for restless legs syndrome on chromosome $2 \mathrm{q}$ in a South Tyrolean population isolate. Am.J.Hum.Genet., 79, 716-723.

Price,R.A., Kidd,K.K., Cohen,D.J., Pauls,D.L. \& Leckman,J.F. 1985. A twin study of Tourette syndrome. Arch.Gen.Psychiatry, 42, 815-820.

Rakyan,V.K., Down,T.A., Thorne,N.P., Flicek,P., Kulesha,E., Graf,S., Tomazou,E.M., Backdahl,L., Johnson,N., Herberth,M., Howe,K.L., Jackson,D.K., Miretti,M.M., Fiegler,H., Marioni,J.C., Birney,E., Hubbard,T.J., Carter,N.P., Tavare,S. \& Beck,S. 2008. An integrated resource for genome-wide identification and analysis of human tissue-specific differentially methylated regions (tDMRs). Genome Res., 18, 1518-1529.

Randolph,C., Hyde,T.M., Gold,J.M., Goldberg,T.E. \& Weinberger,D.R. 1993. Tourette's syndrome in monozygotic twins. Relationship of tic severity to neuropsychological function. Arch.Neurol., 50, 725-728.

Rangarajan,S., Rangarajan,S. \& D'Souza,G.A. 2007. Restless legs syndrome in an Indian urban population. Sleep Med., 9, 88-93.

Rende,R.D., Plomin,R. \& Vandenberg,S.G. 1990. Who discovered the twin method? Behav.Genet., 20, 277-285.

Rothdach,A.J., Trenkwalder,C., Haberstock,J., Keil,U. \& Berger,K. 2000. Prevalence and risk factors of RLS in an elderly population: the MEMO study. Memory and Morbidity in Augsburg Elderly. Neurology, 54, 1064-1068. 
Rottach,K.G., Schaner,B.M., Kirch,M.H., Zivotofsky,A.Z., Teufel,L.M., Gallwitz,T. \& Messer,T. 2008. Restless legs syndrome as side effect of second generation antidepressants. J.Psychiatr.Res., 43, 70-75.

Ruottinen,H.M., Partinen,M., Hublin,C., Bergman,J., Haaparanta,M., Solin,O. \& Rinne,J.O. 2000. An FDOPA PET study in patients with periodic limb movement disorder and restless legs syndrome. Neurology, 54, 502-504.

Rutkove,S.B., Matheson,J.K. \& Logigian,E.L. 1996. Restless legs syndrome in patients with polyneuropathy. Muscle Nerve, 19, 670-672.

Schiottz-Christensen,E. 1969. Chorea Huntington and epilepsy in monozygotic twins. Eur.Neurol., 2, 250-255.

Schormair,B., Kemlink,D., Roeske,D., Eckstein,G., Xiong,L., Lichtner,P., Ripke,S., Trenkwalder,C., Zimprich,A., Stiasny-Kolster,K., Oertel,W., Bachmann,C.G., Paulus,W., Hogl,B., Frauscher,B., Gschliesser,V., Poewe,W., Peglau,I., Vodicka,P., Vavrova,J., Sonka,K., Nevsimalova,S., Montplaisir,J., Turecki,G., Rouleau,G., Gieger,C., Illig,T., Wichmann,H.E., Holsboer,F., Muller-Myhsok,B., Meitinger,T. \& Winkelmann,J. 2008. PTPRD (protein tyrosine phosphatase receptor type delta) is associated with restless legs syndrome. Nat.Genet., 40, 946-948.

Sevim,S., Dogu,O., Camdeviren,H., Bugdayci,R., Sasmaz,T., Kaleagasi,H., Aral,M. \& Helvaci,I. 2003. Unexpectedly low prevalence and unusual characteristics of RLS in Mersin, Turkey. Neurology, 61, 1562-1569.

Siddiqui,S., Kavanagh,D., Traynor,J., Mak,M., Deighan,C. \& Geddes,C. 2005. Risk factors for restless legs syndrome in dialysis patients. Nephron Clin.Pract., 101, c155-c160.

Silber,M.H., Ehrenberg,B.L., Allen,R.P., Buchfuhrer,M.J., Earley,C.J., Hening,W.A. \& Rye,D.B. 2004. An algorithm for the management of restless legs syndrome. Mayo Clin.Proc., 79, 916-922.

Siribaddana,S.H., Ball,H.A., Hewage,S.N., Glozier,N., Kovas,Y., Dayaratne,D., Sumathipala,A., McGuffin,P. \& Hotopf,M. 2008. Colombo Twin and Singleton Study (CoTASS): a description of a population based twin study of mental disorders in Sri Lanka. BMC.Psychiatry, $\mathbf{8}, 49$.

Spector,T.D.\& MacGregor,A.J. 2002. The St. Thomas' UK Adult Twin Registry. Twin.Res., 5, 440-443.

Spector,T.D.\& Williams,F.M. 2006. The UK Adult Twin Registry (TwinsUK). Twin.Res.Hum.Genet., 9, 899-906.

Stefansson,H., Rye,D.B., Hicks,A., Petursson,H., Ingason,A., Thorgeirsson,T.E., Palsson,S., Sigmundsson,T., Sigurdsson,A.P., Eiriksdottir,I., Soebech,E., Bliwise,D., Beck,J.M., Rosen,A., Waddy,S., Trotti,L.M., Iranzo,A., Thambisetty,M., Hardarson,G.A., Kristjansson,K., Gudmundsson,L.J., Thorsteinsdottir,U., Kong,A., Gulcher,J.R., Gudbjartsson,D. \& Stefansson,K. 2007. A genetic risk factor for periodic limb movements in sleep. N.Engl.J.Med., 357, 639-647.

Stiasny,K., Robbecke,J., Schuler,P. \& Oertel,W.H. 2000. Treatment of idiopathic restless legs syndrome (RLS) with the D2-agonist cabergoline--an open clinical trial. Sleep, 23, 349-354. 
Stiasny-Kolster,K., Kohnen,R., Moller,J.C., Trenkwalder,C. \& Oertel,W.H. 2006. Validation of the "L-DOPA test" for diagnosis of restless legs syndrome. Mov Disord., 21, 1333-1339.

Sudarsky,L., Myers,R.H. \& Walshe,T.M. 1983. Huntington's disease in monozygotic twins reared apart. J.Med.Genet., 20, 408-411.

Sun,E.R., Chen,C.A., Ho,G., Earley,C.J. \& Allen,R.P. 1998. Iron and the restless legs syndrome. Sleep, 21, 371-377.

Tan,E.K., Seah,A., See,S.J., Lim,E., Wong,M.C. \& Koh,K.K. 2001. Restless legs syndrome in an Asian population: A study in Singapore. Mov Disord., 16, 577-579.

Tanner,C.M., Goldman,S.M., Lyons,K.E., Aston,D.A., Tetrud,J.W., Welsh,M.D., Langston,J.W. \& Koller,W.C. 2001. Essential tremor in twins: an assessment of genetic vs environmental determinants of etiology. Neurology, 57, 1389-1391.

Tanner,C.M., Ottman,R., Goldman,S.M., Ellenberg,J., Chan,P., Mayeux,R. \& Langston,J.W. 1999. Parkinson disease in twins: an etiologic study. JAMA, 281, 341-346.

Tison,F., Crochard,A., Leger,D., Bouee,S., Lainey,E. \& El Hasnaoui,A. 2005. Epidemiology of restless legs syndrome in French adults: a nationwide survey: the INSTANT Study. Neurology, 65, 239-246.

Torgersen,S. 1979. The determination of twin zygosity by means of a mailed questionnaire. Acta Genet.Med.Gemellol.(Roma.), 28, 225-236.

Trenkwalder,C., Hening,W.A., Walters,A.S., Campbell,S.S., Rahman,K. \& Chokroverty,S. 1999a. Circadian rhythm of periodic limb movements and sensory symptoms of restless legs syndrome. Mov Disord., 14, 102-110.

Trenkwalder,C., Seidel,V.C., Gasser,T. \& Oertel,W.H. 1996. Clinical symptoms and possible anticipation in a large kindred of familial restless legs syndrome. Mov Disord., 11, 389-394.

Trenkwalder,C., Stiasny,K., Pollmacher,T., Wetter,T., Schwarz,J., Kohnen,R., Kazenwadel,J., Kruger,H.P., Ramm,S., Kunzel,M. \& . 1995. L-dopa therapy of uremic and idiopathic restless legs syndrome: a double-blind, crossover trial. Sleep, 18, 681-688.

Trenkwalder,C., Walters,A.S., Hening,W.A., Chokroverty,S., Antonini,A., Dhawan,V. \& Eidelberg,D. 1999b. Positron emission tomographic studies in restless legs syndrome. Mov Disord., 14, 141-145.

Tribl,G.G., Asenbaum,S., Happe,S., Bonelli,R.M., Zeitlhofer,J. \& Auff,E. 2004. Normal striatal D2 receptor binding in idiopathic restless legs syndrome with periodic leg movements in sleep. Nucl.Med.Commun., 25, 55-60.

Trzepacz,P.T., Violette,E.J. \& Sateia,M.J. 1984. Response to opioids in three patients with restless legs syndrome. Am.J.Psychiatry, 141, 993-995.

Turjanski,N., Lees,A.J. \& Brooks,D.J. 1999. Striatal dopaminergic function in restless legs syndrome: 18F-dopa and 11C-raclopride PET studies. Neurology, 52, 932-937. 
Ulfberg,J., Nystrom,B., Carter,N. \& Edling,C. 2001a. Prevalence of restless legs syndrome among men aged 18 to 64 years: an association with somatic disease and neuropsychiatric symptoms. Mov Disord., 16, 1159-1163.

Ulfberg,J., Nystrom,B., Carter,N. \& Edling,C. 2001b. Restless Legs Syndrome among working-aged women. Eur.Neurol., 46, 17-19.

Vieregge,P. 1987. Gilles de la Tourette's syndrome in monozygotic twins.

J.Neurol.Neurosurg.Psychiatry, 50, 1554-1556.

Vieregge,P., Hagenah,J., Heberlein,I., Klein,C. \& Ludin,H.P. 1999. Parkinson's disease in twins: a follow-up study. Neurology, 53, 566-572.

Vieregge,P., Schiffke,K.A., Friedrich,H.J., Muller,B. \& Ludin,H.P. 1992. Parkinson's disease in twins. Neurology, 42, 1453-1461.

Vogl,F.D., Pichler,I., Adel,S., Pinggera,G.K., Bracco,S., De Grandi,A., Volpato,C.B., Aridon,P., Mayer,T., Meitinger,T., Klein,C., Casari,G. \& Pramstaller,P.P. 2006. Restless legs syndrome: epidemiological and clinicogenetic study in a South Tyrolean population isolate. Mov Disord., 21, 1189-1195.

von Spiczak,S., Whone,A.L., Hammers,A., Asselin,M.C., Turkheimer,F., Tings,T., Happe,S., Paulus,W., Trenkwalder,C. \& Brooks,D.J. 2005. The role of opioids in restless legs syndrome: an [11C]diprenorphine PET study. Brain, 128, 906-917.

Walters,A.S. 1995. Toward a better definition of the restless legs syndrome. The International Restless Legs Syndrome Study Group. Mov Disord., 10, 634-642.

Walters,A.S., Hickey,K., Maltzman,J., Verrico,T., Joseph,D., Hening,W., Wilson,V. \& Chokroverty,S. 1996. A questionnaire study of 138 patients with restless legs syndrome: the 'Night-Walkers' survey. Neurology, 46, 92-95.

Walters,A.S., LeBrocq,C., Dhar,A., Hening,W., Rosen,R., Allen,R.P. \& Trenkwalder,C. 2003. Validation of the International Restless Legs Syndrome Study Group rating scale for restless legs syndrome. Sleep Med., 4, 121-132.

Walters,A.S., Wagner,M.L., Hening,W.A., Grasing,K., Mills,R., Chokroverty,S. \& Kavey,N. 1993. Successful treatment of the idiopathic restless legs syndrome in a randomized doubleblind trial of oxycodone versus placebo. Sleep, 16, 327-332.

Walters,A.S., Winkelmann,J., Trenkwalder,C., Fry,J.M., Kataria,V., Wagner,M., Sharma,R., Hening,W. \& Li,L. 2001. Long-term follow-up on restless legs syndrome patients treated with opioids. Mov Disord., 16, 1105-1109.

Ward,C.D., Duvoisin,R.C., Ince,S.E., Nutt,J.D., Eldridge,R. \& Calne,D.B. 1983. Parkinson's disease in 65 pairs of twins and in a set of quadruplets. Neurology, 33, 815-824.

Waserman,J., Lal,S. \& Gauthier,S. 1983. Gilles de la Tourette's syndrome in monozygotic twins. J.Neurol.Neurosurg.Psychiatry, 46, 75-77.

Wetter,T.C., Brunner,J. \& Bronisch,T. 2002. Restless legs syndrome probably induced by risperidone treatment. Pharmacopsychiatry, 35, 109-111. 
Winkelman,J.W. 2006. Considering the causes of RLS. Eur.J.Neurol., 13 Suppl 3, 8-14.

Winkelman,J.W., Chertow,G.M. \& Lazarus,J.M. 1996. Restless legs syndrome in end-stage renal disease. Am.J.Kidney Dis., 28, 372-378.

Winkelmann,J., Lichtner,P., Putz,B., Trenkwalder,C., Hauk,S., Meitinger,T., Strom,T. \& Muller-Myhsok,B. 2006. Evidence for further genetic locus heterogeneity and confirmation of RLS-1 in restless legs syndrome. Mov Disord., 21, 28-33.

Winkelmann,J., Schormair,B., Lichtner,P., Ripke,S., Xiong,L., Jalilzadeh,S., Fulda,S., Putz,B., Eckstein,G., Hauk,S., Trenkwalder,C., Zimprich,A., Stiasny-Kolster,K., Oertel,W., Bachmann,C.G., Paulus,W., Peglau,I., Eisensehr,I., Montplaisir,J., Turecki,G., Rouleau,G., Gieger,C., Illig,T., Wichmann,H.E., Holsboer,F., Muller-Myhsok,B. \& Meitinger,T. 2007. Genome-wide association study of restless legs syndrome identifies common variants in three genomic regions. Nat.Genet., 39, 1000-1006.

Winkelmann,J., Stautner,A., Samtleben,W. \& Trenkwalder,C. 2002. Long-term course of restless legs syndrome in dialysis patients after kidney transplantation. Mov Disord., 17, 1072-1076.

Winkelmann,J., Wetter,T.C., Collado-Seidel,V., Gasser,T., Dichgans,M., Yassouridis,A. \& Trenkwalder,C. 2000. Clinical characteristics and frequency of the hereditary restless legs syndrome in a population of 300 patients. Sleep, 23, 597-602.

Wirdefeldt,K., Gatz,M., Schalling,M. \& Pedersen,N.L. 2004. No evidence for heritability of Parkinson disease in Swedish twins. Neurology, 63, 305-311.

Xiong,L., Jang,K., Montplaisir,J., Levchenko,A., Thibodeau,P., Gaspar,C., Turecki,G. \& Rouleau,G.A. 2007. Canadian restless legs syndrome twin study. Neurology, 68, 1631-1633. 


\section{DANKSAGUNG}

An dieser Stelle danke ich allen Personen, die zum Entstehen der vorliegenden Arbeit mit beigetragen haben.

Mein besonderer Dank gilt Frau PD Dr. Juliane Winkelmann für die exzellente Betreuung bei dieser Arbeit. Zuerst möchte ich mich bei Ihr für die Überlassung dieses außerordentlich spannenden Themas bedanken, was mir zudem die Möglichkeit erbracht hat, mit einem so faszinierenden Probandenkollektiv wie Zwillingen zu arbeiten. Sie hat mir stets den von mir erwünschten Freiraum überlassen, stand mir jedoch zu jeder Zeit mit offenem Ohr konstruktiv zur Seite und unterstützte mich selbstlos durch Ihren kostbaren fachlichen Rat. In guter Atmosphäre konnte so mein wissenschaftliches Interesse wachsen.

Herrn Dr. Andreas Busjahn danke ich für die Bereitstellung des Zwillingskollektives aus dem Zwillingsregister von HealthTwist Berlin, für die fachlichen Ratschläge, mit denen er mir stets zur Seite stand und für seine Unterstützung bei der statistischen Auswertung.

Frau Jelena Golic, Mitarbeiterin im Helmholtz Zentrum, möchte ich besonders für Ihre bereitwillige und professionelle Hilfestellung im Labor sowie bei den zahlreichen organisatorischen Aufgaben danken. Es hat mir immer sehr viel Freude bereitet mit ihr produktiv zusammen zu arbeiten.

Ein ganz besonderer Dank gilt natürlich allen Zwillingen, die mit Interesse, Aufmerksamkeit und persönlichem Aufwand diese Arbeit unterstützt haben und ohne die dieses Projekt nicht hätte durchgeführt werden können.

Zuletzt möchte ich mich noch bei meiner Familie und bei meinen Freunden bedanken, die mich während der ganzen Arbeit, soweit möglich, fachlich und moralisch unterstützt haben, besonders Thilo Weinzierl, der durch seine unendliche Geduld und sein Verständnis auch die schwierigsten Phasen souverän entschärfen und mich immer wieder neu motivieren konnte.

Diese Arbeit widme ich meinen Eltern, um ihnen an dieser Stelle nochmals all meinen Dank auszusprechen, für das, was sie mir bisher alles ermöglicht haben. Ohne ihren Rückhalt in sämtlichen Lebenslagen und Situationen und ihre aufopfernde Unterstützung wäre dies alles nicht möglich gewesen. 


\section{LEBENSLAUF}

Name:

Groß

Vorname:

Nadine

Geburtsdatum:

07. Juni 1979

Geburtsort:

Illingen

Familienstand:

ledig

Schulausbildung:

1985-1989

Grundschule Dirmingen

1989-1998

Illtalgymnasium Illingen/Saar

Berufsausbildung:

10/1998-06/2000

Ausbildung zur Kauffrau im Groß- und Außenhandel,

Raab Karcher Baustoffe GmbH, Illingen und Homburg/Saar

Abschluss im Juni 2000

$06 / 2000-10 / 2000$

Kaufmännische Angestellte,

Raab Karcher Baustoffe GmbH, Homburg/Saar

$12 / 2000-03 / 2002$

Ausbildung zur Veterinärmedizinisch-technischen

Assistentin, Staatliches Veterinäruntersuchungsamt, Krefeld

Studium:

2002-2004

Studium der Humanmedizin, vorklinischer Abschnitt, LudwigMaximilians-Universität, München

2004-2008

Studium der Humanmedizin, klinischer Abschnitt,

Technische Universität München

Seit 02/2009

Assistenzärztin im Klinikum rechts der Isar, Klinik für

Neurologie 


\section{Anamnesebogen}

Datum:

\section{Angaben zur Person:}

1.1. Name:

1.2. Vorname:

1.3. Geburtsname:

1.4. Adresse:

Telefon

Email:

\section{Familienstand}

2.1. Verheiratet, mit Ehepartner(in) zusammen lebend

2.2. Verheiratet, von Ehepartner(in) getrennt lebend

2.3. Lebe mit einem Partner zusammen

2.4. Geschieden....... $\square_{4}$
2.5. Verwitwet ........ $\square 5$
2.6. Ledig ............... $\square 6$

3. Ausbildung und Tätigkeit

3.1. Welchen höchsten Schul- bzw. Hochschulabschluss haben Sie?

Abschluss 9.Klasse oder weniger..

Abschluss 10. Klasse

Abitur
Fachschule

Uni-/(Fach-)Hochschulstudium

3.2. Trifft eine der folgenden Angaben auf Ihre derzeitige Situation zu?

In Schulausbildung.

In Hochschulausbildung

Hausfrau/Hausmann

Altershalber in Rente/pensioniert

Vorzeitig in Rente/pensioniert.
Arbeitslos gemeldet

Freiwilliges soziales/ökologisches Jahr

Umschulung/ABM.

Erwerbstätig (voll und teil)

Nichts davon trifft zu

3.4. Beruf

\section{Körpermaße}

4.1. Wie groß sind Sie? (in $\mathrm{cm}$ )

4.2. Wie viel wiegen Sie? (auf ganze $\mathrm{kg}$ runden)*

4.3. Taillen-/Bundweite (ohne zu schnüren um die Taille, in $\mathrm{cm}$ )

4.4. Hüft-/Gesäßumfang (an der stärksten Stelle des Gesäßes, in cm)

(*Für Frauen: falls Sie z. Zt. schwanger sind, schätzen Sie bitte die Maße vor der Schwangerschaft)

4.5. Hat sich Ihr Körpergewicht, insgesamt gesehen, in den letzten 3 Jahren verändert?

(Falls Sie ab- und zugenommen haben, wählen Sie bitte das aus, was am ehesten auf Sie zutrifft.) Nein, in etwa gleich geblieben Ich weiß nicht

Ja, eher zugenommen Um wie viel $\mathrm{kg}$ ?

Ja, eher abgenommen Um wie viel $\mathrm{kg}$ ?

5. Wie häufig verrichten Sie anstrengende körperliche Tätigkeiten (z.B. Schwimmen, Laufen, Aerobic, Fahrrad fahren usw.)?

selten/nie. weniger als einmal pro Woche einmal pro Woche

Wie viel Stunden im Durchschnitt pro Woche? 2-3mal pro Woche

4-6mal pro Woche

täglich

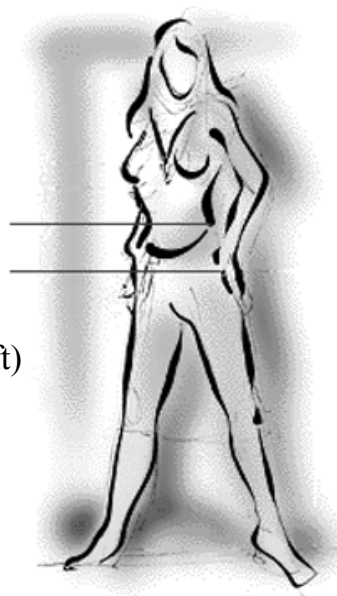


6. Haben Sie jemals regelmäßig Zigaretten (mind. 1 Zigarette pro Tag) geraucht? $\mathrm{Ja}$ Nein

6.1. Wenn Ja, wie alt waren Sie, als Sie begannen regelmäßig zu rauchen? Alter Jahre

6.2. Wie viel Jahre rauchen Sie bzw. haben Sie insgesamt geraucht? Jahre: Rauch(t)e weniger als $1 \mathrm{Jahr}$

6.3. Wie viel Zigaretten rauch(t)en Sie im Durchschnitt pro Tag? Anzahl

6.4. Rauchen Sie jetzt noch? Ja Wie alt waren Sie, als Sie aufgehört haben zu rauchen? Alter

6.5. Zigarren-/Pfeifenraucher $\mathrm{Ja}$ Nein

7. Wie oft trinken Sie im Durchschnitt alkoholische Getränke?

nie $\square_{0}$ weniger als einmal $\square$ pro Woche mehrmals $\square_{2}$
pro Woche

täglich Wroche

Wie viele Gläser trinken Sie im Durchschnitt pro Woche?

Anzahl Gläser

Ist das meistens $\quad$ Wein $\square_{1} \quad$ Bier $\square_{2} \quad$ hochprozentige Spirituosen

\section{Allergien / Hauterkrankungen}

8.1. Waren Sie schon einmal beim Hautarzt? ja $\square_{1}$ nein $\square$

8.2. Haben Sie manchmal eine laufende oder verstopfte, juckende Nase, ohne erkältet zu sein? Ja $\square 1 \quad$ Nein $\square$ 0 wenn ja, haben Sie dabei auch tränende, juckende Augen?

8.3. Hatten Sie mehrfach wiederkehrende juckende, schuppende Hautveränderungen, die stärker oder schwächer über mindestens 6 Monate auftraten? Ja $\square_{1} \quad$ Nein $\square_{0}$ Wenn ja, trat der Ausschlag in Ellenbeuge oder Kniekehle auf (Beugenekzem)? Ja $\square$ N Nein

8.4. Wurde bei Ihnen jemals die Diagnose atopisches Ekzem, Neurodermitis oder endogenes Ekzem gestellt?

Ja $\square_{1} \quad$ Nein $\square_{0}$ Wenn ja, wie häufig waren Sie deshalb beim Arzt? nie $\square 0$ gelegentlich ständig $\square_{2}$

9. Wurde bei Ihnen jemals ein hoher Blutdruck festgestellt? ja $\square_{1} \quad$ Nein $\square_{0} \quad$ ich weiß nicht wenn ja, wann (Lebensjahr)

höchste Blutdruckwerte: mmHg oder Blutdruck nicht bekannt

wurde/wird der Bluthochdruck behandelt

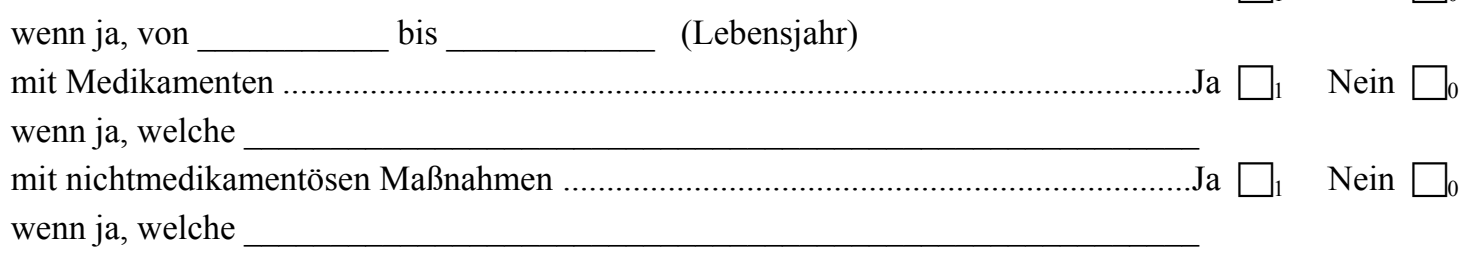

10. Diabetes mellitus (Zuckerkrankheit):

Wurde bereits eine Zuckerkrankheit festgestellt?

Ja $\square$ nein $\square$, ich weiß nicht wenn ja, wann (Lebensjahr)

wurde/wird der Diabetes behandelt

Ja $\square$ Nein $\square$ wenn ja, mit Diät $\mathrm{Ja}$ mit Insulin Ja mit anderen Medikamenten .Ja $\square_{1}$ Nein $\square$ Angabe der Medikamente Behandlung von bis (Lebensjahr)

Nein $\square$, Nein $\square_{0}$ 
11. Wurde bei Ihnen jemals ein erhöhter Cholesterinspiegel festgestellt?

Ja $\square$ nein $\square 0 \quad$ ich weiß nicht $\square 9$ wenn ja, wann (Lebensjahr)

wurde/wird der hohe Cholesterinspiegel behandelt? Ja $\square$ Nein

wenn ja, mit Diät Ja

$\square$ Nein mit Medikamenten ..Ja

Nein Angabe der Medikamente

Behandlung von bis (Lebensjahr)

\section{Weitere Erkrankungen}

12.1. Haben Sie einen Schlaganfall erlitten? Ja $\square_{1} \quad$ Nein $\square_{0}$ wenn ja, wann (Lebensjahr)

12.2. Haben Sie einen Herzinfarkt erlitten? $\mathrm{Ja}$ Nein wenn ja, wann (Lebensjahr)

12.3. Haben Sie Missempfindungen wie Kribbeln, „Ameisenlaufen“ oder Schmerzen an den Beinen, verbunden mit einem Bewegungsdrang? Ja $\square$ nein $\square_{0}$ ich weiß nicht $\square$

12.4. Treten diese Symptome nur in Ruhe bzw. beim Einschlafen auf und lassen sie sich durch Bewegung bessern? Ja $\square_{1} \quad$ nein $\square_{0}$ ich weiß nicht

12.5. Sind diese Symptome abends oder nachts schlimmer als morgens? ..... Ja $\square$ nein $\square 0$ ich weiß nicht $\square$

12.6. Wie würden Sie insgesamt die Qualität Ihres Schlafes während des letzten Jahres beurteilen? sehr schlecht $\square_{1} \quad$ ziemlich schlecht $\square_{2} \quad$ ziemlich gut $\square_{3} \quad$ sehr gut $\square_{4}$

12.7. Haben Sie Schwierigkeiten beim Einschlafen? Ja $\square_{1}$ nein $\square_{0} \quad$ ich weiß nicht $\square 9$

12.8 Haben Sie Schwierigkeiten beim Durchschlafen? Ja $\square_{1}$ nein $\square_{0}$ ich weiß nicht

12.9. Weitere bisher nicht erwähnte chronische Erkrankungen: Ja $\square_{1}$ nein $\square_{0} \quad$ ich weiß nicht

13. Welche weiteren Medikamente (außer der „Pille“ - siehe unten - und den bereits unter 9. - 11. angegebenen) nehmen Sie zur Zeit ein?

\section{Die folgenden Fragen betreffen nur Frauen:}

14.1. Hormonelle Schwangerschaftsverhütung (einschließlich anderer medizinischer Gründe).

Nehmen Sie zurzeit die „Pille“ $\mathrm{Ja}$ Nein $\square$ Wenn ja, welches Präparat?

14.2. Hormonersatz-Therapie in Zusammenhang mit den Wechseljahren.

Nehmen Sie zurzeit Hormonpräparate, d.h. Östrogene und/oder Gestagene im

Zusammenhang mit den (bevorstehenden) Wechseljahren bzw. nach Entfernung beider

Eierstöcke im Rahmen einer sogenannten Hormonersatz-Therapie? Ja

Nein

Wenn ja, welches Präparat?

Weitere Bemerkungen: 
Bitte zurücksenden an:

Dr. Busjahn

Franz-Volhard-Klinik

Wiltbergstr. 50

13125 Berlin 


\section{Zwillingsstudie}

München, August 2005

Sehr geehrte/r Herr/Frau

Sie und Ihr Zwillingsgeschwister haben sich vor einiger Zeit beim Berliner Zwillingsregister HealthTwiSt angemeldet und dabei einen Fragebogen zu Ihrem Gesundheitszustand ausgefüllt.

In Zusammenarbeit mit dem Institut für Humangenetik des Forschungszentrums für Umwelt und Gesundheit (GSF) und dem Max-Planck-Institut für Psychiatrie in München führen wir jetzt eine Untersuchung zum Thema Schlaf und „unruhige Beine“ durch. Hierbei geht es um den Einfluss von genetischen Faktoren auf den Schlaf sowie Einflussfaktoren, die zu Veränderungen des Schlafprofils führen können.

Sie selbst oder Ihr Zwilling haben in Ihrem Fragebogen Beschwerden angegeben, die auf eine Beeinträchtigung der Schlafqualität hinweisen. Deshalb würden wir gerne ein Telefoninterview von max. 20 Minuten Dauer durchführen und Ihnen anschließend nochmals einen Fragebogen zusenden. Natürlich entstehen für Sie dabei keine Kosten.

Bitte füllen Sie das beiliegende Formular bezüglich Ihrer Erreichbarkeit aus und senden Sie dies möglichst bald im beiliegenden vorfrankierten Rückumschlag direkt an die Kollegen aus München zurück. Frau Nadine Groß oder Frau Dr. Stephanie Hauk werden sich telephonisch mit Innen zum gewünschten Zeitpunkt in Verbindung setzen. Selbstverständlich werden alle erhobenen Daten nur in anonymisierter Form ausgewertet und persönliche Daten nicht weitergegeben.

Für Rückfragen können Sie sich jederzeit mit den Studienleitern Frau Dr. Juliane Winkelmann vom Institut für Humangenetik und dem Max-Planck-Institut für Psychiatrie (089-3187-3525) oder Herrn Dr. Andreas Busjahn von HealthTwiSt (0800-1289467) in Verbindung setzen.

Herzlichen Dank für Ihre Mithilfe und Unterstützung unseres Forschungsprojektes.

Mit freundlichen Grüßen

Dr. habil. Andreas Busjahn

HealthTwiSt GmbH, Berlin
Dr. med. Juliane Winkelmann Institut für Humangenetik, München 
GSF-Forschungszentrum

Institut für Humangenetik

Geb. 34

Dr. Winkelmann/ Groß

Ingolstädter Landstraße 1

D-85764 Neuherberg/München

\section{Rückantwort}

Name:

Vorname:

Straße:

Nr.:

PLZ:

Wohnort:

Geburtsdatum:

Telefonnummer:

/

alternativ:

I

Am besten bin ich um

Uhr zu erreichen.

Sonstiges: 


\begin{tabular}{|l|l|l|l|}
\hline Zentrum/Ort & Pat.-ID & Untersucher & Datum \\
\hline
\end{tabular}

Name:

Geschlecht: männlich

Geburtsdatum: weiblich

Vorname:

$>$ Zygotie nach Auskunft des Patienten: eineiig
$\square$
zweieiig
unbekannt

\section{Sozialanamnese: \\ Familienstand:}

ledig $\square$

verheiratet

geschieden $\square$

verwitwet $\square$

zusammenlebend $\square$

Haben Sie Kinder?

Zwillingsgeschwister: Name:

Vorname:

Haben Sie noch weitere Geschwister?

$>$ Wie sind Sie und Ihr Zwillingsgeschwister aufgewachsen?

getrennt wenn getrennt,

ab wann?

zusammen

wie lange?

Beruf:

Schulabschluss

$\square$ ohne

$\square$ Hauptschule

$\square$ Realschule

$\square$ Fachhochschulreife

$\square$ Abitur

Berufsausbildung

$\square$ keine

$\square$ Ausbildung/Lehre

$\square$ Fachschule

$\square$ Meister

$\square$ Fachhochschule

$\square$ Universität

$\square$ andere/weitere
Aktuell ausgeübte Tätigkeit

$\square$ arbeitslos

$\square$ Ausbildung

$\square$ Angestellte/r

$\square$ selbständig

$\square$ Rentner/in

$\square$ Hausfrau-/mann

$\square$ sonstiges

\section{Schlafstörungen:}

D Haben Sie Schwierigkeiten beim Einschlafen?
ja $\square$
nein
unbekannt

- Wie lange benötigen Sie zum Einschlafen? $\min$

- Subjektiv geäußerte Gründe für Einschlafverzögerung:

Haben Sie Schwierigkeiten beim Durchschlafen?
ja $\square$
nein $\square$
unbekannt

- Wie häufig wachen Sie nachts auf? 
- Was tun Sie dann?

Wie lange benötigen Sie wieder zum Einschlafen? $\min$

- Subjektiv geäußerte Gründe für Aufwachen

Weitere Daten zu Ihrem Schlaf:

\begin{tabular}{|l|r|ll|}
\hline & Werktags & Wochenende & \\
\hline $\begin{array}{l}\text { Wann gehen Sie abends zu } \\
\text { Bett? }\end{array}$ & Uhr & Uhr \\
\hline Wann stehen sie morgens auf? & Uhr & & Uhr \\
\hline $\begin{array}{r}\text { Gesamtschlafdauer } \\
\text { Nacht } \\
\text { Tag }\end{array}$ & Std. & Std. & Std. \\
\cline { 2 - 5 }
\end{tabular}

$>$ Sind sie tagsüber oft müde oder schläfrig?
ja $\square$
nein
unbekannt

> Haben Sie jemals irgendwelche schlaffördernde Medikamente genommen, z.B. Benzodiazepine, Antidepressiva, Neuroleptika, Alkohol, nicht rezeptpflichtige Medikamente etc.?
ja
$\square$, welche? nein

$>$ Nehmen Sie derzeit irgendwelche schlaffördernde Medikamente, z.B. Benzodiazepine, Antidepressiva, Neuroleptika, Alkohol, nicht rezeptpflichtige Medikamente etc.?

ja $\square$, welche? nein

$>$ Waren Sie schon einmal in einem Schlaflabor, in einer Schlafambulanz oder haben Sie wegen Schlafschwierigkeiten einen Arzt aufgesucht?
ja $\square$
nein
unbekannt

wenn ja, Ergebnis:

D Haben Ihre Eltern, Großeltern oder Geschwister häufig über Schlafstörungen geklagt?
ja
nein
unbekannt

\section{RLS-Beschwerden:}

$>$ Haben Sie manchmal ein Unruhegefühl oder einen Bewegungsdrang in den Beinen, verbunden mit Missempfindung in den Beinen?
ja
nein
unbekannt

$>$ Verschlechtern sich der Bewegungsdrang oder die Missempfindungen durch Inaktivität/Ruhe?
ja
nein
unbekannt

$>$ Bessern sich der Bewegungsdrang oder die Missempfindungen durch Bewegung wie Gehen, Strecken, Massieren, .....zumindest solange die Bewegung anhält?
ja
nein
unbekannt

Nehmen der Bewegungsdrang oder die Missempfindungen am Abend oder in der Nacht zu? Sind die Beschwerden zu diesen Zeiten deutlicher vorhanden?

ja $\square \quad$ nein $\square \quad$ unbekannt 
$>$ Sind Sie aufgrund des Bewegungsdrangs oder der Missempfindung gezwungen aufzustehen und umherzulaufen?
ja
nein
unbekannt

Wodurch spüren Sie eine Besserung der Beschwerden?

Wie oft treten die Beschwerden auf?

6-7x wöchentlich

$4-5 x$ wöchentlich

$2-3 x$ wöchentlich

$2-4 x$ monatlich

$1 \mathrm{x}$ monatlich

mindestens $1 \times$ jährlich aber

weniger als $1 \mathrm{x}$ monatlich

weniger als $1 \mathrm{x}$ jährlich

Zu welcher Tageszeit treten die Beschwerden hauptsächlich auf?

vormittags
nachmittags
abends
nachts
keine bestimmte
Tageszeit
Sonstige Angaben:

ca. Uhr

ca. Uhr

ca. Uhr

ca. Uhr

Sonstige Angaben:

Wann sind die Beschwerden zum allerersten Mal aufgetreten?

Im Alter von

Jahren jetziges Alter

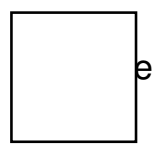

$>$ Verlauf der Beschwerden über die Zeit

immer gleich

wechselnd vorhanden

immer zunehmend

mal schlagartig verschwunden

Wie würden Sie die Missempfindungen spontan beschreiben?

\begin{tabular}{llll}
\hline Würden Sie die Beschwerden charakterisieren als: & \\
- Missempfindungen & ja $\square$ & nein & $\square$ \\
- Kribbeln & ja $\square$ & nein & $\square$ \\
- Ziehen & ja $\square$ & nein & $\square$ \\
- Reißen & ja $\square$ & nein & $\square$ \\
- Stechen & ja $\square$ & nein & $\square$ \\
- Schmerzen & ja $\square$ & nein & $\square$ \\
- Jucken & ja $\square$ & nein & $\square$
\end{tabular}

> Betreffen die Beschwerden eher die Haut/Oberfläche der Beine oder kommen sie „Von innen“? Oberfläche/Haut „von innen“

$>$ Wo treten die Beschwerden auf?

Fuß

Unterschenkel 
Oberschenkel

Hände

Arme

Sonstige Angaben:

Wie treten die Beschwerden bevorzugt auf?

$\begin{array}{llll}\text { 口einseitig: } & \text { nur rechts } & \square & \text { nur links } \\ \text { पbeidseitig: } & \text { gleichzeitig } & \square & \text { abwechselnd } \\ \text { Sonstiges: } & & \end{array}$

Haben Sie manchmal unwillkürliche Bewegungen oder Zuckungen der Beine in der Nacht?
ja
nein
unbekannt

Bestätigt durch Bettpartner?
ja
nein
unbekannt

wenn ja, wachen Sie davon auf?

ja $\square$ nein $\square \quad$ unbekannt

Haben Sie manchmal unwillkürliche krampfartige Bewegungen oder Zuckungen („Ausschlagen“) der Beine während Ruhephasen am Tag festgestellt?
ja $\square$
nein
unbekannt

Gibt es noch weitere Familienmitglieder, die unter RLS-Beschwerden leiden?

$>$ Haben Ihre Eltern, Großeltern oder Geschwister sich jemals über irgendwelche Beschwerden in den Beinen geäußert?
ja $\square$
nein
unbekannt

$>$ Wie waren die Beschwerden in der Schwangerschaft? (Anzahl und Jahreszahl aller Schwangerschaften erfragen!,)

\begin{tabular}{|l|l|l|l|l|}
\hline & 1. SWS & 2. SWS & 3. SWS & 4. SWS \\
\hline besser & $\square$ & $\square$ & $\square$ & $\square$ \\
\hline schlechter & $\square$ & $\square$ & $\square$ & $\square$ \\
\hline unverändert & $\square$ & $\square$ & $\square$ & $\square$ \\
\hline nicht vorhanden & $\square$ & $\square$ & $\square$ & $\square$ \\
\hline
\end{tabular}

$>$ Hat/hatte Ihr Zyklus Einfluss auf die Beschwerden?

wenn ja:
ja
nein $\square$
unbekannt

\begin{tabular}{|l|l|l|l|l|}
\hline & $1 .-7 \mathrm{Tag}$ & $8 .-14 \mathrm{Tag}$ & $15 .-21 . \mathrm{Tag}$ & 22. -28.Tag \\
\hline Beginn der & & & & \\
Beschwerden & & & & \\
\hline Ende der & & & & \\
Beschwerden & & & & \\
\hline Sonstige \\
Verteilung der \\
Beschwerden
\end{tabular}

$>$ Nehmen/nahmen Sie jemals Hormonpräparate ein?
ja $\square$
nein $\square$
unbekannt

\section{wenn ja,}

welche Hormonpräparate? , seit

haben diese Hormonpräparate einen Einfluss auf Ihre Beschwerden?
ja
nein
unbekannt 
> Hat der Genuss von Alkohol einen Einfluss auf diese Beschwerden?
ja
nein
unbekannt

Haben Sie jemals wegen dieser Beschwerden Medikamente eingenommen wie:

$>$

- Schmerzmittel (Aspirin, Paracetamol, Benuron,)

$\mathrm{ja} \square$

- L-Dopa (Madopar, Nacom, Isicom, Restex)

$\mathrm{ja} \square$

- Opiate (Valoron, Tramadol)

$\mathrm{ja} \square$

- Dopaminagonisten (Cabaseril, Sifrol, Requip, Parkotil)

$\mathrm{ja} \square$

- Schlaf- oder Beruhigungsmittel

$\mathrm{ja} \square$

- Andere Medikamente

$\mathrm{ja} \square$

nein $\square$ unbekannt $\square$
nein $\square$ unbekannt $\square$
nein $\square$ unbekannt $\square$
nein $\square$ unbekannt $\square$
nein $\square$ unbekannt $\square$
nein $\square$ unbekannt $\square$

wenn ja, haben sich die Beschwerden durch diese Medikamente gebessert?

ja $\square$ nein $\square$ unbekannt

Welche Medikamente nehmen Sie aktuell wegen dieser Beschwerden (RLS-Beschwerden) ein?

$>$ Wurde bei Ihnen schon einmal ein Eisenmangel festgestellt?

ja $\square \quad$ nein $\square$ unbekannt

wenn ja,

wann?:

Ursache?:

Therapie?:

Litten Sie in Ihrer Kindheit unter Wachstumsschmerzen?
ja
nein
unbekannt

Wurde bei Ihnen in der Kindheit eine Aufmerksamkeitsdefizit-Hyperaktivitätsstörung (ADHS) diagnostiziert? (oder wurden sie als Zappelphilipp bezeichnet)
ja
nein
unbekannt

\section{Psychiatrische Erkrankungen:}

$>$ Waren Sie jemals in psychiatrischer Behandlung?
ja
wenn ja, weshalb?

nein

Haben Sie sich jemals über einen längeren Zeitraum traurig oder niedergeschlagen gefühlt? (ohne besonderen Grund/Ursache)
ja
nein
unbekannt

$>$ Fühlten Sie sich jemals über längere Zeit antriebslos und hatten wegen dieser Beschwerden Schwierigkeiten Ihren Alltag (Beruf, Familie, Freizeitaktivitäten, etc.) zu bewältigen?
ja
nein
unbekannt

> Litten Sie jemals unter einem Gefühl der Angst, welches Sie bestimmte Situationen vermeiden ließ oder zu einer Einschränkung des alltäglichen Lebens in vielen Bereichen (Beruf, Familie, Freizeitaktivitäten, etc.) führte?
ja
nein
unbekannt 
Weitere Erkrankungen:

Delche sonstigen Medikamente nehmen Sie regelmäßig ein?

\begin{tabular}{|l|l|l|l|l|}
\hline Erkrankung & ja & nein & $\begin{array}{l}\text { unbe- } \\
\text { kannt }\end{array}$ & Bemerkung/Therapie \\
\hline Nierenerkrankung & & & & \\
\hline Dialysepflicht & & & & \\
\hline Diabetes mellitus & & & & \\
\hline Eisenmangel & & & & \\
\hline Polyneuropathie & & & & \\
\hline Orthopädische & & & \\
\hline Erkrankungen & & & & \\
\hline Hypertonus & & & & \\
\hline Herzerkrankungen & & & & \\
\hline Schilddrüsen-erkrankung & & & & \\
\hline Rheumatoide Arthritis & & & & \\
\hline Maligne Erkrankungen & & & & \\
\hline Migräne & & & & \\
\hline Tinnitus & & & & \\
\hline paVK & & & & \\
\hline Operationen & & & & \\
\hline Sonstiges & & & & \\
\hline Diagnose: & & & \\
\hline
\end{tabular}

\section{Essentielle Kriterien:}

1. $\square$ Bewegungsdrang der Beine gewöhnlich mit Missempfindungen verbunden

2. $\square$ Bewegungsdrang oder Missempfindungen verschlechtern sich durch Inaktivität

3. $\square$ Bewegungsdrang oder Missempfindungen bessern sich durch Bewegung wie Gehen, Strecken, Massieren ....... zumindest solange die Bewegung anhält.

4. $\square$ Bewegungsdrang oder Missempfindungen sind am Abend oder in der Nacht schlechter

\section{Diagnose-Sicherheit:}

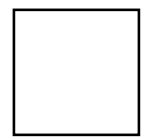

$1=$ RLS und alle 4 Diagnostischen Kriterien erfüllt

+ unterstützt durch Ansprechen auf eine dopaminerge Therapie oder Polysomnographie

$2=\mathrm{RLS}$ und alle 4 diagnostischen Kriterien erfüllt

$3=$ RLS wahrscheinlich (nur 3 von 4 Kriterien erfüllt)

4= RLS möglich: (weniger als 3 Kriterien erfüllt)

$5=$ Sicher kein RLS (bestätigt durch telef. Kontakt, bisher niemals RLS Beschwerden)

$6=$ Diagnose unbekannt

7= sonstiges (Anamnese unklar ect.) Kommentar: 
Kommentar: 


\section{Beurteilungs-Skala der Internationalen RLS-Studiengruppe (IRLS)}

Bitte lassen Sie den Patienten/die Patientin in den folgenden zehn Fragen den Schweregrad seiner/ ihrer Beschwerden einschätzen. Die Beurteilung sollte der Patient/die Patientin vornehmen und nicht der Untersucher, aber der Untersucher sollte für Erklärungen zur Verfügung stehen, falls dem Patienten/der Patientin etwas unklar ist. Der Untersucher kreuzt die Antworten des Patienten/ der Patientin auf dem Fragebogen an.

\section{In der letzten Woche...}

1. Wie stark würden Sie die RLS-Beschwerden in Ihren Beinen oder Armen einschätzen?

$\square_{4}$ sehr

2. Wie stark würden Sie Ihren Drang einschätzen, sich wegen Ihrer RLS-Beschwerden bewegen zu müssen?

$\square_{4}$ sehr

3. Wie sehr wurden die RLS-Beschwerden in Ihren Beinen oder Armen durch Bewegung gelindert?

$\square_{4}$ überhaupt nicht gelindert $\square_{3} \begin{gathered}\text { ein wenig } \\ \text { gelindert }\end{gathered}$

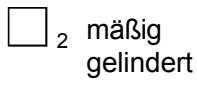

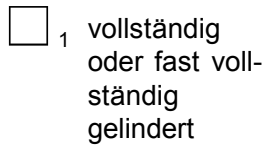

gelindert
0 Es mussten keine RLS-Beschwerden gelindert werden.

4. Wie sehr wurde Ihr Schlaf durch Ihre RLS-Beschwerden gestört?

$\square$ sehr

ziemlich

$\square_{2}$ mäßig

1 leicht überhaupt nicht

5. Wie müde oder schläfrig waren Sie tagsüber wegen Ihrer RLS-Beschwerden? 


\section{Beurteilungs-Skala der Internationalen RLS-Studiengruppe (IRLS)}

6. Wie stark waren lhre RLS-Beschwerden insgesamt?

$\square$, sehr

$\square$, ziemlich

$\square$, mäßig

leicht

nicht vorhanden

7. Wie oft sind Ihre RLS-Beschwerden aufgetreten?

$\square$ 4 sehr oft (das heißt an 6 bis 7 Tagen in der Woche)
$\square_{3}$ oft (das heiß: an 4 bis 5 Tagen in der Woche)
$\square_{2}$ manchmal (das heißt an 2 bis 3 Tagen in der Woche)

$\square_{0}$ überhaupt nicht

(das heiß an einem Tag in der Woche)

8. Wenn Sie RLS-Beschwerden hatten, wie stark waren diese durchschnittlich?

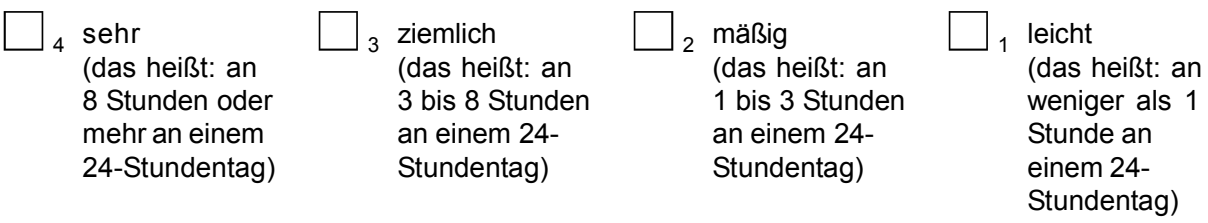

9. Wie sehr haben sich Ihre RLS - Beschwerden auf Ihre Fähigkeit ausgewirkt, Ihren Alltagstätigkeiten nachzugehen, z. B. ein zufriedenstellendes Familien-, Privat-, Schul- oder Arbeitsleben zu führen?

10. Wie stark haben Ihre RLS-Beschwerden Ihre Stimmung beeinträchtigt, waren Sie z.B. wütend, niedergeschlagen, traurig, ängstlich oder gereizt? 